\title{
Improvements to Air Force Strategic Basing Decisions
}

Constantine Samaras, Rachel Costello, Paul DeLuca, Stephen J. Guerra, Kenneth Kuhn, Anu Narayanan, Michael Nixon, Stacie L. Pettyjohn, Nolan Sweeney, Joseph V. Vesely, Lane F. Burgette 
Library of Congress Cataloging-in-Publication Data is available for this publication.

ISBN: 978-0-8330-9205-2

Published by the RAND Corporation, Santa Monica, Calif.

(C) Copyright 2016 RAND Corporation

RAND $^{\circledR}$ is a registered trademark.

\section{Limited Print and Electronic Distribution Rights}

This document and trademark(s) contained herein are protected by law. This representation of RAND intellectual property is provided for noncommercial use only. Unauthorized posting of this publication online is prohibited. Permission is given to duplicate this document for personal use only, as long as it is unaltered and complete. Permission is required from RAND to reproduce, or reuse in another form, any of its research documents for commercial use. For information on reprint and linking permissions, please visit www.rand.org/pubs/permissions.html.

The RAND Corporation is a research organization that develops solutions to public policy challenges to help make communities throughout the world safer and more secure, healthier and more prosperous. RAND is nonprofit, nonpartisan, and committed to the public interest.

RAND's publications do not necessarily reflect the opinions of its research clients and sponsors.

\section{Support RAND}

Make a tax-deductible charitable contribution at www.rand.org/giving/contribute

www.rand.org 


\section{Preface}

The U.S. Air Force manages any proposed significant changes and additions regarding the location of weapon systems and personnel through its strategic basing process, and the Air Force has conducted more than 100 strategic basing decisions since 2009. Some notable recent examples of strategic basing decisions are the evaluations of which installations will host the F-35 and KC-46A major weapon systems. Air Force basing decisions are public, frequent, and occasionally contentious. Because these decisions affect force posture, local economies, and public trust, it is imperative that the decisionmaking process be objective and reproducible. The Air Force employs a three-step enterprise-wide process to ensure consistency when it makes basing decisions. In the first step, a set of criteria is developed to evaluate an installation's suitability to support a basing decision. The basing decision criteria are developed by the applicable major command (MAJCOM), approved by the Headquarters Air Force (HAF) and the Secretary of the Air Force (SecAF), and briefed to Congress. In the second step, individual basing scores for the defined criteria are assembled by the MAJCOM, and a small set of candidate bases, usually four to six, is selected for site surveys. In the final step, a preferred base is selected. The results of each step are approved by HAF and SecAF and briefed to Congress. The credibility of this process is dependent on these data calls resulting in high-quality data that are then analyzed in a transparent and objective manner.

This report is an independent analysis of the Air Force's basing process and the quality of the underlying data. It seeks to inform decisionmakers on potential improvements to the data and assessment criteria used in making basing decisions. It seeks to address three questions:

1. Are basing decision criteria aligned with Air Force intentions?

2. Are the data used in the Air Force's strategic basing decisionmaking process authoritative, consistent, and auditable?

3. Is there potential for broader Air Force strategic or portfolio-wide inputs to strengthen the basing decisionmaking process?

In answering the first question, we examined the actual data source for each base in enterprise-wide KC-46 and F-35 basing decisions. To assess the second question, we examined the desired and actual impact of each decision criterion for the past 25 basing actions. In addressing the potential for inclusion of strategic inputs, we assessed the historical impact of strategic inputs and possible mathematical techniques to incorporate such inputs into the current basing process.

The research reported here was sponsored by the U.S. Air Force and conducted within the Resource Management Program of RAND Project AIR FORCE. 


\section{RAND Project AIR FORCE}

RAND Project AIR FORCE (PAF), a division of the RAND Corporation, is the U.S. Air Force's federally funded research and development center for studies and analyses. PAF provides the Air Force with independent analyses of policy alternatives affecting the development, employment, combat readiness, and support of current and future air, space, and cyber forces. Research is conducted in four programs: Force Modernization and Employment; Manpower, Personnel, and Training; Resource Management; and Strategy and Doctrine. The research reported here was prepared under contract FA7014-06-C-0001.

Additional Information about PAF is available on our website:

http://www.rand.org/paf/

This report documents work originally shared with the U.S. Air Force in October 2014. The draft report, issued in February 2015, was reviewed by formal peer reviewers and U.S. Air Force subject matter experts. 


\section{Contents}

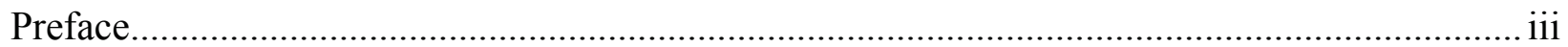

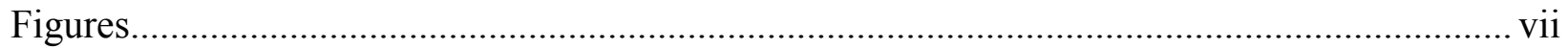

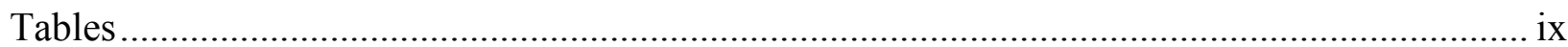

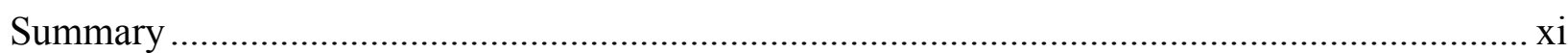

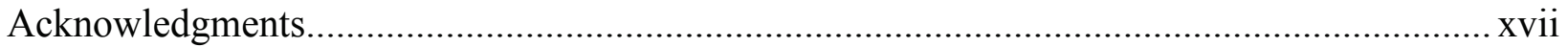

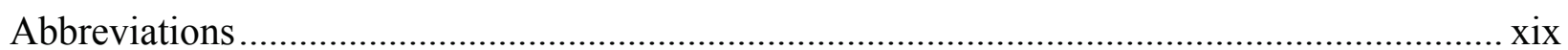

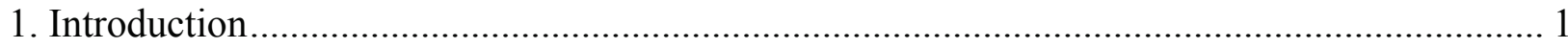

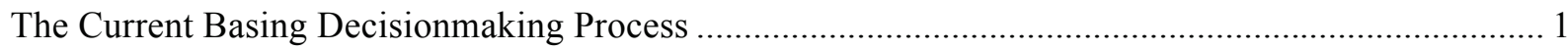

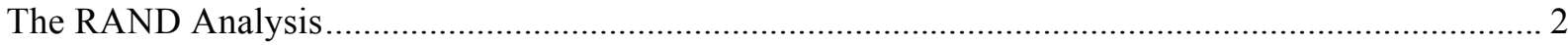

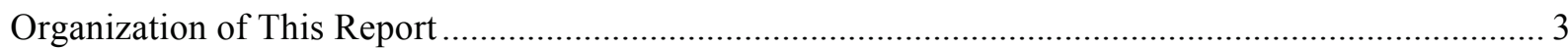

2. Current Air Force Strategic Basing Process and Governance ........................................... 5

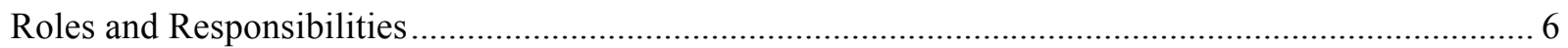

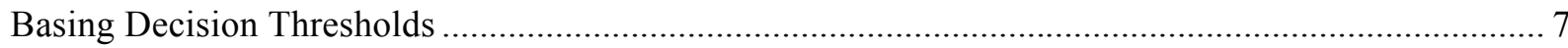

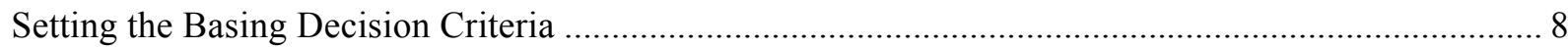

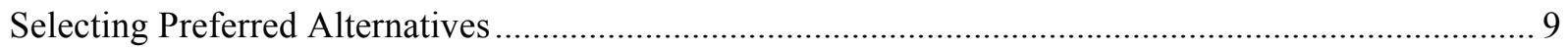

3. Is the Air Force's Basing Process Aligned with Its Objectives? .......................................... 13

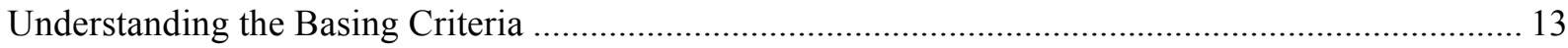

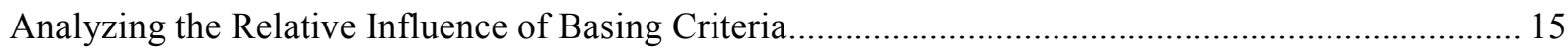

4. Assessing Basing Data Quality .................................................................................. 23

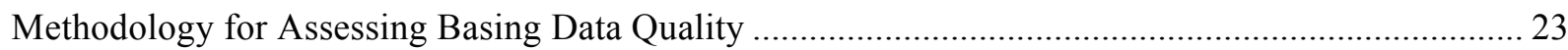

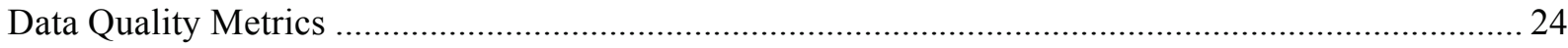

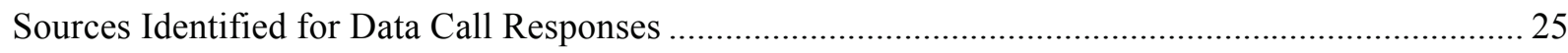

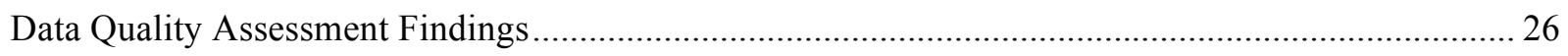

Recommendations to Improve the Auditability of Data Quality ......................................................... 27

5. Implementation Challenges and Potential Improvements ............................................. 31

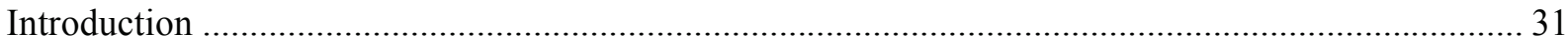

Challenges and Recommendations for the Collection of Basing Data ................................................ 31

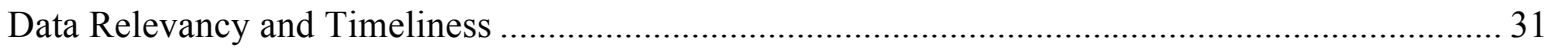

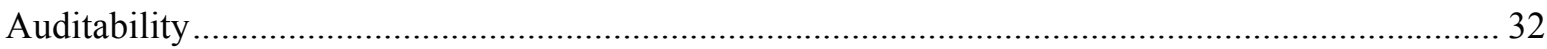

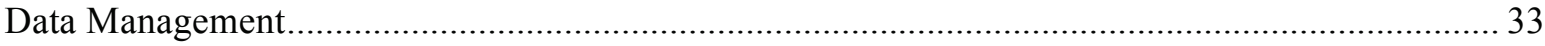

Challenges and Recommendations for Criteria and Process .......................................................... 33

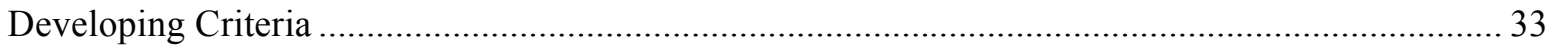

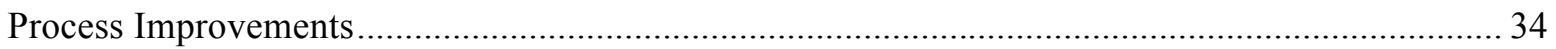

Challenges and Recommendations for Including Strategic Considerations ........................................ 35

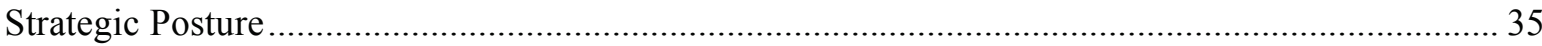

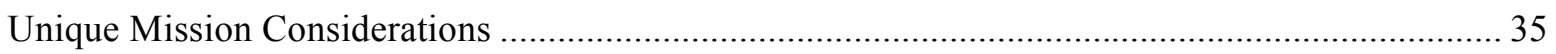




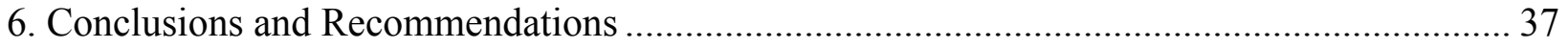

Air Force Data Quality Is Sufficient to Support Decisionmaking...................................................... 37

The Air Force Should Institute an Initial Screening Process............................................................... 38

Appendix A. Detailed Analysis of Basing Decision Criteria …............................................ 39

Appendix B. Base Realignment and Closure 2005 ............................................................... 49

Appendix C. Generalized Boosted Model ......................................................................... 61

Appendix D: The Role of Strategy in Basing Decisions at Home and Abroad ......................... 63

Appendix E: Basing Decisionmaking Processes of the U.S. Army and U.S. Navy ................... 79

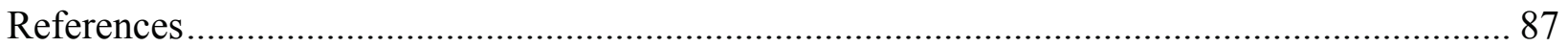




\section{Figures}

Figure S.1 Standard U.S. Air Force Strategic Basing Process and Governance ........................ xii

Figure 2.1 Standard U.S. Air Force Strategic Basing Process and Governance........................... 6

Figure 2.2 An Example of Basing Criteria ........................................................................ 9

Figure 2.3 Ranked Candidate Bases List for KC-46A Decision ............................................. 10

Figure 3.1 Criteria Weights Assigned in Selected U.S. Air Force Basing Actions ..................... 16

Figure 3.2 Ranked Candidate Bases List for KC-46A Decision ........................................... 17

Figure 3.3 Mission Scores of Bases Evaluated for the KC-46A Basing Decision ..................... 20

Figure D.1 Special Use Airspace in 1999 (left) and Airspace Ceded as a Part of BRAC

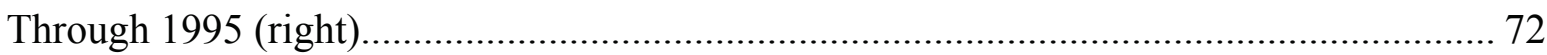





\section{Tables}

Table S.1 Reduced Data Collection Enabled by Various Mission Score Thresholds ................. Xv

Table 3.1 General Criteria Evaluated in the U.S. Air Force Strategic Basing Process ............... 14

Table 3.2 Relative Influence of F-35 Criteria Categories on Basing Process Outcomes ............ 19

Table 3.3 Relative Influence of KC46A Criteria Categories on Basing Process Outcomes ........ 19

Table 3.4 Reduced Data Collection Enabled by Various Mission Score Thresholds................. 21

Table 4.1 Sources Used to Answer Mission Basing Criterion Questions................................... 25

Table 4.2 Sources Used to Answer Capacity Basing Criterion Questions ............................... 25

Table 4.3 Sources Used to Answer Environment Basing Criterion Questions.......................... 26

Table 4.4 Sources Used to Answer Cost Basing Criterion Questions ...................................... 26

Table 4.5 Recommended Data Sources to Specify Across Basing Actions ............................. 28

Table 4.6 Recommended Data Sources to Standardize Across Basing Actions......................... 28

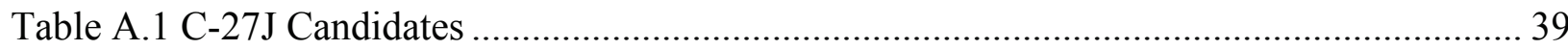

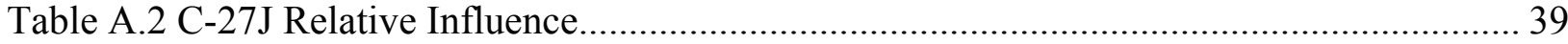

Table A.3 F-35 One-Squadron Candidates ........................................................................... 40

Table A.4 F-35 One-Squadron Relative Influence ............................................................... 40

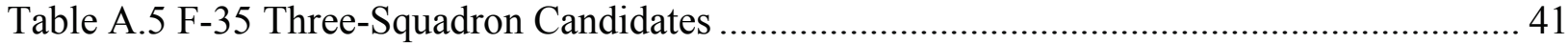

Table A.6 F-35 Three-Squadron Relative Influence............................................................... 41

Table A.7 F-35 Training Candidates .............................................................................. 41

Table A.8 F-35 Training Relative Influence...................................................................... 42

Table A.9 KC-46A MOB1 Candidates.................................................................................. 42

Table A.10 KC-46A MOB1 Relative Influence ................................................................... 43

Table A.11 KC-46A MOB2 Candidates ................................................................................... 43

Table A.12 KC-46A MOB2 Relative Influence ............................................................... 43

Table A.13 KC-46A Training Base Candidates ................................................................... 44

Table A.14 KC-46A Training Base Relative Influence.......................................................... 44

Table A.15 LiMA Candidates................................................................................................... 44

Table A.16 LiMA Relative Influence ................................................................................. 45

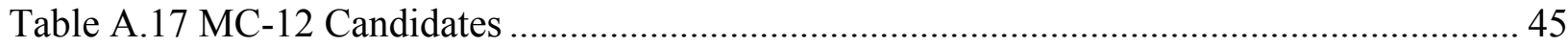

Table A.18 MC-12 Relative Influence........................................................................... 45

Table A.19 MQ-1/9 RSO Regular Air Force Candidates ....................................................... 46

Table A.20 MQ-1/9 RSO Regular Air Force Relative Influence ............................................ 46

Table A.21 MQ-1/9 RSO AFRC Candidates......................................................................... 46

Table A.22 MQ-1/9 RSO AFRC Relative Influence ........................................................... 47

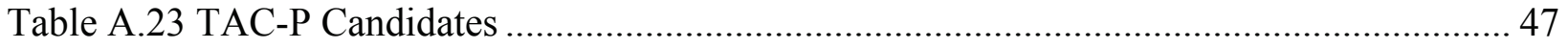

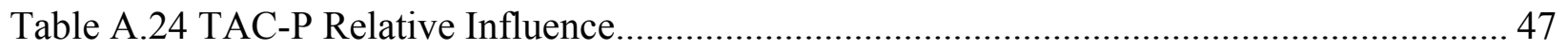


Table B.1 Department of Defense Criteria for the 2005 BRAC Round .................................. 50

Table B.2 Air Force Basing Principles and Imperatives........................................................ 52

Table B.3 Estimated Growth from All DoD Sources at and Near BRAC-Affected Military Bases

FY 2006 Through 2012, as of March 2008............................................................... 56

Table B.4 BRAC Recommendations with the Largest Increases in One-Time Estimated Costs

from FY 2009 to FY 2010 (\$ millions) .................................................................. 58

Table E.1 Comparison of Service Basing Decisionmaking Processes .................................... 86 


\section{Summary}

The U.S. Air Force manages any proposed significant changes and additions regarding the location of weapon systems and personnel through its strategic basing process, and the Air Force has conducted more than 100 strategic basing decisions since 2009. Some notable recent examples of strategic basing decisions are the evaluations of which installations will host the F-35 and KC-46A major weapon systems. Air Force basing decisions are public, frequent, and occasionally contentious. Because these decisions affect force posture, local economies, and public trust, it is imperative that the decisionmaking process be objective and reproducible. Unfortunately, a small number of these decisions resulted in eroded local confidence in the process. For example, news media reports suggested that the decision to base F-35s at Burlington, Vermont, was either a result of faulty data or undue political influence (Bender, 2013). Such examples highlight the need for strong empirical processes employing the best available data.

This report focuses on the procedures and data pertinent to the Air Force's strategic basing decision process. Specifically it focuses on three questions:

- Are basing decision criteria aligned with Air Force intentions?

- Are the data used in the Air Force's basing decisionmaking process authoritative, consistent, and auditable?

- Is there potential for broader Air Force strategic or portfolio-wide inputs to strengthen the basing decisionmaking process?

\section{Current Basing Decisionmaking Process}

The Air Force employs a three-step enterprise-wide process, shown in Figure S.1, to ensure consistency when it makes strategic basing decisions, such as choosing an installation to host new weapon systems, major changes in installation personnel, or hosting tenants on installations.

- First, the applicable major command (MAJCOM) develops criteria to evaluate an installation's suitability to support the proposed basing action. Criteria include, but are not limited to, an installation's ability to execute the mission, capacity to host the unit, environmental impact of the unit, and economic factors, such as locality and construction cost factors associated with individual installations. Each criterion is further broken down into a number of attributes that define that criterion. Once Headquarters Air Force (HAF) and the Secretary of the Air Force (SecAF) approve the evaluation criteria, they are briefed to Congress.

- In the second step, individual basing scores for the defined basing criteria are assembled by the MAJCOM, and all of the bases are screened to determine the appropriateness of hosting the basing action at each location. Using these scores, a small set of candidate 
bases, usually four to six, is selected for on-site surveys, which are approved by the HAF and the SecAF and then briefed to Congress.

- In the final step following the site surveys, a preferred installation is selected. As in the previous steps, this is approved by HAF and the SecAF, then briefed to Congress. The basing action proceeds through National Environmental Policy Act (NEPA) compliance and is eventually implemented at the installation.

The Air Force's process has a high level of interaction with Congress, and the Air Force provides briefing updates at several points in the process. In the Army and Navy's basing process, Congress is notified after a decision has been made.

Figure S.1

Standard U.S. Air Force Strategic Basing Process and Governance

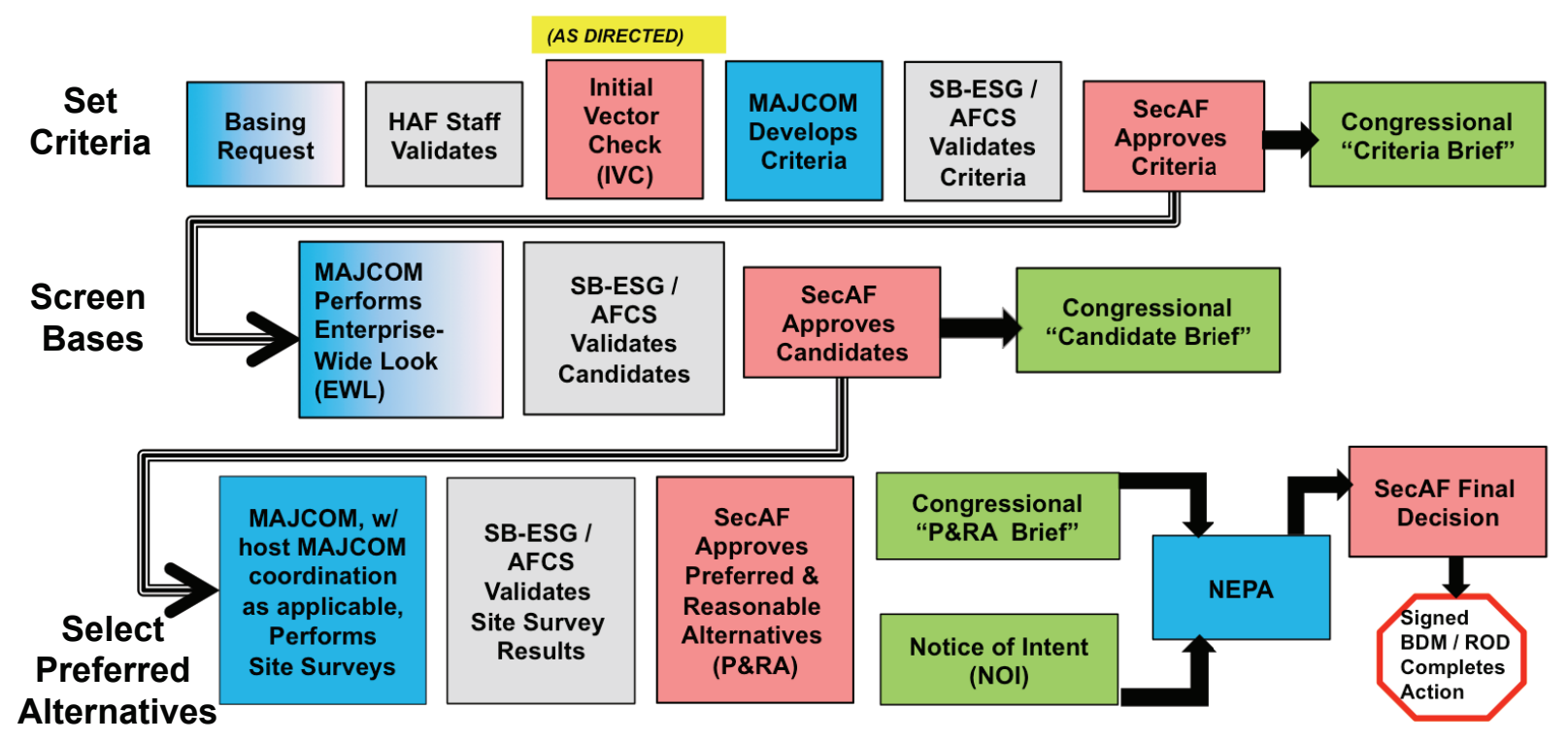

SOURCE: Pohlmeier, 2012.

NOTES: Blue boxes represent actions for MAJCOM/base-level personnel. Gray boxes represent actions for HQ/Air Staff personnel. Red boxes represent meetings/approval from SecAF/Chief of Staff of the Air Force. Green boxes represent congressional interaction/briefings. SB-ESG = Strategic Basing Executive Steering Group; AFCS = Air Force Corporate Structure; P\&RA = preferred and reasonable alternatives; $B D M=$ basing decision memo; ROD = record of decision.

\section{Does the Current Basing Process Always Align with Air Force Objectives?}

The basing criteria used to evaluate candidate bases consist of individual attributes important to the basing action under consideration. For example, is there fuel storage, runway space, and ramp space available for the units being considered? For each basing action, there are 100 total points available if an installation meets all of the criteria at the maximum desired level. This scoring system enables a comparison of installations across the enterprise. In a majority of the basing decisions analyzed, these attributes were grouped into four categories: mission, capacity, environment, and cost. 
Mission criteria include attributes of an individual installation that affect the mission, such as weather, airspace, and proximity to ranges. If proximity to Army and Navy operations, training, or ranges is necessary to enable jointness between the services for a specific weapon system beddown, then the Air Force includes jointness as part of the mission criteria. Capacity criteria evaluate whether an installation's existing infrastructure can accommodate the proposed basing action. The environmental criteria represent the existing conditions at an installation that might inhibit accommodating the proposed mission, such as air quality, land use, and incompatible development areas due to noise or encroachment issues. The cost criteria represent the regional variation in federal employee salaries, construction capital costs, and military basic allowance for housing $(\mathrm{BAH})$ rates.

To understand the basing process outcomes, we analyzed the data for 25 relevant basing actions. These data included scoring criteria, categories and weights, and points assigned from individual installation responses across the USAF enterprise. We assessed how well the weight assigned by the Air Force to each scoring category (e.g., mission, capacity) aligned with the actual influence of these categories on the choice of candidate bases using a model developed by RAND called the Generalized Boosted Model (GBM). GBM calculates the "relative influence" of each attribute on the probability of an installation either scoring in the top 10 percent of installations or becoming a site survey candidate. The model assigns relative influence to each category by iteratively attempting to replicate the actual results through a bottom-up analytical process.

The GBM results analytically validate what is an intuitive and expected outcome of the basing process as currently structured - installations that can perform the mission and that have currently available capacity should be competitive for a site survey. However, while our analysis shows that a good mission score is necessary to be considered for a site visit, we also found that, when it came to actually being selected for a site visit, the capacity score was usually more important. This suggests that, in practice, the mission category screens candidates, and the capacity criteria category determines site selection.

\section{Assessing Basing Data Quality}

We examined data quality along three dimensions: authoritativeness, consistency, and auditability. Authoritativeness measures the extent to which sources used to answer data call questions align with authoritative or credible sources. Consistency measures the extent to which candidate bases for a given action use the same sources to answer the same questions, and the extent to which a given base consistently answers the same question for different actions. Auditability measures the extent to which data sources are documented and traceable.

We found that the data used to make basing decisions are authoritative and consistent, but the auditability of the data call and response process can be improved. Therefore, a majority of "data 
errors" may be unrelated to data quality and result from the data collection process or human error, or potentially both.

\section{Role of Strategy in Basing Decisions}

The Air Force tends to approach basing decisions in the continental United States (CONUS) and outside of the continental United States (OCONUS) as completely separate processes. Specifically, the Air Force and the U.S. government choose and maintain overseas bases principally for their strategic and diplomatic value, while the Air Force chooses and maintains domestic bases according to other criteria, such as access to training ranges, utilizing existing capacity, and satisfying political considerations. Consequently, the CONUS basing process is influenced by the potential impact that base closures could have on their surrounding communities and the efforts of elected officials to keep bases in their districts open. As discussed in this report, the Air Force basing decision process is rooted in assessing a base's ability to support the mission of the unit being based, its capacity to support the unit, and both cost and environment issues associated with the basing action. However, the current domestic basing process does not include a portfolio-wide assessment of individual decisions or explicitly incorporate broader Air Force strategic concerns. In some cases, strategic considerations are included in the mission criteria established to evaluate installations. The lack of strategic input is a post-Cold War phenomenon. Prior to the successful employment of long-range intercontinental ballistic missiles (ICBMs), the Air Force established bases in northeastern United States to support heavy bombers. Following the introduction of ICBMs, the survivability of CONUS bases in the event of a preemptive Soviet strike shifted the Air Force toward more bases in southern portions of the United States. As the Air Force plans for new weapon systems and force structures, incorporating strategic concerns across the portfolio of basing decisions would help to maximize capabilities and minimize life-cycle costs.

\section{Observations and Recommendations}

\section{The Air Force Should Institute an Initial Screening Process}

Our analysis found that the current basing process is designed so that installations with high mission scores are advanced toward site selection, but that capacity scores largely influence the final candidate list. To reduce the cost and time of conducting the existing strategic basing process, the Air Force should consider using centralized data to answer mission-related questions that can initially screen candidate bases for suitability. With a reduced set of potential installations to consider, the detailed capacity and environmental data collection efforts could focus on those installations with competitive mission scores. An initial screening process based on mission scores would maintain equity by considering all installations in the enterprise, but 
collecting detailed capacity, environmental, and cost data only on installations that can best achieve the desired mission.

The Air Force could apply lessons learned from previous basing actions and military judgment to set a potential mission score threshold for screening. Setting the threshold too high could overlook bases that might otherwise be selected as candidates, while setting the threshold too low would expand the number of installations required to provide detailed capacity analyses. From our sample of 25 basing decisions, we analyzed 12 enterprise-wide look basing actions to see what mission score thresholds would have meaningfully reduced the size of the data call without omitting any bases eventually chosen as candidates for a site selection survey. Over the 12 basing actions, 1,531 total data calls were sent to CONUS installations. These data calls require personnel at MAJCOMs or headquarters to transmit, receive, and analyze the information, as well as civil engineering and other personnel at each installation to respond to each data call. For our sample, all of the installations selected for a site selection survey received at least 35 percent of the maximum possible mission score, and most received at least 50 percent. This means that, for the 12 actions in our sample, 626 to 882 data call responses would have been saved if the detailed data calls were limited to installations with high mission scores (Table S.1).

Table S.1

Reduced Data Collection Enabled by Various Mission Score Thresholds

\begin{tabular}{lcc}
\hline Threshold & $\begin{array}{c}\text { Data Requests to } \\
\text { Installations }\end{array}$ & $\begin{array}{c}\text { Reduction in Data Call } \\
\text { Responses }\end{array}$ \\
\hline No threshold & 1,531 & - \\
Mission score at least $50 \%$ of max possible & 649 & 882 \\
Mission score at least 40\% of max possible & 831 & 700 \\
Mission score at least 35\% of max possible & 905 & 626 \\
\hline NOTE: Sample analyzed consisted of 12 decisions in USAF's strategic basing process that considered \\
installations across USAF's CONUS enterprise.
\end{tabular}

Using mission criteria to screen bases prior to selecting bases for further consideration can reduce the data collection burden on the enterprise by nearly half, with no decrease in the quality of the ultimate basing decision.

\section{Air Force Data Quality Is Sufficient to Support Decisions}

The data currently used are of sufficient quality to support USAF basing decisions. Our analysis found the data to be authoritative and consistent, but the auditability of underlying data used in the basing action process is weak. It is challenging to trace specific sources used to answer questions, even when responsible parties are identified in a MAJCOM-provided data call template, as is the case for the $\mathrm{KC}-46 \mathrm{~A}$ basing actions. There is no data call template used for other basing actions, making it even more difficult to identify underlying data sources. Improved 
auditability will allow for more efficient review by HAF and other parties. The combination of improved auditability and increased review should decrease the potential for human error in the basing decisionmaking process, which accounts for a majority of the publicly disputed basing decisions. 


\section{Acknowledgments}

We are grateful to Acting Assistant Secretary of the Air Force for Installations, Environment and Logistics Kathleen Ferguson for her sponsorship and support throughout the execution of this research. We thank the professionals at Headquarters Air Force who provided guidance, time, and information, including Deputy Assistant Secretary of the Air Force for Installations Timothy Bridges, Col Frank Freeman III, Lt Col Dennis Burgart, Andrew Mendoza, Mark Pohlmeier, and Nugent Nguyen. We met with and corresponded with scores of individuals and organizations throughout the Air Force who gave freely of their time and perspectives. They are too numerous to list individually, but we especially thank Kevin Flood, Geno Patriarca, and Richard Rankin for repeatedly giving us so much of their time and insights.

Many RAND colleagues contributed crucial analysis, insights, critiques, and advice in the course of this research. The constant support, substantive input, and critical guidance provided by Laura H. Baldwin, former director of the Resource Management Program within RAND Project AIR FORCE, is greatly appreciated. We are grateful for the contributions, feedback, and assistance received from RAND colleagues Sean Bednarz, Grover Dunn, Katheryn Giglio, Stephanie Lonsinger, Leslie Lunger, Jason Mastbaum, Ronald McGarvey, Laura Novacic, Daniel Romano, and Anthony Rosello. We are especially thankful for the comments, suggestions, and critiques of the reviewers at RAND: Irv Blickstein, Edward Keating, and Scott Savitz. Their feedback has considerably strengthened this research. 



\section{Abbreviations}

AAC

AAF

AF/A1MR

AF/A2R

$\mathrm{AF} / \mathrm{A} 3 \mathrm{O}$

AF/A4L

AF/A5X

$\mathrm{AF} / \mathrm{A} 7 \mathrm{C}$

AF/A8P

AF/A8PB

AF/A8X

AF/A9R

AF/A10

$\mathrm{AF} / \mathrm{JA}$

$\mathrm{AF} / \mathrm{RE}$

AFB

AFCS

AMC

ASIP

$\mathrm{BAH}$

BAR

BCEG

BRAC

BRRP

COBRA

CONUS

CSAF

DoD

GAO

GBM

GDPR
Army Air Corps

Army Air Force

USAF Manpower, Organization and Resources, Manpower Requirements

Division

USAF Directorate for Intelligence, Surveillance and Reconnaissance

Resources

USAF Director of Operations

USAF Logistics, Nuclear Weapons, Munitions and Missile Maintenance

Division

USAF Director of Operational Planning, Policy, \& Strategy

USAF Civil Engineers

USAF Director of Programs

USAF/Strategic Basing Division (the owner of the USAF Strategic Basing

Process)

USAF Director of Strategic Planning

USAF Resource Analyses

USAF Strategic Deterrence and Nuclear Integration

USAF Judge Advocate General

USAF Reserve

Air Force Base

Air Force Corporate Structure

Air Mobility Command

Army Stationing and Installation Plan

basic allowance for housing

Basing Action Request

Base Closure Executive Group

Base Realignment and Closure

Basing Request Review Panel

Cost of Base Realignment Actions

continental United States

Chief of Staff of the Air Force

U.S. Department of Defense

U.S. Government Accountability Office

Generalized Boosted Model

Global Defense Posture Realignment 


\begin{tabular}{|c|c|}
\hline HAF & Headquarters Air Force \\
\hline ICBM & intercontinental ballistic missile \\
\hline IMC & information for members of Congress \\
\hline IVC & Initial Vector Check \\
\hline $\mathrm{JCS}$ & Joint Chiefs of Staff \\
\hline MAJCOM & major command \\
\hline MCI & Mission Compatibility Index \\
\hline MOB & main operating base \\
\hline NEPA & National Environmental Policy Act \\
\hline NSC-68 & National Security Council Report 68 \\
\hline OCONUS & outside of the continental United States \\
\hline OPS & operational basing \\
\hline OSD & Office of the Secretary of Defense \\
\hline P\&RA & preferred and reasonable alternatives \\
\hline RCAF & Royal Canadian Air Force \\
\hline SAC & Strategic Air Command \\
\hline SAF/AQX & Deputy Assistant Secretary of the Air Force for Acquisition Integration \\
\hline $\mathrm{SAF} / \mathrm{FMB}$ & Deputy Assistant Secretary of the Air Force for Budget \\
\hline $\mathrm{SAF} / \mathrm{GC}$ & Department of the Air Force General Counsel \\
\hline $\mathrm{SAF} / \mathrm{IE}$ & $\begin{array}{l}\text { Assistant Secretary of the Air Force for Installations, Environment, and } \\
\text { Logistics }\end{array}$ \\
\hline $\mathrm{SAF} / \mathrm{IEB}$ & $\begin{array}{l}\text { Deputy Assistant Secretary of the Air Force for Basing and Infrastructure } \\
\text { Analysis }\end{array}$ \\
\hline $\mathrm{SAF} / \mathrm{IEE}$ & $\begin{array}{l}\text { Assistant Secretary of the Air Force for Installations, Environment, and } \\
\text { Energy }\end{array}$ \\
\hline $\mathrm{SAF} / \mathrm{IEI}$ & Deputy Assistant Secretary of the Air Force for Installations \\
\hline $\mathrm{SAF} / \mathrm{LL}$ & USAF Directorate of Legislative Liaison \\
\hline $\mathrm{SAF} / \mathrm{PA}$ & USAF Director of Public Affairs \\
\hline $\mathrm{SAF} / \mathrm{US}(\mathrm{M})$ & USAF Office of Business Transformation \\
\hline SB-ESG & Strategic Basing Executive Steering Group \\
\hline SecAF & Secretary of the Air Force \\
\hline SME & subject matter expert \\
\hline TFI & Total Force Integration \\
\hline USAF & United States Air Force \\
\hline WIDGET & Web-based Installation Data Gathering and Entry Tool \\
\hline
\end{tabular}




\section{Introduction}

The U.S. Air Force (USAF) manages any proposed significant changes and additions regarding the location of weapon systems and personnel through its strategic basing process, and the Air Force has conducted more than 100 strategic basing decisions since 2009. Some notable recent examples of strategic basing decisions are the evaluations of which installations will host the F-35 and KC-46A major weapon systems. USAF basing decisions are public, frequent, and occasionally contentious. Because these decisions affect force posture, local economies, and public trust, it is imperative that the decisionmaking process be objective and justifiable. Unfortunately, a small number of these decisions resulted in eroded local confidence in the process. For example, news media reports suggested that the recent decision to base F-35s at Burlington, Vermont, was either a result of faulty data or undue political influence (Bender, 2013).

The economic importance of airbases and personnel to local stakeholders has been present from the beginning of the Air Force. Local interests influenced the location of the first airbase that the Army purchased in 1916. In its search for a suitable piece of land for an air training facility, the Army considered over a dozen locations and narrowed it down to two choicesHampton, Virginia, or Aberdeen, Maryland — based on physical requirements. Aiming to secure the economic benefits that come with a large military base, a group of Hampton citizens tipped the balance in favor of Langley Field by offering to sell the land at a steeply discounted rate and to build a railroad line and other essential infrastructure (Brown, 1990). Installations remain desirable to local interests, and such examples highlight the need for strong empirical processes employing the best available data during the basing process. This will help maximize USAF capabilities and minimize life-cycle costs.

\section{The Current Basing Decisionmaking Process}

The Air Force employs a three-step enterprise-wide process to ensure consistency when it makes basing decisions. In the first step, a set of criteria, composed of individual criterion to be assessed for each installation, is developed to evaluate an installation's suitability to support a basing decision. The criteria are grouped by category and include, but are not limited to, mission, capacity, environment, and costs. Mission criteria include attributes of an individual installation that affect the mission, such as weather, airspace, and proximity to ranges. Capacity criteria evaluate whether an installation's existing infrastructure, such as hangar availability, ramp space, and classroom space, can accommodate the proposed basing action. The environmental criteria represent the existing conditions at an installation that might inhibit accommodating the proposed mission, such as air quality, land use, and incompatible development areas due to noise 
or encroachment issues. The cost criteria represent the regional variation in federal employee salaries, construction capital costs, and military basic allowance for housing (BAH) rates, but generally do not include outlays required to support an individual basing decision. The basing decision criteria are developed by the applicable major command (MAJCOM), approved by the Headquarters Air Force (HAF) and the Secretary of the Air Force (SecAF), and briefed to Congress.

In the second step, individual basing scores for the defined criteria are assembled by the MAJCOM and compared. A small set of candidate bases, usually four to six, is selected for site surveys. This list of candidate bases is also developed by the MAJCOM, approved by HAF and SecAF, and briefed to Congress.

In the final step following the site surveys, a preferred base is selected. As in the previous steps, this is approved by HAF and SecAF and briefed to Congress. The credibility of this

process is dependent on these data calls resulting in high-quality data that are then analyzed in a transparent and objective manner.

\section{The RAND Analysis}

RAND was engaged to conduct an independent analysis of the USAF's basing process. The purpose of this analysis is to inform decisionmakers on potential improvements to the quality of data and assessment criteria used in making these decisions. In considering the USAF's basing decisionmaking process, we considered three questions:

- Are basing decision criteria aligned with Air Force intentions?

- Are the data used in the Air Force basing decisionmaking process authoritative, consistent, and auditable?

- Is there potential for broader USAF strategic or portfolio-wide inputs to strengthen the basing decisionmaking process?

In answering the first question, we examined the actual data source for each base in enterprise-wide KC-46 and F-35 basing actions. We used these two basing decisions because they represent the bedding down of new major weapon systems across two lead MAJCOMs, have a broad scope, and have extensive available data. Our examination entailed contacting bases to ascertain the data source for each decision criterion. To assess the second question, we examined the desired and actual impact of each decision criterion for 25 relevant basing actions. Using statistical analysis, the actual impact of each criterion can be determined and compared with its desired impact. Finally, in addressing the potential for inclusion of strategic inputs into the basing decisionmaking process, we assessed the historical impact of strategic inputs and possible mathematical techniques to incorporate such inputs into the current basing process. 


\section{Organization of This Report}

The remainder of this report is organized as follows: Chapter Two describes the current USAF strategic basing process in some detail and specifically describes where data are collected and assessed. Chapter Three assesses whether the current USAF process provides desired outcomes and explores potential process improvements. Chapter Four specifically evaluates the quality of data used in the USAF basing decisionmaking process. Chapter Five describes the challenges presented by the current basing process. Chapter Six offers a series of findings and recommendations based on our research.

A detailed analysis of the basing decision criteria evaluated in Chapter Three and a description of the 2005 Base Realignment and Closure (BRAC) process are included in Appendixes A and B, respectively. Appendix $\mathrm{C}$ provides additional detail on the Generalized Boosted Model (GBM) (Ridgeway, 2009) used to assess how well the weight assigned by the Air Force to each scoring category (e.g., mission, capacity) aligned with the actual influence of these categories on the choice of candidate bases. Appendix D expounds on the historical role of strategy in domestic USAF basing decisions. Appendix E describes the basing decisionmaking processes employed by the U.S. Army and U.S. Navy. 



\section{Current Air Force Strategic Basing Process and Governance}

To standardize decisions regarding major changes to weapon systems, personnel, and tenants on installations, the Air Force developed an enterprise-wide strategic basing process in 2009 (AFI 10-503, 2010), with HAF acting as the clearinghouse for all basing actions. The Air Force Strategic Basing Division at HAF (AF/A8PB) is the designated office for managing the strategic basing process and has critical roles across the life cycle of a basing decision. The process, shown in Figure 2.1, involves numerous actors with varying incentives, information, and resources. The process can be divided into three stages: setting the criteria, screening bases, and selecting preferred alternatives.

- First, the Strategic Basing Division designates the proponent MAJCOM, who then develops criteria to evaluate an installation's suitability to support the proposed basing action and submits the criteria back to the Strategic Basing Division. Criteria include, but are not limited to, an installation's ability to execute the mission, capacity to host the unit, environmental impact of the unit, and economic factors, such as locality and construction cost factors associated with individual installations. Each criterion is further broken down into a number of attributes that define that criterion. Once HAF and the SecAF approve the evaluation criteria, they are briefed to Congress.

- In the second step, individual basing scores for the defined basing criteria are assembled by the MAJCOM, and all of the bases are screened to determine the appropriateness of hosting the basing action at each location. Using these scores, a small set of candidate bases, usually four to six, is selected for on-site surveys, which are approved by HAF and the SecAF and then briefed to Congress.

- In the final step following the site surveys, a preferred installation is selected. As in the previous steps, this is approved by HAF and the SecAF, then briefed to Congress. The basing action proceeds through National Environmental Policy Act (NEPA) compliance and is eventually implemented at the installation.

USAF's process has a high level of interaction with Congress, and the USAF provides briefing updates at several points in the process. In the Army and Navy's basing process, Congress is notified after a decision has been made, as discussed in Appendix E. 
Figure 2.1

Standard U.S. Air Force Strategic Basing Process and Governance

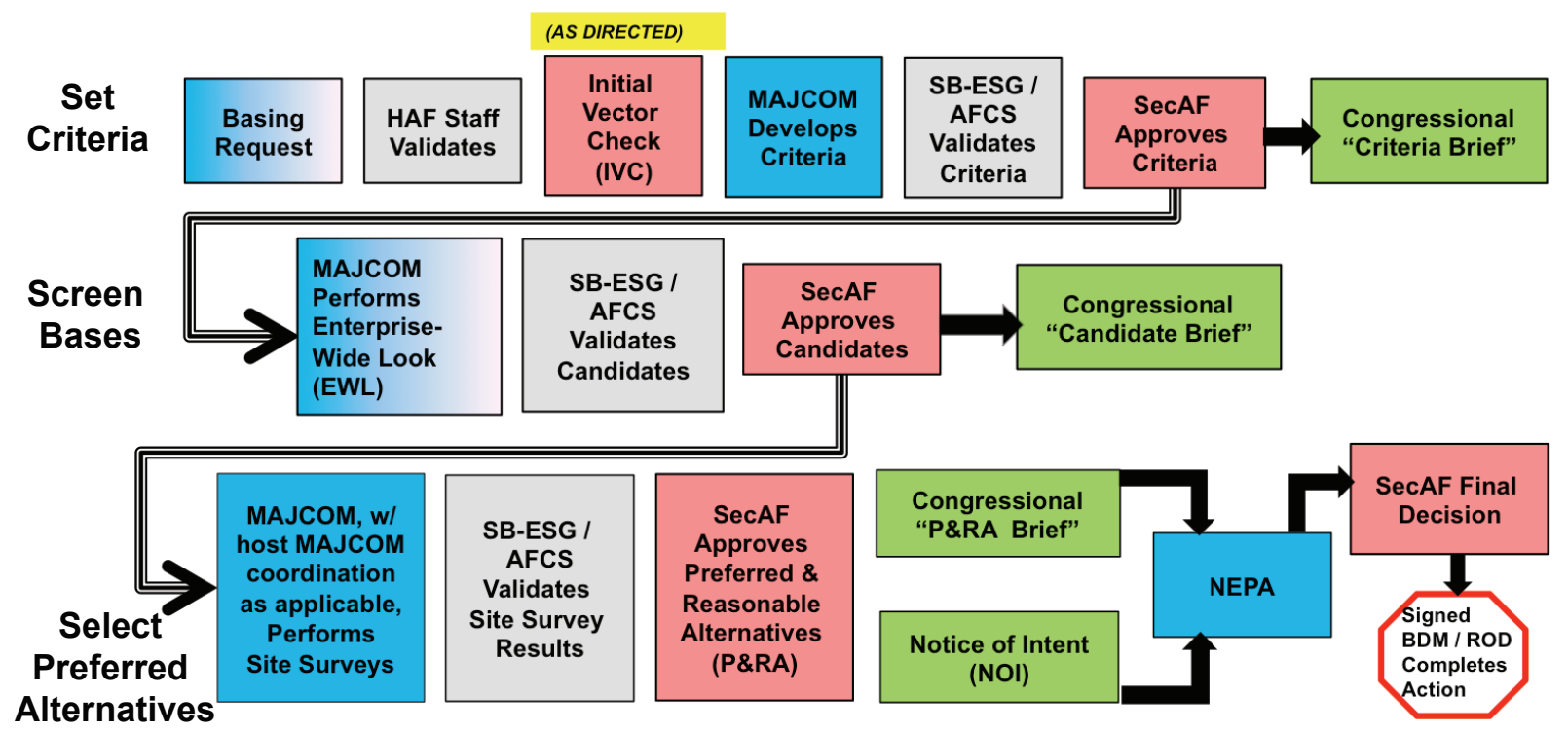

SOURCE Pohlmeier, 2012.

NOTES: Blue boxes represent actions for MAJCOM/base-level personnel. Gray boxes represent actions for HQ/Air Staff personnel. Red boxes represent meetings/approval from SecAF/Chief of Staff of the Air Force (CSAF). Green boxes represent congressional interaction/briefings. SB-ESG = Strategic Basing Executive Steering Group; AFCS = Air Force Corporate Structure.

\section{Roles and Responsibilities}

HAF actions are the responsibility of the Strategic Basing Executive Steering Group (SB-ESG). The SB-ESG reviews and evaluates USAF concepts of operations, basing objectives, criteria, policies, programming, and planning and makes recommendations to the SecAF and the Chief of Staff of the Air Force (CSAF). The SB-ESG is composed of one- and two-star general officers and civilian equivalents and chaired by the Secretary of the Air Force for Installations, Environment and Logistics (SAF/IE). ${ }^{1}$ The Basing Requests Review Panel (BRRP) supports the SB-ESG as the first level of the Air Force Strategic Basing Structure for basing review and decisions. The BRRP is chaired by AF/A8PB and includes O-6 and civilian equivalents. ${ }^{2}$

The lead MAJCOM for the action submits a Basing Action Request (BAR) to AF/A8PB. For example, this action could be the relocation of a major training center, or the bedding down of a new weapon system. The requester provides the action title, requester contact information, the

\footnotetext{
${ }^{1}$ Membership of the SB-ESG includes representatives from the following: AF/A1MR, AF/A2R, AF/A3O, AF/A4L, AF/A5X, AF/A7C, AF/A8P, AF/A8X, AF/A9R, AF/A10, AF/RE, AF/JA; SAF/IEI, SAF/FMB, SAF/GC, SAF/IEE, $\mathrm{SAF} / \mathrm{AQX}, \mathrm{SAF} / \mathrm{LL}, \mathrm{SAF} / \mathrm{PA}, \mathrm{SAF} / \mathrm{US}(\mathrm{M})$, and NGB/CF.

2 Membership of the BRRP includes representatives from the following areas: AF/A1MZ, AF/A3O-B, AF/A5X, AF/A7CAI, AF/A7CIB, AF/A8PB, AF/A8X, AF/A9R, AFLOA/JACE, SAF/GCN, SAF/LLP, SAF/PAX, and SAF/IEI.
} 
mission design series affected, the type of action, the anticipated Environmental Impact Analysis Process, the type of unit involved, the property owner, the lead MAJCOM, the lead MAJCOM action officer contact information, and the installations affected.

Some actions must be coordinated with non-USAF entities. When USAF entities propose moves onto non-USAF installations, including joint bases owned by other services, the basing proponent's lead MAJCOM submits a BAR to AF/A8PB and receives HAF approval prior to pursuing a basing option with a non-USAF entity. Once approved by HAF, AF/A8PB will coordinate the request on behalf of the proponent MAJCOM. When non-USAF entities request to move onto USAF installations, including USAF-owned joint bases, the entity's top-level headquarters element for approving a basing action submits the BAR to AF/A8PB. The proposed host MAJCOM basing office and AF/A8PB assist with the development of criteria for the enterprise-wide look. In most cases, the host MAJCOM is designated as the lead MAJCOM and the standard USAF strategic basing process is followed (Air Force Instruction 10-503, 2010, paragraph 1.1).

\section{Basing Decision Thresholds}

The first step in the strategic basing process is for HAF to validate the BAR and determine whether the request should go through the strategic basing process. AF/A8PB may enter any special interest action, regardless of size or scope, into the strategic basing process. However, typically, to be considered a basing action, the request must meet all of the following threshold criteria:

- a manpower increase or decrease greater than 50 positions on the Unit Manning Document

- a weapon system change

- including additions, subtractions, or mission baseline design replacement

- excluding tail number swaps and block/spiral upgrades

- an inter-MAJCOM action involving 25 or more manpower positions

- a unit which is activated or inactivated at the squadron level or higher

- the addition, subtraction, or relocation on or off base of a general officer/Senior Executive Service billet, except National Guard Bureau general officers moving under Title 32

- a non-USAF entity requesting to move onto or add 25 or more manpower positions onto USAF property.

There are exceptions that will exclude an action from the strategic basing process even if it meets the above thresholds. Exceptions include

- BRAC actions

- contingency operations

- Total Force Integration actions

- responsibilities for Total Force Integration 
- real estate enhanced use leases

- some non-estate enhanced use real estate actions

- depot source repair actions

- banks and credit unions

- post offices

- grazing and croplands

- utility and road easements

- utility and roads granted by lease and license

- military exchange retail, warehouse, and support operations

- commissaries

- Morale, Welfare, and Recreation support activities (archery clubs, riding stables, etc.)

- base support activities (American Red Cross, labor union offices, etc.).

$\mathrm{AF} / \mathrm{A} 8 \mathrm{~PB}$ may choose to expedite actions that are considered too urgent or too simple for the full strategic basing process. Expedited actions will skip directly to the site survey. Expedited actions must be simple, specialized, or time-sensitive. Simple actions have minimal mission and environmental impact on any installation selected to support the basing requirement and, therefore, do not need SecAF/CSAF approval. Specialized actions support unique mission requirements, which limit the enterprise of potential installations to specific locations. Timesensitive actions already have SecAF/CSAF support for an accelerated decision timeline. Expedited processes often include actions that support special operations or are for other service or government tenants moving onto Air Force Bases. Once HAF has decided whether the request will follow the standard basing process, follow the expedited process, or falls outside of the basing process, there is an Initial Vector Check (IVC) with the SecAF.

\section{Setting the Basing Decision Criteria}

The proponent MAJCOM develops criteria for the enterprise-wide look. The process begins when the MAJCOM submits the BAR Part 1, which describes the purpose of action, the rationale, the type of facilities, the size of facilities and/or acres required, the present and projected force structure, the urgency of the proposed action, the projected environmental action, the impact if not approved, the benefit to the Air Force, and the base selection criteria. The MAJCOMs tailor criteria for each basing action as shown in Figure 2.2. SB-ESG provides broad guidance on the development of criteria and validates them before submitting them to HAF and SecAF for approval. Once approved, the criteria for this basing decision are briefed to Congress. As a result of this particular criteria system, comparisons between bases can be counterintuitive. For example, in adding up the total scores, one "Mission" point has the same impact as one "Environmental" point. As a result, a base with a relatively high "Mission" score may receive a lower grade than a base with better "Capacity" and "Environmental" scores. Appendix A discusses the details on individual basing decisions that reflect these challenges. 
Figure 2.2

An Example of Basing Criteria

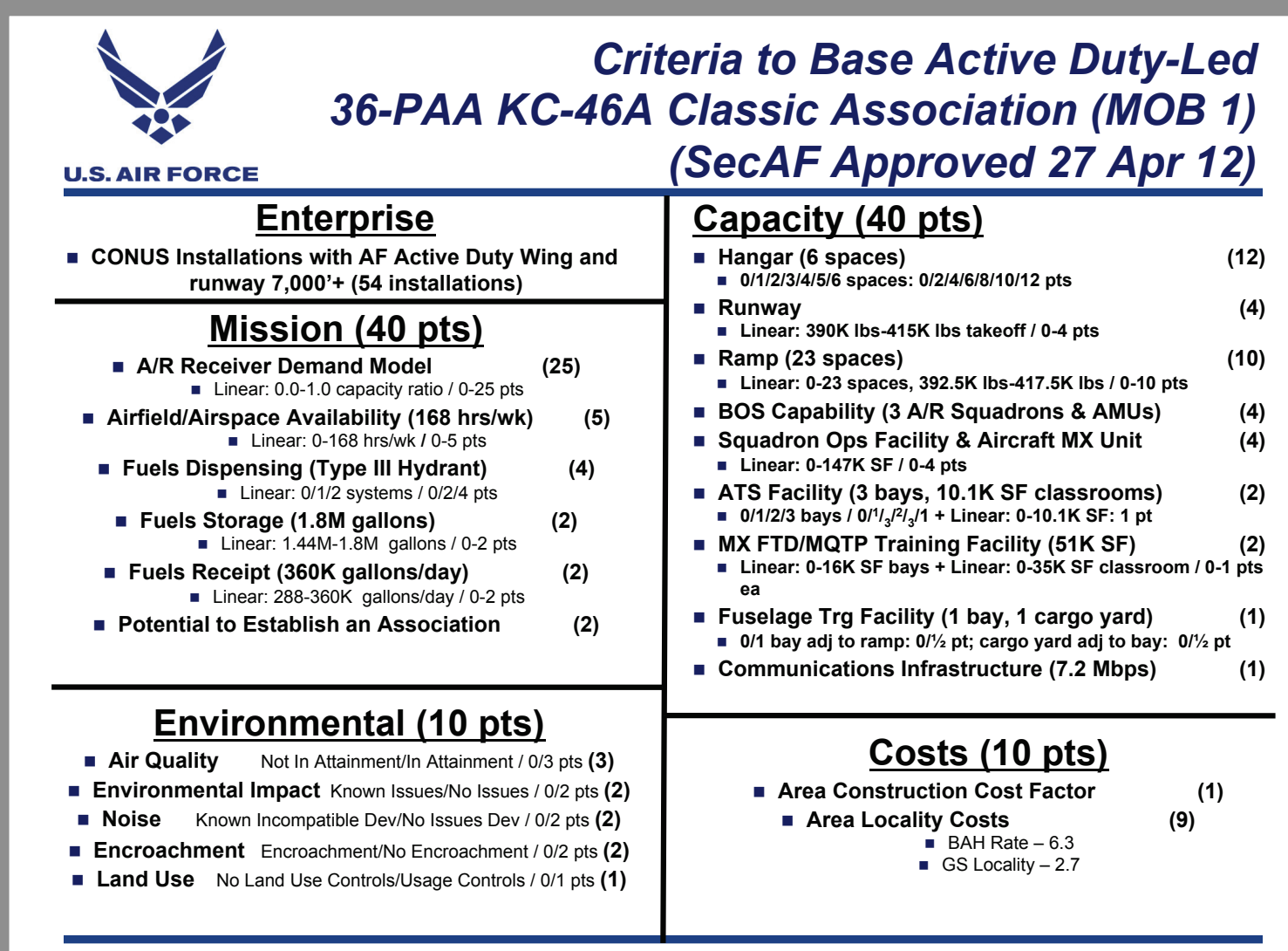

Integrity-Service-Excellence

SOURCE: Pohlmeier, 2012.

\section{Selecting Preferred Alternatives}

Once the basing criteria are approved, the proponent MAJCOM performs the enterprise-wide look. A data call is submitted to all installations considered in the action. The MAJCOM collects responses and scores all bases according to agreed criteria. The scored and ranked enterprisewide list of bases is submitted to SB-ESG/Air Force Corporate Structure (AFCS) in the BAR Part 2. The SB-ESG/AFCS then validates the candidates.

The members of the BRRP examine all of the scores and then apply military judgment to determine the number of installations to site survey and create a ranked candidate list (see Figure 2.3 for an anonymized example). BRRP members look for natural breaks and clusters in the scores, as well as for strategically important locations to create a candidate list of installations. Weapon system stakeholders and subject matter experts (SMEs) are included in this process by invitation only. The BRRP may host a conference to develop the candidate list of installations to receive site surveys. Once the SecAF approves the candidate list, the BRRP submits the site 
survey list in alphabetical order along with the site survey control number to the proponent MAJCOM. SecAF/CSAF approves candidates prior to assigning a site survey control number. The underlying scores are data-driven and objective, but enabling BRRP members to use military judgment introduces some subjectivity into the selection of a group of candidate bases for site surveys. However, allowing the BRRP members and USAF leadership to bring their experience and tacit knowledge into the selection of a broader group of candidate installations likely enables inclusion of potentially successful locations that would otherwise have been omitted.

Figure 2.3

Ranked Candidate Bases List for KC-46A Decision

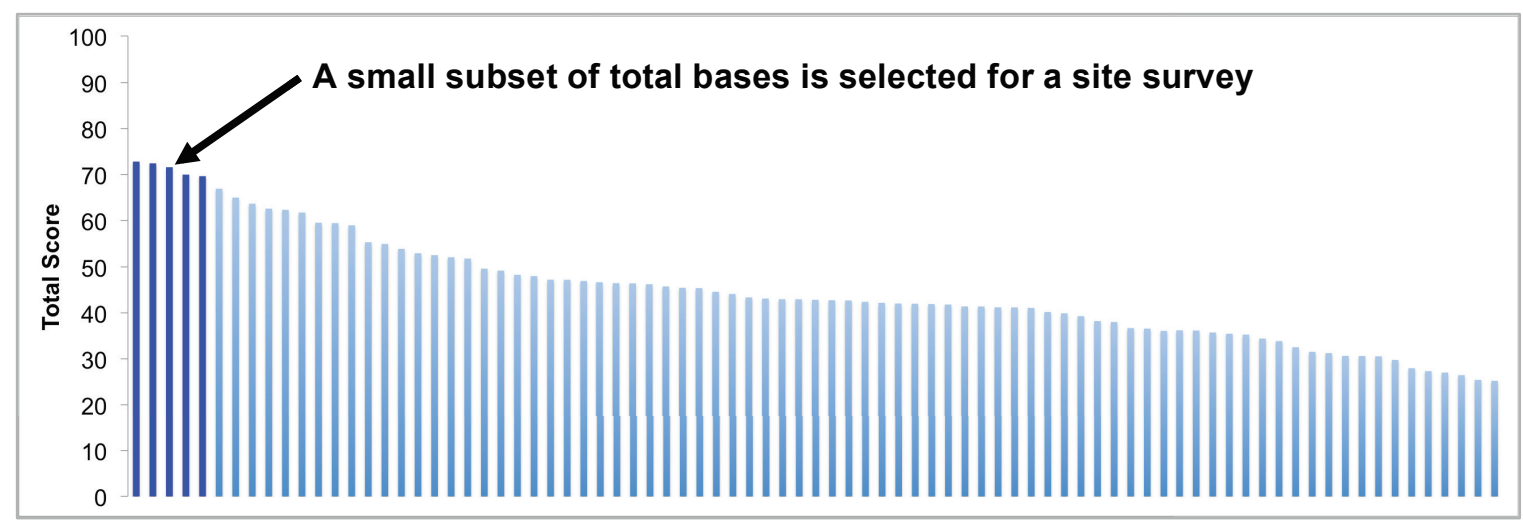

The lead proponent MAJCOM conducts site surveys of the candidate bases in coordination with the host MAJCOM and installations. After the survey is complete, the entity conducting the site survey is responsible for ensuring that the space remains available until a final basing decision is made. Follow-on surveys do not require additional approval, and they use the same site survey control number. The SB-ESG/AFCS validates site survey results.

Within 60 days of completing the last site survey, the proponent MAJCOM submits the BAR Part 3. The final BAR includes the cost, force protection requirements, the Environmental Impact Analysis Process, the evaluation of sites, the impact to existing missions, the recommendation, and alternatives. Once the preferred basing alternative is selected, SecAF makes the final decision and signs the alternative list for decision/approval, and the Base Decision Memorandum or Record of Decision. The SecAF also approves the Preferred and Reasonable Alternatives (P\&RA) brief. There is a final congressional P\&RA briefing and a Notice of Intent.

In the final phase of the process, USAF completes NEPA approval. NEPA approval includes the Environmental Impact Analysis Process and the Environmental Baseline Survey. The proponent MAJCOM must comply with NEPA requirements and should integrate the Environmental Impact Analysis Process during the initial planning stages to avoid delays. The final P\&RA briefing is subject to the results of NEPA approval. 
When SecAF signs the Basing Decision Memorandum, the action is complete and the MAJCOM is cleared to execute. Congressional engagement occurs throughout the process and includes a criteria briefing, a candidate briefing, and a P\&RA briefing.

Data enter the strategic basing process at five points: when the basing criteria are proposed, when the basing criteria are finalized, when the questions are framed for the data call, when the MAJCOMs and installations respond to the data call, and, finally, when data are obtained on site visits. In Chapter Three, we examine the basing criteria and the installation scores resulting from the data call. In Chapter Four, we take a closer look at how questions are framed for the data call and the data sources used in response to the data call. 



\section{Is the Air Force's Basing Process Aligned with Its Objectives?}

The USAF strategic basing process was developed so that the basing decisions for weapon systems and personnel could consider options across the USAF enterprise and use transparent criteria for evaluation. The intended outcome of all basing actions is the identification of a preferred alternative that is superior to other choices across criteria established for each basing action. As discussed in Chapter Two, these criteria are proposed by the lead MAJCOM, validated by the SB-ESG, approved by HAF and the SecAF, and briefed to Congress. These criteria determine the type of data collected from the candidate installations across the USAF enterprise, the level of effort required for data gathering, and, ultimately, which bases are selected for site visits as candidates for the proposed basing action. The criteria scores and weighting represent USAF priorities for the specific basing action, and, ideally, the results of basing actions would reflect the importance of these criteria. In this chapter, we evaluate the relative influence of initial scoring criteria in observed results of basing decisions, and we propose methods to reduce the level of effort required in the basing process while ensuring the alignment of results to USAF objectives.

\section{Understanding the Basing Criteria}

The basing criteria used to evaluate candidate bases across the USAF enterprise consist of individual attributes important to the basing action under consideration. Some basing actions require access to available airspace and measures of runway capabilities. Other basing actions require quantification of existing facilities on the installation that can be repurposed. These are a sample of the sometimes 20 or more criteria that are tailored for each basing action and then assigned a scoring rubric, which is used to evaluate responses received from installations. A list of criteria for a specific basing action was provided in Figure 2.2, and a list of general criteria evaluated across basing actions is listed in Table 3.1. For each basing action, there are 100 total points available if an installation meets all of the criteria at the maximum desired level. This scoring system enables a comparison of installations across the enterprise for each basing action. 
Table 3.1

General Criteria Evaluated in the U.S. Air Force Strategic Basing Process

\begin{tabular}{llll}
\hline \multicolumn{1}{c}{ Mission } & \multicolumn{1}{c}{ Capacity } & \multicolumn{1}{c}{ Environment } & \multicolumn{1}{c}{ Cost } \\
\hline - Airspace & - Administrative space & - Air quality non- & - Local area \\
- Expertise and & - Base size & attainment & construction cost \\
synergies & - Child care & - Encroachment & factors \\
- Proximity to demand, & - Classified/SAP work & - Land-use controls & - Local basic allowance \\
training, and & - space & - Noise impacts & for housing rates \\
requirements & - Communications & - Other environmental & - Government service \\
- Weather & - Dining & impacts & \\
& - Facility power/HVAC & & \\
& - Fitness center & & \\
& - Fuel capability & & \\
& - Hangars & & \\
& - Lodging factors \\
& - Medical & & \\
& - Operations support & & \\
& - Ramp capability & & \\
& - Runway capability & \\
& - Training facilities & \\
& - Storage space & \\
\hline
\end{tabular}

NOTES: HVAC = heating, ventilation, and air conditioning; SAP = special access programs. In some basing actions, criteria usually listed in capacity such as fuel capabilities, were listed as mission requirements. Our analysis assigned these general criteria to gain an understanding of the types of information gathered during the basing process.

The Air Force groups the individual scoring criteria into several categories. Across the basing actions we examined, these categories were primarily mission, capacity, cost, and environment. Each individual criterion has a maximum point score possible. Mission criteria include attributes of an individual installation that affect the mission, such as weather, airspace, and proximity to ranges. There are a few instances where mission criteria include infrastructure, such as the capability to receive, store, and dispense sufficient volumes of fuel, but the majority of mission criteria are largely a function of geography and outside the Air Force's control. If proximity to Army and Navy operations, training, or ranges is necessary to enable jointness between the services for a specific weapon system beddown, then the USAF includes jointness as part of the mission criteria. Capacity criteria evaluate whether an installation's existing infrastructure can accommodate the proposed basing action. These include criteria on available ramp space; hangars; capacity for such functions as administration, medical, and dining; and other infrastructure that could be added to an installation through construction. For some basing actions, the timing of when existing installation facilities will be ready to accommodate the proposed mission is characterized as a separate category than capacity, whereas in most basing actions, this is captured as part of the capacity category. The cost criteria used in the basing process represent the regional variation in federal employee salaries, construction capital costs, and military basic allowance for housing $(\mathrm{BAH})$ rates. These criteria represent regional economic factors, which are one input to life-cycle costs of basing actions, but the potentially larger operating costs of performing a specific mission from an individual installation are not 
captured in these criteria. Finally, environmental criteria represent the existing conditions at an installation that might inhibit accommodating the proposed mission, such as air quality, land use, and incompatible development areas due to noise or encroachment issues.

To understand the basing process outcomes, we obtained the data for 25 basing actions that used the strategic basing process. These data included scoring criteria, categories and weights, and points assigned from individual installation responses across the USAF enterprise. Across these basing actions, there were 373 individual criteria uniquely tailored to each action. Many of these criteria sought the same general information, but questions differed based on the specific requirements of each basing action. From all of the criteria used across the 25 actions examined, we characterized 29 general areas of information gathered, as shown in Table 3.1.

Of the 100 points possible for each basing action, mission and capacity criteria were assigned more weight across the larger recent basing actions we examined, although there is still variation among the weightings. The proponent MAJCOM develops the criteria and the weights, with approval from AF/A8PB and SecAF, as discussed in Chapter Two. For the F-35 basing decision, Air Combat Command assigned mission criteria 60 points and capacity 25 points; for the $\mathrm{KC}$ 46A basing decision, Air Mobility Command (AMC) assigned mission and capacity criteria 40 points each. Figure 3.1 illustrates the criteria weights for each action, separated by the proponent MAJCOM.

\section{Analyzing the Relative Influence of Basing Criteria}

Using the criteria, weighting, and observed outcomes of the basing process, we characterized the relative influence of the criteria on the Air Force's final decisions. We narrowed our data sample to the 20 basing actions since 2009 that involved data calls for at least 10 installations. Of these, we focused on the 12 actions for which candidate bases had been selected by the Air Force for site surveys and hence were under final consideration for the basing action. For each of these 12 actions, the data we used included the list of installations in the data call, the scoring criteria, the scores assigned to each base for each question, and the list of selected candidates. These 12 actions include basing decisions across aircraft categories, including fighter, tanker and transport aircraft, and are representative of likely future basing decisions.

Across our data sample, we observed that the bases scoring in the top 10 percent of the total available points were often those selected for a site survey as candidate bases for the basing action. As an example, Figure 3.2 shows the anonymized total scores for each installation evaluated for the KC-46A Second Main Operating Base (MOB2) basing action; the five highestscoring bases were selected for a site survey. This is consistent with the expected results of the USAF basing process - the highest total scores would be identified through the enterprise-wide look, and HAF and the SecAF would select groups of high-scoring candidates for site surveys. 
Figure 3.1

Criteria Weights Assigned in Selected U.S. Air Force Basing Actions

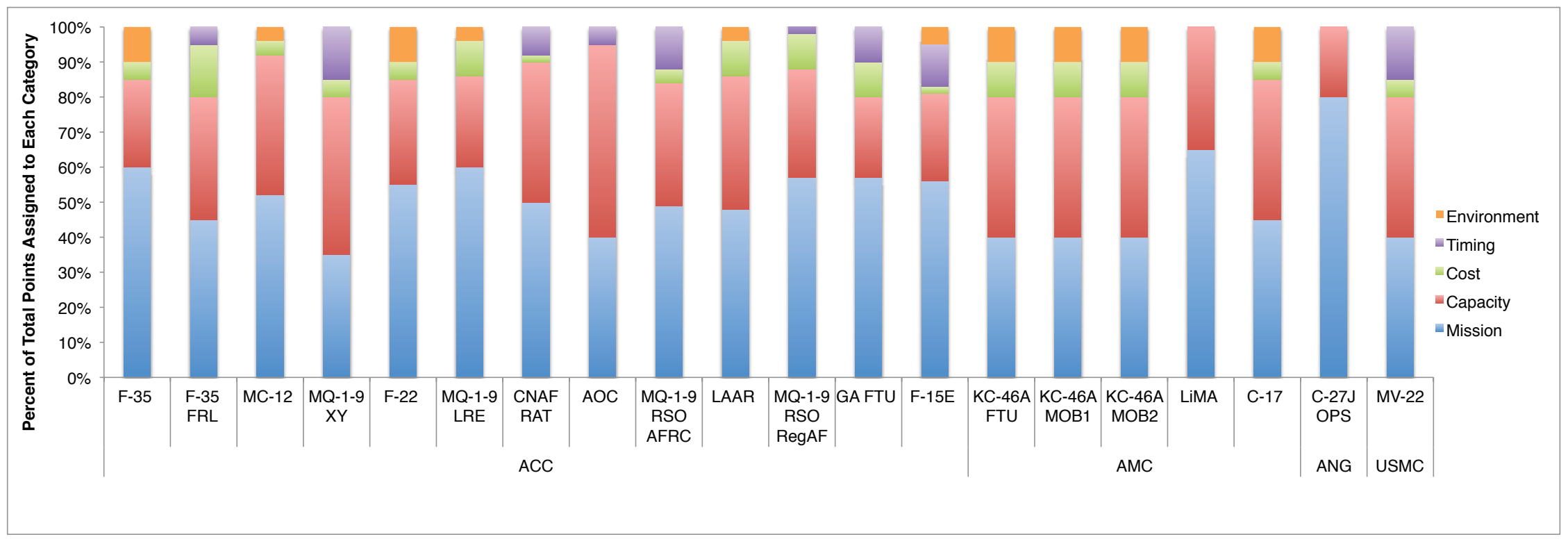

SOURCE: U.S. Air Force.

NOTES: $A O C=$ Air and Space Operations Center; LAAR = Light Attack/Armed Reconnaissance; CNAF = Component Numbered Air Force; RAT = Rapid Augmentation Team; RSO = Remote Split Operations; LRE = Launch and Recovery Element; LiMA = Light Mobility Aircraft; FTU = Formal Training Unit; $\mathrm{FRL}=\mathrm{F}-35$ Reprogramming Laboratory. 
Figure 3.2

Ranked Candidate Bases List for KC-46A Decision

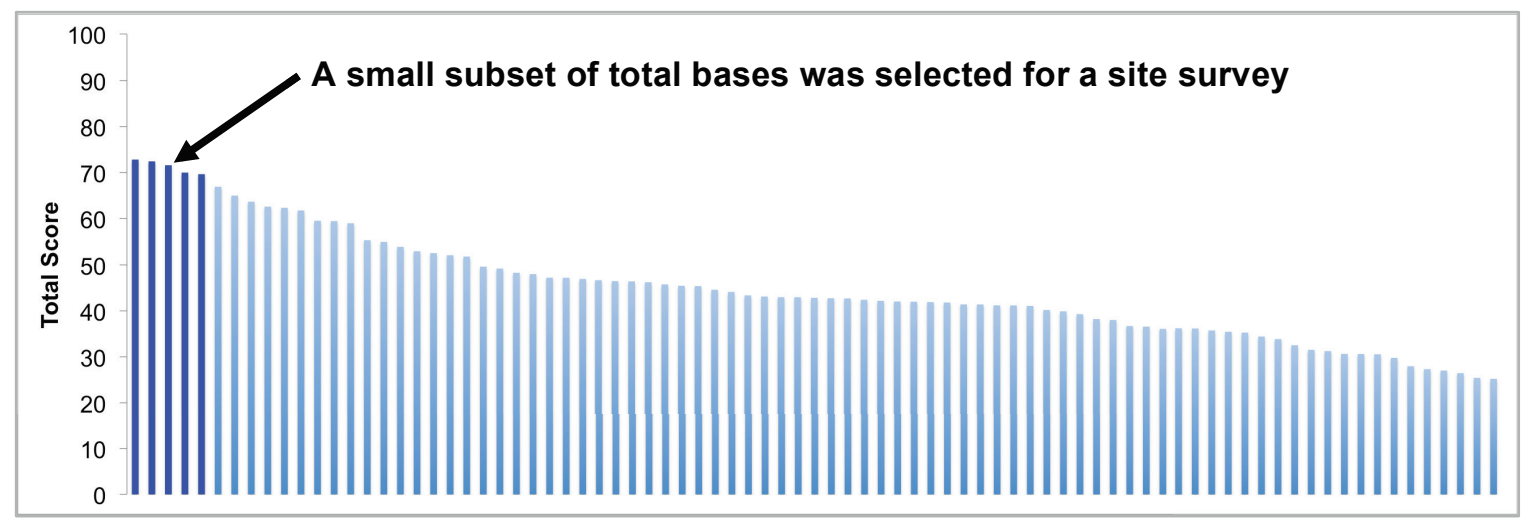

NOTE: The same figure appeared in Chapter Two as Figure 2.3.

Each installation has different weather, airspace, available facilities, and other attributes, and we observed these differences through a large variation in individual criterion scores across installations. Given the differences between installations for data elements, some criterion may be overvalued or undervalued when total scores are examined. For the 12 basing actions in our sample, we assessed the alignment between the Air Force's desired attributes, expressed as relative weight assigned by the Air Force to each scoring category (e.g., mission, capacity, cost, environment) and the actual influence of these categories for the bases chosen to advance in the basing process. To determine the effect of each category on the result, we used a model developed by RAND called the Generalized Boosted Model (GBM) (Ridgeway, 2009). A description of GBM is included in Appendix C.

Using the criteria weights, installation scores, and actual candidates selected for site surveys for each basing action, GBM calculates the "relative influence" of each attribute on the probability of an installation either scoring in the top 10 percent of installations or becoming a site survey candidate. The model assigns relative influence to each category by iteratively attempting to replicate the actual results through a bottom-up analytical process. For example, if there are 100 bases in an enterprise-wide look from which six candidates were selected, GBM initially gives each installation a 6 percent chance of becoming a candidate. On the next iteration, GBM may split the bases into installations scoring less than half of the available points in the mission category and installations scoring more than half of available points in the mission category, which alters their probabilities of becoming a candidate. Installations scoring less than half in the mission category would receive a particular (lower) probability of becoming a candidate, while the others would receive a higher probability. At the next iteration, the model splits the bases again, maybe giving an extra probability of being a candidate to installations that have a capacity score greater than half of the available points for that criterion. For each iteration, GBM automatically attempts multiple splits and adjustments. It then chooses the 
change that best improves the model fit to actual results, both in terms of the split and the adjustment to the probabilities on either side of the split.

During this process, GBM tracks how much the model fit was improved by each split and keeps track of which variables were split in order to achieve that gain. The improvements in model fit are normalized and termed the "relative influence" of the variable. If the mission score were a bigger driver of model fit than the capacity score, then mission score would have a higher relative influence than capacity score.

GBM avoids overfitting in two ways. First, GBM makes small changes between iterations. For each iteration, the adjustments to the probabilities are smaller than those that would optimize the fit, so changes to the probabilities are spread over the important variables. Second, GBM uses cross-validation by randomly splitting the dataset into ten groups. The model is fit on nine of the groups and predicts the outcome in the remaining group. The number of iterations that achieves the best out-of-sample prediction is considered to be the correct level of complexity, and is used to fit the entire dataset.

Applying GBM to the 12 basing actions in our dataset, we found that, for most, a good mission score was necessary to be potentially considered for a site visit, but when it came to actually being selected for a site visit, the capacity score was usually more important. We present detailed results below for the two largest basing actions under consideration by the USAF, for the F-35 Joint Strike Fighter and the KC-46A tanker. Table 3.2 shows results for the F-35 operational base actions, and Table 3.3 shows the results for the $\mathrm{KC}-46 \mathrm{~A}$ operational base actions. For both the F-35 and KC-46A actions, the mission criteria were important to achieving a high score, but either capacity or cost criteria determined site visits. The USAF assigned a weight of 60 percent for the mission criteria for the F-35 operational base actions, and our model found that mission criteria had a relative influence of 44 percent for the F-35 first Operational Basing (OPS1) action and 68 percent for the F-35 third Operational (OPS3) ${ }^{1}$ action to score in the top 10 percent of installations. The Air Force assigned a weight of 40 percent for the KC-46A actions, and the calculated relative influence for a top score was higher. The KC46-A first Main Operating Base (MOB1) mission criteria had a 46 percent relative influence, and the MOB2 mission criteria had a 61 percent relative influence. This means for both the F-35 and the KC-46A basing actions, scoring well on mission criteria was a relatively important factor for the bases with the top scores. Since the bases with the top scores were more likely to be further considered for a site survey, the mission criteria effectively screened out many of the candidates lacking high mission scores from being considered for a site survey.

\footnotetext{
${ }^{1}$ The F-35A OPS1 is located in the continental United States (CONUS), the OPS2 is located outside the continental United States (OCONUS), and the OPS3 is located in CONUS. OPS1 and OPS3 are examined in this report.
} 
Table 3.2

Relative Influence of F-35 Criteria Categories on Basing Process Outcomes

\begin{tabular}{|c|c|c|c|c|c|c|c|c|}
\hline & \multicolumn{4}{|c|}{ Relative Influence to Score in Top $10 \%$} & \multicolumn{4}{|c|}{ Relative Influence to Receive a Site Visit } \\
\hline & Mission & Capacity & Cost & Environment & Mission & Capacity & Cost & Environment \\
\hline $\begin{array}{l}\text { Assigned } \\
\text { weights }\end{array}$ & 60 & 25 & 10 & 5 & 60 & 25 & 10 & 5 \\
\hline $\begin{array}{l}\text { Relative } \\
\text { influence for } \\
\text { F-35 OPS1 }\end{array}$ & 44 & 30 & 18 & 9 & 11 & 74 & 8 & 7 \\
\hline $\begin{array}{l}\text { Relative } \\
\text { influence for } \\
\text { F-35 OPS3 }\end{array}$ & 68 & 17 & 8 & 7 & 19 & 19 & 57 & 5 \\
\hline
\end{tabular}

NOTE: F-35 OPS1 is the active duty beddown; F-35 OPS3 is the ANG beddown.

Table 3.3

Relative Influence of KC46A Criteria Categories on Basing Process Outcomes

\begin{tabular}{lcccc|cccc}
\hline & \multicolumn{3}{c|}{ Relative Influence to Score in Top 10\% } & \multicolumn{4}{c}{ Relative Influence to Receive a Site Visit } \\
\cline { 2 - 9 } & Mission & Capacity & Cost & Environment & Mission & Capacity & Cost & Environment \\
\hline $\begin{array}{l}\text { Assigned } \\
\text { weights }\end{array}$ & 40 & 40 & 10 & 10 & 40 & 40 & 10 & 10 \\
$\begin{array}{l}\text { Relative } \\
\text { influence for } \\
\text { KC46A MOB1 }\end{array}$ & 46 & 28 & 16 & 9 & 18 & 66 & 14 & 3 \\
$\begin{array}{l}\text { Relative } \\
\text { influence for } \\
\text { KC46A MOB2 }\end{array}$ & 61 & 21 & 12 & 6 & 24 & 73 & 3 & 1 \\
\hline
\end{tabular}

NOTE: KC46A MOB1 is the first main operating base; KC46A MOB2 is the second main operating base.

When we used GBM to assess the relative influence of criteria on which installations received site surveys, capacity criteria had far greater relative influence than the weight assigned by the Air Force for all but the F-35 OPS3 action, for which cost criteria had the greatest relative influence. This means for both the F-35 and the KC-46A basing actions, scoring well on mission criteria was not the most important factor for the selection of site surveys. Because most of the installations selected for a site survey had relatively high mission scores, capacity and cost scores became an important distinguishing variable that helped determine site selection candidates. The GBM results analytically validate what is an intuitive and expected outcome of the basing process as currently structured - installations that can perform the mission and that have currently available capacity should be competitive for a site survey.

Our analytical verification that the mission criteria category screens candidates and the capacity criteria category determines site selection enables a potential streamlining of the basing decisionmaking procedure. The current process relies on detailed data calls to as many as 205 installations for each basing action. As discussed previously and shown in Figure 2.2, these data 
calls can have 20 or more individual attributes about mission, capacity, cost, and environment, for which each installation is responsible to provide data. Since high mission scores are essential for consideration as a potential basing action candidate, the initial enterprise-wide data analysis could be limited to only bases able to fulfill the mission requirements. Collecting mission data first and screening installations by mission score would eliminate the need for labor- and timeintensive capacity data collection efforts at installations unable to support the proposed mission. Once a set of viable installations is created through this initial screening, data calls and a more detailed assessment of capacity and environmental attributes could be initiated. Cost data for regional economic factors are readily available and could be added into the analysis at any point in the analysis.

The strategy of initially screening installations for mission capabilities maintains an enterprise-wide scope, but limits the initial assessment to mission data, much of which could be collected at the headquarters or MAJCOM level. As an example, Figure 3.3 presents the mission scores for the $\mathrm{KC}-46 \mathrm{~A}$ MOB2 basing action. Bases selected as site survey candidates for this action are highlighted in dark blue. If bases that received less than 50 percent of available mission points had been screened from this action, 37 bases would have been removed from the data call, without affecting the list of candidate bases.

Figure 3.3

Mission Scores of Bases Evaluated for the KC-46A Basing Decision

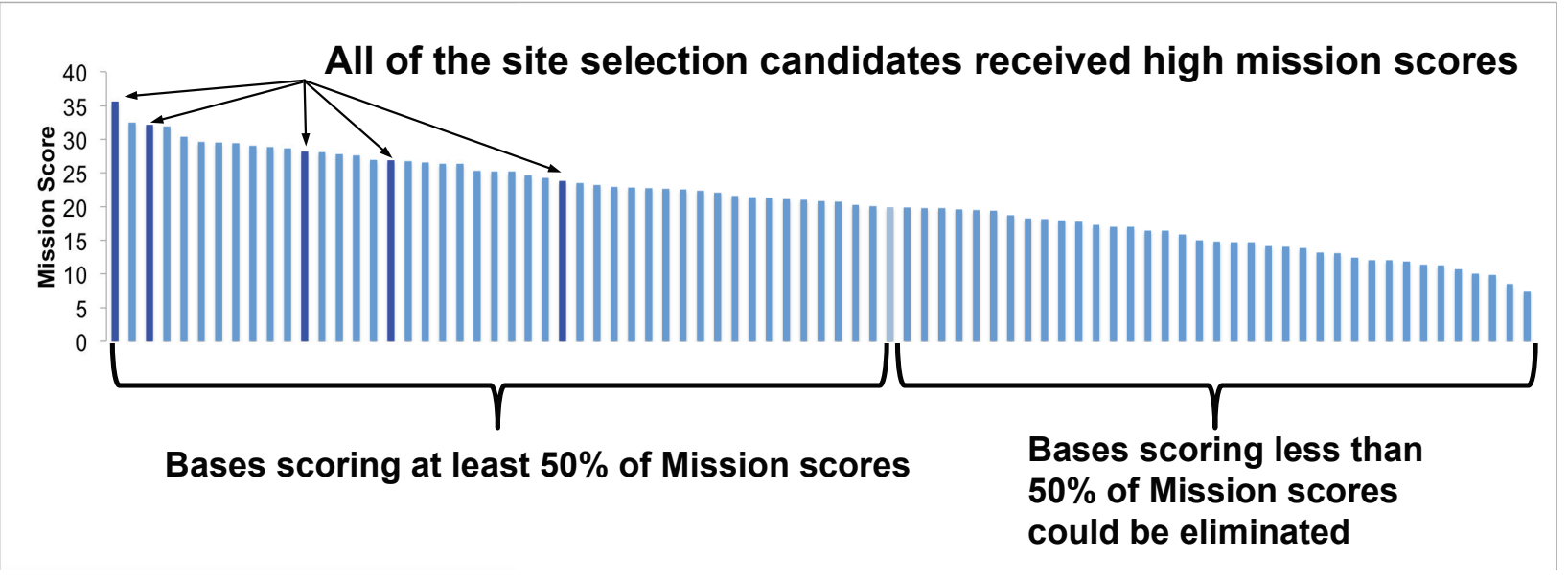

The Air Force could apply lessons learned from previous basing actions and military judgment to set a potential mission score threshold for screening. Setting the threshold too high could overlook bases that might otherwise be selected as candidates, while setting the threshold too low would expand the number of installations required to provide detailed capacity analyses. We analyzed the 12 enterprise-wide look basing actions in our sample to see what mission score thresholds would have meaningfully reduced the size of the data call without omitting any bases eventually chosen as candidates for a site selection survey. Over the 12 basing actions, 1,531 
total data calls were sent to CONUS installations. These data calls require personnel at MAJCOMs or headquarters to transmit, receive, and analyze the information, as well as civil engineering and other personnel at each installation to respond to each data call. For our sample, all of the installations selected for a site selection survey received at least 35 percent of the maximum possible mission score, and most received at least 50 percent. This means that for the 12 actions in our sample, 626 to 882 data call responses would have been saved if the detailed data calls were limited to installations with high mission scores (Table 3.4).

Table 3.4

Reduced Data Collection Enabled by Various Mission Score Thresholds

\begin{tabular}{lcc}
\hline Threshold & $\begin{array}{c}\text { Data Requests to } \\
\text { Installations }\end{array}$ & $\begin{array}{c}\text { Reduction in Data Call } \\
\text { Responses }\end{array}$ \\
\hline No threshold & 1,531 & - \\
Mission score at least $50 \%$ of max possible & 649 & 882 \\
Mission score at least $40 \%$ of max possible & 831 & 700 \\
Mission score at least 35\% of max possible & 905 & 626 \\
\hline
\end{tabular}

NOTE: Sample analyzed consisted of 12 decisions in USAF's strategic basing process that considered installations across USAF's CONUS enterprise.

Choosing a mission score threshold of 50 percent of the total points possible would have captured 30 of the 33 bases selected as site survey candidates for the 12 actions in our sample. There were three exceptions, demonstrating that mission score thresholds should not be set arbitrarily. Grand Forks Air Force Base (AFB) in the KC-46A MOB1 action earned 38 percent of the available mission points, Boise Air Terminal AGS earned 40 percent of the available mission points for the $\mathrm{C}-27 \mathrm{~J}$ action and 49 percent of the available mission points for the $\mathrm{F}-35$ training action. Choosing a mission score of 35 percent would have captured all 33 bases selected as candidates in our sample, and still eliminated the need for 626 data calls.

Our analysis found that the current basing process is designed so that installations with high mission scores are advanced toward site selection, but capacity scores largely influence the final candidate list. To reduce the cost and time of conducting the existing strategic basing process, the Air Force should consider using mission criteria with centralized data to initially screen candidate bases for suitability. Efforts to update and integrate USAF databases are ongoing, but priority should be given to automation and centralization of mission data to have the greatest impact on the strategic basing process. With a reduced set of potential installations to examine, the detailed capacity and environmental data collection efforts could focus only on those installations with competitive mission scores. Our analysis found that initially screening installations based on mission scores would reduce data needs and level of effort, while maintaining an enterprise-wide look and desired basing outcomes. An initial screening process based on mission scores would maintain equity by considering all installations in the enterprise but collecting detailed capacity, environmental, and cost data only on installations that can best 
achieve the desired mission. What we also observed but did not analyze here is that there is an underlying trade-off between mission and capacity in the existing basing process, and explicitly monetizing these trade-offs is a way to improve basing actions going forward. 


\section{Assessing Basing Data Quality}

The Air Force has conducted more than 100 basing actions since 2009. In the previous chapter, we discussed the methodology the Air Force uses to assess and compare the relative merits of individual bases. In this chapter, we assess the quality of the underlying data used to make basing decisions, since poor data quality could lead to poor decisions, even if the employed processes are sound.

\section{Methodology for Assessing Basing Data Quality}

As part of the process for evaluating installations for a given basing action, the Air Force scores candidate installations on several attributes that are relevant to the particular action. (See Table 3.1 for a list of the types of attributes generally considered across basing actions.) Data calls are sent to all candidate bases requesting responses to questions pertaining to the attributes of interest. Responses to these data calls are then scored based on a predefined rubric that specifies both the relative weight of each attribute (i.e., its contribution to the overall score) and a scoring system that maps possible responses to a number of points that each response would receive.

The attributes generally fall under the four key basing criteria - mission, capacity, cost, and environment. ${ }^{1}$ The weights assigned to each of the criteria and to their constituent attributes, as well as the mapping of responses to scores, vary by action. For all basing actions, the sum of the assigned weights equals 100 points.

In our assessment of the quality of basing data, we primarily focused on the data sources used by candidate installations across basing actions to answer data call questions. Specifically, we aimed to assess the authoritativeness, consistency, and auditability of the data sources used by candidate installations when they respond to data calls. ${ }^{2}$ It is important to note that our assessment does not entail directly verifying the accuracy of the responses provided. In assessing data consistency, we did analyze responses to a few data call questions, but even in this aspect of our assessment, differences in tailored data call question structure made analyzing responses to all questions infeasible.

We used the KC-46A and the F-35 basing actions as case studies to gather information on the sources used to respond to the data calls. For these five basing actions, we focused on the 16 candidate installations that passed the initial screening and were chosen for site visits. ${ }^{3}$

\footnotetext{
${ }^{1}$ Occasionally, additional criteria, such as timeliness, are considered, but for a majority of actions, the assessed criteria are limited to the four key ones mentioned here.

2 These metrics are defined and discussed in this chapter.

${ }^{3}$ Altus AFB was chosen for a site visit for both the MOB1 and Formal Training Unit actions.
} 
Data pertaining to the KC-46A MOB1, MOB2, and Formal Training Unit tanker actions are available in a template specified by $\mathrm{AMC}$ and used for this specific basing action as further discussed below. In addition to requiring responses to data call questions, this template lists HAF-specified sources to use for a subset of the questions and requires that responsible entities at each installation sign off on all responses. For data call questions with no corresponding HAFspecified source, such as the $\mathrm{KC}-46 \mathrm{~A}$ tanker actions, we contacted responsible parties listed in the data call template at the different installations to identify the data sources used. For the F-35 actions, we began at the MAJCOM level and followed a trail of contacts at the installations to identify data sources used.

\section{Data Quality Metrics}

We focused our data quality assessment around three questions:

1. Are the data sources authoritative?

2. Are the sources consistently used across installations and across basing actions?

3 . Is the process through which data calls are answered auditable?

Authoritativeness measures the extent to which sources used to answer data call questions align with authoritative or credible sources. We consider a source to be authoritative if it has any of the following four owner types: USAF, non-USAF U.S. Department of Defense (DoD), nonDoD government, or SME knowledge. We also categorize data sources by access level, where the level of access could be either "limited access" or "public." Access level, while not directly related to the metrics we use for assessing data quality, could have implications for accountability. For instance, if a publicly available source is either not used or used improperly, this would have implications for the credibility of the basing process in the event that errors are discovered post-decisionmaking.

Consistency measures the extent to which candidate bases for a given action use the same sources to answer the same questions, and the extent to which a given base consistently answers the same question for different actions. To assess the latter, we analyzed responses provided to data call questions (as opposed to data sources used) when feasible.

Auditability measures the extent to which data sources are documented and traceable. Data that are auditable enable others to check specified sources and locate the data used to underpin the basing process. For the KC-46A tanker actions, approximately half of the data call questions have HAF-specified data sources associated with them. These sources are inherently auditable because they are documented in the AMC-instituted template. For the remaining KC-46A attributes and for attributes pertaining to the F-35 actions, we considered the data sources to be auditable if respondents either provided a direct source or a point of contact who was able to identify the data source. 


\section{Sources Identified for Data Call Responses}

Tables 4.1-4.4 categorize data call attributes by whether pertinent sources of data are HAFspecified, the types of sources used, and the actual sources used by the majority of queried installations in our sample set.

Table 4.1

Sources Used to Answer Mission Basing Criterion Questions

\begin{tabular}{lccl}
\hline Attribute & $\begin{array}{c}\text { HAF-Specified/ } \\
\text { Not Specified }\end{array}$ & Source Type & \\
\hline Fuel storage & Specified & Limited access USAF & Base Support Plan \\
Fuel receipt & Specified & Limited access USAF & Base Support Plan \\
$\begin{array}{l}\text { Temporary student } \\
\text { housing }\end{array}$ & Specified & Limited access USAF & $\begin{array}{l}\text { Unaccompanied Housing Utilization } \\
\text { Report from ACES }\end{array}$ \\
$\begin{array}{l}\text { Weapon system } \\
\text { training facility }\end{array}$ & Specified & Limited access USAF & $\begin{array}{l}\text { Real Property Inventory Detail Report } \\
\text { Fuselage training }\end{array}$ \\
Sirfield/airspace & Specified & Limited access USAF & $\begin{array}{l}\text { Real Property Inventory Detail Report } \\
\text { SAF-ILE(a) 7115 from ACES }\end{array}$ \\
\hline
\end{tabular}

Table 4.2

Sources Used to Answer Capacity Basing Criterion Questions

\begin{tabular}{|c|c|c|c|}
\hline Attribute & $\begin{array}{l}\text { HAF-Specified/ } \\
\text { Not Specified }\end{array}$ & Source Type & Source \\
\hline $\begin{array}{l}\text { Housing (Military } \\
\text { Housing Privatization } \\
\text { Initiative) }\end{array}$ & Specified & Limited access USAF & $\begin{array}{l}\text { Unaccompanied Housing Utilization Report from } \\
\text { ACES }\end{array}$ \\
\hline $\begin{array}{l}\text { Permanent party } \\
\text { housing }\end{array}$ & Specified & Limited access USAF & $\begin{array}{l}\text { Unaccompanied Housing Utilization Report from } \\
\text { ACES }\end{array}$ \\
\hline Gym/fitness center & Specified & Limited access USAF & $\begin{array}{l}\text { Real Property Inventory Detail Report SAF- } \\
\text { ILE(a) } 7115 \text { from ACES }\end{array}$ \\
\hline $\begin{array}{l}\text { Squadron } \\
\text { Operations/Aircraft } \\
\text { Maintenance Unit } \\
\text { area }\end{array}$ & Specified & Limited access USAF & $\begin{array}{l}\text { Real Property Inventory Detail Report SAF- } \\
\text { ILE(a) } 7115 \text { from ACES }\end{array}$ \\
\hline $\begin{array}{l}\text { Aircrew training } \\
\text { system facility }\end{array}$ & Specified & Limited access USAF & $\begin{array}{l}\text { Real Property Inventory Detail Report SAF- } \\
\text { ILE(a) } 7115 \text { from ACES }\end{array}$ \\
\hline $\begin{array}{l}\text { Maintenance training } \\
\text { facility }\end{array}$ & Specified & Limited access USAF & $\begin{array}{l}\text { Real Property Inventory Detail Report SAF- } \\
\text { ILE(a) } 7115 \text { from ACES }\end{array}$ \\
\hline Runway dimensions & Not specified & Limited access DoD & $D o D F L I P$ \\
\hline Hangar spaces & Not specified & Tacit knowledge & As-built drawings, measurements \\
\hline Ramp capacity & Not specified & $\begin{array}{l}\text { Limited access USAF; } \\
\text { Public DoD }\end{array}$ & Geobase maps; PCI report \\
\hline
\end{tabular}




\begin{tabular}{|c|c|c|c|}
\hline Attribute & $\begin{array}{l}\text { HAF-Specified/ } \\
\text { Not Specified }\end{array}$ & Source Type & Source \\
\hline $\begin{array}{l}\text { Ramp hydrant } \\
\text { dispensers }\end{array}$ & Not specified & Tacit knowledge & Base engineer \\
\hline $\begin{array}{l}\text { Medical/dental } \\
\text { facilities }\end{array}$ & Not Specified & Tacit knowledge & Base engineer \\
\hline $\begin{array}{l}\text { Communications } \\
\text { infrastructure }\end{array}$ & Not Specified & Tacit knowledge & Base engineer \\
\hline
\end{tabular}

Table 4.3

Sources Used to Answer Environment Basing Criterion Questions

\begin{tabular}{lccl}
\hline Attribute & $\begin{array}{c}\text { HAF-Specified/ } \\
\text { Not Specified }\end{array}$ & Source Type & Source \\
\hline Air quality & Specified & Public government & EPA National Ambient Air Quality Standards \\
Environmental impacts & Specified & Public government & NPS National Register of Historic Places \\
Noise & Specified & Public DoD & Air Installation Compatible Use Zone \\
Encroachment & Specified & Public government & HUD Clear Zone and Accident Potential Zones \\
Land use controls & Not specified & Public government & $\begin{array}{l}\text { State-level land use policies aggregated by } \\
\text { base engineer }\end{array}$ \\
\hline
\end{tabular}

Table 4.4

Sources Used to Answer Cost Basing Criterion Questions

\begin{tabular}{|c|c|c|c|}
\hline Attribute & $\begin{array}{l}\text { HAF-Specified/ } \\
\text { Not Specified }\end{array}$ & Source Type & Source \\
\hline Local area cost factor & Not specified & Public DoD & $\begin{array}{l}\text { UFC 3-701-01 DoD Facilities } \\
\text { Pricing Guide }\end{array}$ \\
\hline Area $\mathrm{BAH}$ rate & Not specified & Public DoD & $\begin{array}{l}\text { Defense Travel Management } \\
\text { Office }\end{array}$ \\
\hline GS locality factor & Not specified & Public DoD & Office of Personnel Management \\
\hline
\end{tabular}

\section{Data Quality Assessment Findings}

We found that the data used to make basing decisions are authoritative and consistent, but the auditability of the data call and response process is weak. Therefore, a majority of "data errors" may be unrelated to data quality and result from the data collection process or human error, or possibly both.

Data used to make basing decisions are derived from authoritative sources. Specifically, the majority of data call questions pertaining to the mission basing criterion are answered using standard USAF or DoD sources, and base civil engineers, who are SMEs, answer the rest. Capacity questions are answered using limited access USAF sources or SME tacit knowledge. Environment questions are answered using standard, publicly available DoD and other 
government sources. Cost questions are answered using standard, publicly available DoD sources.

Sources used to answer data call questions are also consistent. A detailed look at responses to calls for data about weather days, runway length, and local area cost factors revealed that a given installation provided the same answers across basing actions. For the KC-46A tanker actions, HAF-specified sources are consistently used across candidate bases. When data sources are unspecified, there is little variation in the types of sources used to answer data call questions. Other attributes had notable differences in the data call question structure and were therefore not suitable for assessing consistency.

The underlying data used in the basing action process are weak in terms of auditability. It is challenging to trace specific sources used to answer questions, even when responsible parties are identified in a MAJCOM-provided data call template, as is the case for the tanker actions. There is no data call template used for other actions, making it even more difficult to identify underlying data sources.

In summary, we conclude that USAF resources would be best spent in trying to specify and standardize sources and data call protocols when possible, and to focus attention on limiting the number of candidates to which queries are sent by using a more targeted selection process, such as the one described in Chapter Three.

\section{Recommendations to Improve the Auditability of Data Quality}

Since auditability is weak, our recommendations focus on improving this aspect of the data quality. However, the benefits of implementing these recommendations may also extend to the authoritativeness and consistency of data quality.

The Air Force can increase auditability by specifying sources whenever possible, by requiring that data call responses include sources used and responsible parties, and by limiting the number of queried bases per action.

First, we recommend that the sources listed in Table 4.5 be HAF-specified across actions. Currently, there is no suggestion or requirement that installations use these sources when responding to data calls, but we found that several installations already use these sources in answering data call questions. In addition to improving auditability, specifying these sources would enhance consistency by further reducing variability in the data sources used by different installations across basing actions. 
Table 4.5

Recommended Data Sources to Specify Across Basing Actions

\begin{tabular}{ll}
\hline Attribute & \multicolumn{1}{c}{ Potential Specified Source } \\
\hline Airfield/airspace & DoD Flight Information Publication (FLIP) \\
Runway dimensions & DoD Flight Information Publication (FLIP) \\
Ramp capacity & GeoBase maps; PCI report \\
Local area cost factor & UFC 3-701-01 DoD Facilities Pricing Guide \\
BAH rate & Defense Travel Management Office BAH Calculator \\
GS locality factor & Office of Personnel Management GS Locality Pay Tables \\
\hline
\end{tabular}

Second, we recommend that HAF standardize the data sources listed in Table 4.6. Currently, these sources are specified in the data call template for AMC actions, but they are not specified for actions originating from other MAJCOMs.

Table 4.6

Recommended Data Sources to Standardize Across Basing Actions

\begin{tabular}{ll}
\hline Attribute & \multicolumn{1}{c}{ Potential Standardized Source } \\
\hline Fuel storage & Base Support Plan \\
Fuel receipt & Base Support Plan \\
Temporary student housing & Unaccompanied Housing Utilization Report from ACES \\
Weapon system training facility & Real Property Inventory Detail Report SAF-ILE(a) 7115 from ACES \\
Fuselage training facility & Real Property Inventory Detail Report SAF-ILE(a) 7115 from ACES \\
Housing (MPHI) & Unaccompanied Housing Utilization Report from ACES \\
Permanent party housing & Unaccompanied Housing Utilization Report from ACES \\
Gym / fitness center & Real Property Inventory Detail Report SAF-ILE(a) 7115 from ACES \\
Sq ops / AMU facilities area & Real Property Inventory Detail Report SAF-ILE(a) 7115 from ACES \\
Aircrew training system facility & Real Property Inventory Detail Report SAF-ILE(a) 7115 from ACES \\
Maintenance training facility & Real Property Inventory Detail Report SAF-ILE(a) 7115 from ACES \\
Air quality & EPA National Ambient Air Quality Standards \\
Environmental impacts & NPS National Register of Historic Places \\
Noise & Air Installation Compatible Use Zone \\
Encroachment & HUD Clear Zone and Accident Potential Zones \\
\hline
\end{tabular}

Third, we recommend that a template such as the one currently used by AMC, which requires respondents to include data sources and responsible parties with their data call responses, be standardized across MAJCOMs. In addition to improving auditability, such documentation of responsible parties increases accountability by providing a means to trace responses to specific entities in charge, which could in turn reduce human error. 
Of course, even if auditability were enhanced, this alone would not eliminate all data errors. For instance, outdated versions of specified sources might be accessed, or inappropriate data might be pulled from current specified sources. While there is no way to ensure an error-free process every time a basing decision is made, a couple of steps can be taken to lessen the potential for error:

- Use the mission-threshold approach described in Chapter Three to reduce the number of queried bases and the processing burden. Currently, not all queried installations have equal incentive to respond in-depth to all data calls, so some may be answered in a minimal way. Targeting only those installations that score sufficiently highly on a smaller set of mission-critical requirements could result in increased diligence in using the right data sources and providing more thorough responses to data calls.

- While steps should be taken to improve all aspects of the basing decision process to achieve the highest data quality possible, it is important to keep in mind that attributes for which related data are publicly available are more readily open to scrutiny. For instance, sources listed (either currently used or recommended) for environment-related attributes in Table 4.3 and cost-related attributes in Table 4.4 are publicly available. It is important to not just specify sources for these attributes but also to take measures to ensure that such sources are properly accessed and used. 



\section{Implementation Challenges and Potential Improvements}

\section{Introduction}

The planning, execution, and results of the Air Force strategic basing process involve Air Force stakeholders from across the department. Data are required from each stakeholder during the basing process, and each stakeholder has incentives and preferences for specific basing outcomes. Like any decision with multiple stakeholders, there are likely potential misalignments of these incentives with obtaining optimal objectives. Similarly, stakeholders often experience implementation challenges, and have ideas for potential improvements. To gather insights on the strategic basing process across the major Air Force stakeholders, we conducted in-depth semistructured interviews with more than 40 stakeholders. These included military officers, DoD civilian managers, and Senior Executive Service SMEs. Many of these individuals have been working in basing issues for ten years or more, and deep experience with weapon systems beddowns, previous BRAC rounds, and installation planning was represented. The team conducted interviews with stakeholders at nine MAJCOM headquarters, several civil engineering offices at installations, and military construction agencies, as well as with stakeholders at HAF. The major theme of the interviews was the interviewee's experience with the strategic basing process. The interviews included discussions about the data used to support the process, challenges experienced, and recommendations for improvement. We conducted the interviews both on-site and via telephone on a not-for-attribution basis, to ensure a frank discussion of challenges and recommendations. In this chapter, we summarize major themes that emerged from the interviews and recommend potential improvements to the basing process.

\section{Challenges and Recommendations for the Collection of Basing Data}

\section{Data Relevancy and Timeliness}

It is evident from the interviews that responding to multiple data calls per year on actions where an installation is not competitive for the proposed mission is seen as superfluous by parties responsible for responding to data calls. Gathering requested basing data on installations is often time-intensive, requiring meetings and correspondence with SMEs from multiple disciplines across the local installation. Because questions are generally tailored to each action, respondents must initiate new searches for each data call. Respondents can get frustrated with continuously devoting time to data collection for basing actions that their installations are not suited for. Interviewees acknowledged that HAF's desire to look across the portfolio of bases for each action is important, but felt that it should be balanced with feasibility of supporting the proposed 
mission. Our recommendation to initially screen the enterprise of bases for mission suitability discussed earlier would alleviate some of these concerns.

The data categories collected across the mission, capacity, cost, and environment categories in the basing process have various levels of data perishability. That is, data collected for some categories will be valid for the next few fiscal years, while the validity of other data collected will erode more rapidly. We were told that sometimes facilities noted as available by respondents during data calls often were designated for other uses by the time action from basing decision were initiated. Interviews noted that HAF generally sees all data as perishable, while MAJCOMs and installations would prefer to utilize previous data collection efforts and update these as necessary. The correct level of data perishability is a question of balance and judgment. Data collection efforts are time-intensive, but invalid data could result in undesired basing outcomes. Yet, our examination of the individual data requests revealed that most requests were not identical to previous requests in the same category, because each data call is tailored to the specific requirements of each basing action. This specialization prohibits reusing previously collected data for many categories.

Interviewees often recommended undertaking initial site surveys earlier in the basing process on an expanded list of candidates. These expanded site surveys might be able to reveal inaccuracies and potential environmental issues before a final slate of candidates is prepared for Congress. Expanded resources and personnel would be required to expand the site survey process, and the cost of undertaking earlier site surveys could be weighed against improving options for a basing action, as well as validating on-site data for use in future actions. Finally, the time delay between making basing decisions and executing a basing decision can run over fiscal year boundaries. This can interfere with funding mechanisms and force artificial restarts of decision process elements, interviewees noted.

\section{Auditability}

Interviewees agreed with our findings that enhancing the data auditability is important. Respondents may be biased for particular actions, and this influences the way they answer the questions. Interviewees stressed that, for many respondents to data calls, there are limited consequences for inaccuracy and limited ways that HAF and MAJCOMs can balance the concerns and incentives of wing commanders when installations respond to data calls. When asked about capacity availability, interviewees told us that respondents may wish to reserve capacity for other uses or may be unaware of pending uses. Inaccurate responses, whether intentional or unintentional, are often validated only during a site visit. Hence, without a site visit or enhanced auditability, the incentives and opportunity for inaccuracy exist. Interviewees also noted that, because of the timeline for basing actions, when incorrect information is identified through the site visit process, there is not an opportunity to revisit the list of other candidates and conduct site surveys on other competitive installations. 
For previous basing actions, data collection was largely informal, conducted via email and phone conversations with SMEs. This is challenging for auditability, and for reconstructing sources of information, should internal or external questions arise later. A new approach that standardized data collection was pioneered by AMC for the KC-46A decision. All respondents used an online system to enter data, and respondents were required to provide contact information for themselves and the person locally verifying the data. This system greatly advances auditability and should be replicated across basing actions as appropriate. Yet, as discussed previously, listing the actual data source used is also very important for auditability and should be required.

\section{Data Management}

As the strategic basing process has matured over the past few years, an opportunity now exists to standardize data inputs and manage the collected data in a knowledge management framework. Interviewees expressed a desire for a standardized list of criteria and data sources to be established by HAF for the basing process. The group indicated that more consistent data requests on the questionnaires would hopefully lead to generating better repositories for standardized base characteristics, and minimize confusion and questions from respondents on answering data calls. Interviewees noted ambiguity about responsibility and ownership for aspects of data collection, verification, and management. The focus on HAF-driven standardization enforces the common theme of limited personnel and time availability at the MAJCOMs and installations expressed by interviewees. The group also suggested that HAF provide a single point of contact for each basing action for rapid response to questions from MAJCOMs or installations, which would take a lot of the assumptions out of the process.

\section{Challenges and Recommendations for Criteria and Process}

\section{Developing Criteria}

As described previously, assessment criteria are developed by the proponent MAJCOMs and validated by the SB-ESG. There were a wide variety of opinions and recommendations expressed by interviewees regarding improving assessment criteria, as well as scoring weights and scales. Interviewees acknowledged that MAJCOMs have incentives to tailor criteria to make installations of interest more favorable for particular basing actions. The distribution of installation final scores for basing actions is the interviewees' primary evidence of this occurring. While the incentives exist, it is important to note that optimal basing actions from the Air Force's point of view and a MAJCOM's point of view can, and often will be, similar.

There was a strong desire for consistency in criteria from interviewees, or as one interviewee put it, "We need unity of effort, a common rubric, and a common set of criteria." One interviewee suggested that the scoring criteria map to the Air Force's 12 core functions, to 
increase consistency between basing decisions and discouraging "gaming" of scores for individual decisions. Countering the desire for consistency, some interviewees wanted more flexibility on the criteria and scoring scales, to allow notation of issues that arise during discussions with bases. Interviewees also said that decisions are often made on the basis of available capacity, and that available capacity is too heavily weighted in many basing actions. AMC's approach of using the receiver-demand model (that simulated where tankers would have to fly to refuel fighter aircraft) in the $\mathrm{KC}-46 \mathrm{~A}$ decision helped prioritize mission during the tanker basing process, and could serve as an example for future actions to prioritize mission impacts. It was noted there are separate Air Force and Pentagon standards for floor plans and space. While the Pentagon standards require less space per person, the Air Force standards govern in the basing process, and one interviewee felt that these are "outdated."

Interviewees reported that the cost criteria used in basing decisions are more a proxy for regional economics than basing action costs. These regional economic indicators are important, but including infrastructure costs that improve capacity scores, as well as life-cycle costs of operating at a specific location, would inform the cost portions of basing decisions.

One group of interviewees reported that environmental criteria were neither emphasized enough nor fully developed, relative to the risks that environmental aspects might introduce to successful basing actions. Environmental criteria do not evaluate a basing action within the context of the total capacity for growth at an installation, but rather whether there are issues with adding just this basing action, they stressed. The installation's available capacity for growth in water use, storm water handling, waste management, utility needs, energy production, local air pollutants, and other indicators are not evaluated. Many of these aspects are covered in installation development plans but not explicitly incorporated into the strategic basing process. In addition, the current static criteria do not evaluate the potential for a basing action to improve environmental conditions, such as replacing a more polluting weapon system with a newer, less polluting one. Finally, interviewees argued that NEPA procedures need to be initiated earlier in the basing process, so that the environmental impacts for the range of reasonable alternatives can be evaluated before the decision is made. NEPA is started when candidates are selected, but to fully evaluate alternatives, identify potential challenges, and comply with the timelines of the basing process, the NEPA process should start earlier. An interviewee stressed that the range of alternatives evaluated in NEPA documentation can be narrowed, but the narrowing needs to be "applied on a case-by-case basis and include consideration of the proponent's defined need."

\section{Process Improvements}

Interviewees pointed out that there are ways that proponents can "short-circuit" the traditional basing decision process. Most notably, with the inclusion of new assets, it's often easier to put new asset locations directly into the Program Objective Memorandum. It was indicated that this is the easiest route to align moves with a higher-level basing strategy. Alternatively, basing planners can take advantage of the Total Force Initiative process to reposition assets. However, 
planners indicated that sometimes friction can arise between Reserve and Guard assets and moves. Additionally, many people we talked to pointed to use of contractors rather than Air Force personnel to eliminate the 35-person trigger for the strategic basing process. Another interviewee suggested standardizing estimation of basic infrastructure and personnel requirements for different types of weapon systems, to inform standardized checklists for site surveys.

\section{Challenges and Recommendations for Including Strategic Considerations}

\section{Strategic Posture}

An overarching theme in interviewees' responses was a view that there is a lack of strategic thinking in defining a desired CONUS posture. They felt that strategic posture could be incorporated into the basing process, to inform basing decisions. Interviewees acknowledged the ability to support OCONUS operations from any CONUS location, but noted that there are strategic, performance, and life-cycle cost differences associated with each CONUS location. Strategic thinking is lacking, interviewees said, because the basing process is reactive and driven up from the MAJCOMs instead of coming down from HAF. Common points made include, "Where does the Asia rebalance show up in CONUS basing decisions?" and "What is the role of the Core Function Lead Integrators (CFLIs)?" Military judgment is infused by the CSAF, the SecAF, and the BRRP members, but not according to a codified doctrine or strategic vision. The strategy that is included is not formally articulated or quantified, which would assist in basing process transparency. Defining a CONUS posture would also eliminate uncompetitive candidates from the basing enterprise-wide looks and reduce the time and resources required in the basing process. Finally, the Air Force portfolio of CONUS installations collectively consists of a total capacity, which changes as new weapon systems are bedded down, older systems are retired, and force structure shifts. An individual basing decision to beddown a weapon system at a specific location utilizes capacity at that installation for the life of that weapon system, which may be several decades. Without a defined strategic posture that is flexible in adjusting to new threats or force structure changes, an optimal basing decision for an individual weapon system may be suboptimal across the portfolio of expected and unexpected decisions in the mid- and long-terms. Hence, the Air Force risks bedding down aircraft and weapon systems at locations that it may regret in the future.

\section{Unique Mission Considerations}

Many interviewees were SMEs and noted how the generic strategic basing process was designed for major weapon systems and required adjustment regarding other missions. One concern was with cyber basing actions and the local and regional assets needed to fulfill these missions. Interviewees suggested that units such as the 24th Air Force need to have locations in Silicon 
Valley or Northern Virginia to draw on the existing cyber industrial bases. Similarly, an issue that is not included during existing basing actions is the impact on an existing industrial base by moving units elsewhere.

Satellite command-and-control (C2) basing actions also do not fit well in the traditional basing process enterprise-wide look framework. These actions "need centralization, frequency deconfliction, access to many satellite dishes, accreditation and security staff, and this can only be done at certain Air Force Bases," an interviewee told us. "If you need to build a C2 center or a space operations center, there is limited value in studying lots of bases across the enterprise," this interviewee noted. These special mission needs could be in the strategic basing process, by updating Air Force Instruction (AFI) 10-503. The current instruction says "any special interest item" requires going through the full strategic basing process. In practice, "this allows headquarters to decide what they want to study and is too vague," the interviewee told us. A potential improvement is revising the AFI 10-503 to defer to the existing MAJCOM supplement in certain special cases. 


\section{Conclusions and Recommendations}

Under its current domestic strategic basing decision process, the Air Force considers its entire enterprise of installations for many basing actions. Each installation collects data on 30 to 40 basing criteria to support each decision. This results in a data-intensive process that requires a significant expenditure of resources across the enterprise and is directly dependent on the quality of the underlying data.

RAND evaluated the USAF basing process by considering three questions:

- Are basing decision criteria aligned with Air Force intentions?

- Are the data used in basing decisions authoritative, consistent, and auditable?

- Is there potential for broader USAF strategic or portfolio-wide inputs to strengthen the basing decisionmaking process?

In answering the first question, we identified and examined the actual data sources used by each base to respond to data calls as part of enterprise-wide KC-46 and F-35 basing decisions. To assess the second question, we examined the desired and actual impact of each basing decision criterion for the past 25 basing actions. Using statistical analysis enabled us to determine and compare the actual impact of each basing criterion relative to its desired impact. Finally, in addressing the potential for inclusion of strategic inputs into the basing decisionmaking process, we assessed the historical impact of strategic inputs.

\section{Air Force Data Quality Is Sufficient to Support Decisionmaking}

The data currently used are of sufficient quality to support USAF basing decisions. We examined data quality along three dimensions: authoritativeness, consistency, and auditability. Our analysis found that the data are authoritative and consistent but require improved auditability. Data used to make basing decisions are derived from authoritative sources. Specifically, the majority of data call questions pertaining to the mission criterion are answered using standard USAF or DoD sources, with base civil engineers, who are SMEs, answering the rest. Capacity questions are answered using limited access USAF sources or SME tacit knowledge. Environment questions are answered using standard, publicly available DoD and other government sources. Cost questions are answered using standard, publicly available DoD sources.

Sources used to answer data call questions are consistent. A detailed look at responses to

calls for data about weather days, runway length, and local area cost factors revealed that a given installation provided the same answers across actions. For the KC-46A tanker actions, HAFspecified sources are consistently used across candidate bases. When data sources are unspecified, there is little variation in the types of sources used to answer data call questions. 
Other attributes had notable differences in the data call question structure and were therefore not suitable for assessing consistency.

The auditability of underlying data used in the basing action process is weak. It is challenging to trace specific sources used to answer questions, even when responsible parties are identified in a MAJCOM-provided data call template, as is the case for the tanker actions. There is no data call template used for other basing actions, making it even more difficult to identify underlying data sources. Improved auditability will allow for more efficient HAF review. The combination of improved auditability and increased review should decrease the potential for human error in the basing decisionmaking process, which accounts for a majority of the publicly disputed basing decisions.

\section{The Air Force Should Institute an Initial Screening Process}

Our analysis found that the current basing process is designed so that installations with high mission scores are advanced toward site selection, but that capacity scores largely influence the final candidate list. To reduce the cost and time of conducting the existing strategic basing process, the Air Force should consider using centralized data to answer mission-related questions that can initially screen candidate bases for suitability. Efforts to update and integrate USAF databases are ongoing, but priority should be given to automation and centralization of mission data to have the greatest impact on the strategic basing process. With a reduced set of potential installations to consider, the detailed capacity and environmental data collection efforts could focus only on those installations with competitive mission scores. Our analysis found that initially screening installations based on mission scores would reduce data needs and level of effort, while maintaining an enterprise-wide look and desired basing outcomes. Using mission criteria to screen bases prior to selecting bases for further consideration can reduce the data collection burden on the enterprise by nearly half, with no decrease in the quality of the ultimate basing decision. 


\section{Appendix A. Detailed Analysis of Basing Decision Criteria}

In this appendix, we examine in detail 12 basing actions with a minimum of 10 installations in the enterprise-wide look, and for which we know the list of candidate bases. For each basing action, we show the scores and ranks for the site selection candidates. We rounded scores to the nearest whole number, but considered fractional differences when calculating rank. We also show the relative influence of the score categories for each action as determined by the GBM discussed in Chapter Three.

The first basing action examined is the enterprise-wide look for the C-27J basing action, which considered 94 CONUS and OCONUS installations. The two candidate bases, Boise and Great Falls, received the top two mission scores in CONUS. Mission was weighted so highly that the Great Falls location was able to earn more total points than any other CONUS installation despite receiving zero points for capacity (Table A.1). Our GBM-based model reflects the importance of the mission score in the USAF's process by assigning it a relative influence of 92 percent for this basing action (Table A.2).

Table A.1

C-27J Candidates

\begin{tabular}{|l|c|c|c|c|c|c|}
\hline & \multicolumn{2}{|c|}{ Total } & \multicolumn{2}{c|}{$\begin{array}{c}\text { Mission } \\
\text { (Mission + Manpower + } \\
\text { Increase Regional Lift) }\end{array}$} & \multicolumn{2}{|c|}{$\begin{array}{c}\text { Capacity } \\
\text { (Infrastructure) }\end{array}$} \\
\cline { 2 - 7 } Candidates & Score & Rank & Score & Rank & Score & Rank \\
\hline Boise & 52 & $2 \mathrm{nd}$ & 32 & $3 \mathrm{rd}$ & 20 & $\begin{array}{c}1 \mathrm{st} \\
\text { (6-way tie) }\end{array}$ \\
\hline Great Falls & 51 & $3 \mathrm{rd}$ & 51 & $2 \mathrm{nd}$ & 0 & $\begin{array}{c}3 \mathrm{rd} \\
\text { (66-way tie) }\end{array}$ \\
\hline
\end{tabular}

Table A.2

C-27J Relative Influence

\begin{tabular}{|l|c|c|}
\hline & $\begin{array}{c}\text { Mission } \\
\text { (Mission + Manpower + } \\
\text { Increase FEMA Regional Lift) }\end{array}$ & $\begin{array}{c}\text { Capacity } \\
\text { (Infrastructure) }\end{array}$ \\
\hline AF weight & 80 & 20 \\
\hline $\begin{array}{l}\text { Relative influence } \\
\text { site visit received }\end{array}$ & 92 & 8 \\
\hline
\end{tabular}

The enterprise-wide look for the F-35 one-squadron basing action considered 205 installations. Military judgment was the deciding factor in selection as a candidate base (Table A.3). The preference for bases with high capacity scores is seen in the relative influence 
calculated by GBM. The planned weight of the capacity category was only 25 points, but GBM assigned it a 74 percent relative influence on selection as a candidate base (Table A.4).

Table A.3

F-35 One-Squadron Candidates

\begin{tabular}{|l|c|c|c|c|c|c|c|c|c|c|}
\hline & \multicolumn{2}{|c|}{ Total } & \multicolumn{2}{c|}{$\begin{array}{c}\text { Mission } \\
\text { (Airspace + } \\
\text { Weather) }\end{array}$} & \multicolumn{2}{c|}{$\begin{array}{c}\text { Capacity } \\
\text { (Facilities) }\end{array}$} & \multicolumn{2}{|c|}{ Cost } & \multicolumn{2}{|c|}{ Environment } \\
\cline { 2 - 11 } Candidates & Score & Rank & Score & Rank & Score & Rank & Score & Rank & Score & Rank \\
\hline Shaw AFB & 90 & 7 th & 58 & 15 th & 23 & $\begin{array}{c}4 \text { th } \\
\text { (6-way tie) }\end{array}$ & 4 & $\begin{array}{c}5 \text { th } \\
\text { (5-way tie) }\end{array}$ & 4 & $\begin{array}{c}5 \text { th } \\
\text { (20-way tie) }\end{array}$ \\
\hline Hill AFB & 84 & 29 th & 52 & 62 nd & 23 & $\begin{array}{c}4 \text { th } \\
\text { (6-way tie) }\end{array}$ & 2 & $\begin{array}{c}\text { 26th } \\
\text { (5-way tie) }\end{array}$ & 7 & $\begin{array}{c}3 \text { rd } \\
\text { (29-way tie) }\end{array}$ \\
\hline $\begin{array}{l}\text { Mountain Home } \\
\text { AFB }\end{array}$ & 83 & 32 nd & 52 & 61 st & 18 & $\begin{array}{c}\text { 14th } \\
\text { (14-way } \\
\text { tie) }\end{array}$ & 3 & $\begin{array}{c}\text { 20th } \\
\text { (5-way tie) }\end{array}$ & 10 & $\begin{array}{c}1 \text { st } \\
\text { (29-way tie) }\end{array}$ \\
\hline
\end{tabular}

Table A.4

F-35 One-Squadron Relative Influence

\begin{tabular}{|l|c|c|c|c|}
\hline & $\begin{array}{c}\text { Mission } \\
\text { (Airspace + Weather) }\end{array}$ & $\begin{array}{c}\text { Capacity } \\
\text { (Facilities) }\end{array}$ & Cost & Environment \\
\hline AF weight & 60 & 25 & 5 & 10 \\
\hline $\begin{array}{l}\text { Relative influence } \\
\text { Top 10\% of scores }\end{array}$ & 44 & 30 & 18 & 9 \\
\hline $\begin{array}{l}\text { Relative influence } \\
\text { site visit received }\end{array}$ & 11 & 74 & 7 & 8 \\
\hline
\end{tabular}

The enterprise-wide look for the F-35 three-squadron basing action considered 205 installations. As with the F-35 one-squadron action, military judgment played an important role in candidate selection (Table A.5). However, applying the GBM technique, we see that, despite the importance of the mission category on receiving a high overall score, cost was a driving factor in the selection of candidate bases (Table A.6). 
Table A.5

F-35 Three-Squadron Candidates

\begin{tabular}{|c|c|c|c|c|c|c|c|c|c|c|}
\hline \multirow[b]{2}{*}{ Candidates } & \multicolumn{2}{|c|}{ Total } & \multicolumn{2}{|c|}{$\begin{array}{c}\text { Mission } \\
\text { (Airspace + } \\
\text { Weather) }\end{array}$} & \multicolumn{2}{|c|}{$\begin{array}{l}\text { Capacity } \\
\text { (Facilities) }\end{array}$} & \multicolumn{2}{|c|}{ Cost } & \multicolumn{2}{|c|}{ Environment } \\
\hline & Score & Rank & Score & Rank & Score & Rank & Score & Rank & Score & Rank \\
\hline $\begin{array}{l}\text { Jacksonville IAP } \\
\text { AGS }\end{array}$ & 84 & 11th & 58 & 15th & 15 & $\begin{array}{c}\text { 11th } \\
\text { (22-way tie) }\end{array}$ & 4 & $\begin{array}{c}\text { 2nd } \\
\text { (5-way tie) }\end{array}$ & 7 & $\begin{array}{c}\text { 3rd } \\
\text { (29-way tie) }\end{array}$ \\
\hline McEntire AGB & 81 & 22nd & 57 & $22 n d$ & 15 & $\begin{array}{c}11 \text { th } \\
\text { (22-way tie) }\end{array}$ & 4 & $\begin{array}{c}2 n d \\
\text { (5-way tie) }\end{array}$ & 4 & $\begin{array}{c}5 \text { th } \\
\text { (20-way tie) }\end{array}$ \\
\hline $\begin{array}{l}\text { Burlington IAP } \\
\text { AGS }\end{array}$ & 80 & 27th & 51 & 66th & 15 & $\begin{array}{c}11 \text { th } \\
\text { (22-way tie) }\end{array}$ & 4 & $\begin{array}{c}5 \text { th } \\
\text { (5-way tie) }\end{array}$ & 10 & $\begin{array}{c}1 \mathrm{st} \\
\text { (29-way tie) }\end{array}$ \\
\hline
\end{tabular}

Table A.6

F-35 Three-Squadron Relative Influence

\begin{tabular}{|l|c|c|c|c|}
\hline & $\begin{array}{c}\text { Mission } \\
\text { (Airspace + Weather) }\end{array}$ & $\begin{array}{c}\text { Capacity } \\
\text { (Facilities) }\end{array}$ & Cost & Environment \\
\hline AF weight & 60 & 25 & 5 & 10 \\
\hline $\begin{array}{l}\text { Relative influence } \\
\text { top 10\% of scores }\end{array}$ & 68 & 17 & 8 & 7 \\
\hline $\begin{array}{l}\text { Relative influence } \\
\text { site visit received }\end{array}$ & 19 & 19 & 57 & 5 \\
\hline
\end{tabular}

The enterprise-wide look for the F-35 training basing action (Tables A.7 and A.8) considered 205 installations. Twenty-two bases not selected as candidates scored higher than at least one candidate base, but only two bases not selected had both higher mission and capacity scores than at least one candidate.

Table A.7

F-35 Training Candidates

\begin{tabular}{|c|c|c|c|c|c|c|c|c|c|c|}
\hline \multirow[b]{2}{*}{ Candidates } & \multicolumn{2}{|c|}{ Total } & \multicolumn{2}{|c|}{ Mission } & \multicolumn{2}{|c|}{ Capacity } & \multicolumn{2}{|c|}{ Cost } & \multicolumn{2}{|c|}{ Environment } \\
\hline & Score & Rank & Score & Rank & Score & Rank & Score & Rank & Score & Rank \\
\hline Luke AFB & 89 & 1st & 57 & $\begin{array}{c}1 \mathrm{st} \\
\text { (2-way } \\
\text { tie) }\end{array}$ & 24 & $1 \mathrm{st}$ & 4 & $\begin{array}{c}14 \text { th } \\
\text { (3-way tie) }\end{array}$ & 4 & $\begin{array}{c}5 \text { th } \\
\text { (20-way tie) }\end{array}$ \\
\hline Holloman AFB & 74 & 6 th & 56 & 4th & 5 & $\begin{array}{c}25 \text { th } \\
\text { (4-way tie) }\end{array}$ & 4 & $\begin{array}{c}12 \text { th } \\
\text { (4-way tie) }\end{array}$ & 9 & $\begin{array}{c}\text { 2nd } \\
\text { (25-way tie) }\end{array}$ \\
\hline $\begin{array}{l}\text { Boise Air Terminal } \\
\text { AGS }\end{array}$ & 59 & 25th & 29 & 29th & 18 & 4th & 4 & $\begin{array}{c}\text { 6th } \\
\text { (3-way tie) }\end{array}$ & 7 & $\begin{array}{c}\text { 3rd } \\
\text { (29-way tie) }\end{array}$ \\
\hline
\end{tabular}


Table A.8

F-35 Training Relative Influence

\begin{tabular}{|l|c|c|c|c|}
\hline & Mission & Capacity & Cost & Environment \\
\hline AF weight & 60 & 25 & 5 & 10 \\
\hline $\begin{array}{l}\text { Relative influence } \\
\text { site visit received }\end{array}$ & 79 & 10 & 10 & 1 \\
\hline
\end{tabular}

The enterprise-wide look for the KC-46A MOB1 basing action (Tables A.9 and A.10) considered 54 installations. The top four highest-scoring installations were selected as candidates. The capacity score had the greatest impact on the selection of bases for the KC-46A action. The top five highest-scoring bases for capacity had scores within five points of each other. However, the sixth-placed base in capacity was five points behind the fifth-placed base. None of the other score categories had a clear dividing line between installations that were or were not selected as candidates. Grand Forks' high capacity and environment scores kept it in the top four bases despite scoring below 43 other installations in its mission score. All but one of the nonselected bases scoring above Grand Forks in mission had much lower capacity scores. The exception was MacDill AFB, which beat Grand Forks in both mission and capacity, but was edged out by Grand Forks' perfect environment score.

Table A.9

KC-46A MOB1 Candidates

\begin{tabular}{|c|c|c|c|c|c|c|c|c|c|c|}
\hline \multirow[b]{2}{*}{ Candidates } & \multicolumn{2}{|c|}{ Total } & \multicolumn{2}{|c|}{ Mission } & \multicolumn{2}{|c|}{ Capacity } & \multicolumn{2}{|c|}{ Cost } & \multicolumn{2}{|c|}{ Environment } \\
\hline & Score & Rank & Score & Rank & Score & Rank & Score & Rank & Score & Rank \\
\hline $\begin{array}{l}\text { McConnell } \\
\text { AFB }\end{array}$ & 71 & $1 \mathrm{st}$ & 32 & 5 th & 26 & 2nd & 8 & 20th & 4 & $\begin{array}{l}7 \text { th } \\
\text { (9-way } \\
\text { tie) }\end{array}$ \\
\hline Altus AFB & 66 & 2nd & 29 & 8th & 23 & $3 r d$ & 9 & $2 n d$ & 6 & $\begin{array}{c}5 \text { th } \\
\text { (8-way } \\
\text { tie) }\end{array}$ \\
\hline Fairchild AFB & 63 & $3 r d$ & 23 & 20th & 26 & $1 \mathrm{st}$ & 7 & 39th & 6 & $\begin{array}{l}\text { 5th } \\
\text { (8-way } \\
\text { tie) }\end{array}$ \\
\hline $\begin{array}{l}\text { Grand Forks } \\
\text { AFB }\end{array}$ & 55 & 4 th & 15 & $43 r d$ & 21 & 5 th & 9 & 12th & 10 & $\begin{array}{c}\text { 1st } \\
\text { (3-way } \\
\text { tie) }\end{array}$ \\
\hline
\end{tabular}


Table A.10

KC-46A MOB1 Relative Influence

\begin{tabular}{|l|c|c|c|c|}
\hline & Mission & Capacity & Cost & Environment \\
\hline AF weight & 40 & 40 & 10 & 10 \\
\hline $\begin{array}{l}\text { Relative influence } \\
\text { top 10\% of scores }\end{array}$ & 46 & 28 & 16 & 9 \\
\hline $\begin{array}{l}\text { Relative influence } \\
\text { site visit received }\end{array}$ & 18 & 66 & 14 & 3 \\
\hline
\end{tabular}

The enterprise-wide look for the KC-46A MOB2 basing action (Tables A.11 and A.12) considered 83 installations. The top five highest-scoring installations were selected as candidates. Even though the mission and capacity scores were both worth 40 points, the capacity scores had a much wider variance across installations than the mission scores. The larger variance gave capacity scores more influence on candidate selection.

Table A.11

KC-46A MOB2 Candidates

\begin{tabular}{|l|c|c|c|c|c|c|c|c|c|c|}
\hline & \multicolumn{2}{|c|}{ Total } & \multicolumn{2}{c|}{ Mission } & Capacity & \multicolumn{2}{c|}{ Cost } & \multicolumn{2}{c|}{ Environment } \\
\cline { 2 - 11 } Candidates & Score & Rank & Score & Rank & Score & Rank & Score & Rank & Score & Rank \\
\hline $\begin{array}{l}\text { Pease Int'l } \\
\text { Trade Port }\end{array}$ & 73 & 1 st & 32 & 3 rd & 30 & 2 nd & 5 & 76 th & 6 & $\begin{array}{c}5 \text { th } \\
\text { (13-way tie) }\end{array}$ \\
\hline Forbes Field & 72 & 2 nd & 27 & 17 th & 29 & 3 rd & 9 & 19 th & 8 & $\begin{array}{c}3 \text { rd } \\
\text { (10-way tie) }\end{array}$ \\
\hline McGuire & 72 & 3 rd & 36 & 1 st & 26 & 7 th & 5 & 70 th & 5 & $\begin{array}{c}6 \text { th } \\
\text { (14-way tie) }\end{array}$ \\
\hline Rickenbacker & 70 & 4 th & 24 & 27 th & 34 & 1 st & 8 & 32 nd & 4 & $\begin{array}{c}7 \text { th } \\
\text { (4-way tie) }\end{array}$ \\
\hline Pittsburgh & 70 & 5 th & 28 & 12 th & 28 & 4 th & 7 & 61 st & 7 & $\begin{array}{c}\text { 4th } \\
\text { (11-way tie) }\end{array}$ \\
\hline
\end{tabular}

Table A.12

KC-46A MOB2 Relative Influence

\begin{tabular}{|l|c|c|c|c|}
\hline & Mission & Capacity & Cost & Environment \\
\hline AF Weight & 40 & 40 & 10 & 10 \\
\hline $\begin{array}{l}\text { Relative influence } \\
\text { top 10\% of scores }\end{array}$ & 61 & 21 & 12 & 6 \\
\hline $\begin{array}{l}\text { Relative influence } \\
\text { site visit received }\end{array}$ & 24 & 73 & 3 & 1 \\
\hline
\end{tabular}

The enterprise-wide look for the KC-46A training squadron basing action (Tables A.13 and A.14) considered 54 installations. The two candidates chosen received both the top two total 
scores and the top two mission scores. McConnell AFB was part of a two-way tie for fourth place in the capacity category, making its high mission score the deciding factor. Both candidates received mediocre environment scores and good cost scores.

Table A.13

KC-46A Training Base Candidates

\begin{tabular}{|l|c|c|c|c|c|c|c|c|c|c|}
\hline \multirow{2}{*}{ Candidates } & \multicolumn{2}{|c|}{ Total } & \multicolumn{2}{c|}{ Mission } & \multicolumn{2}{c|}{ Capacity } & \multicolumn{2}{c|}{ Cost } & \multicolumn{2}{c|}{ Environment } \\
\cline { 2 - 11 } & Score & Rank & Score & Rank & Score & Rank & Score & Rank & Score & Rank \\
\hline Altus AFB & 88 & 1 st & 34 & 1 st & 39 & 1 st & 9 & 2nd & 6 & $\begin{array}{c}5 \text { th } \\
\text { (9-way tie) }\end{array}$ \\
\hline McConnell AFB & 71 & 2nd & 26 & 2nd & 33 & $\begin{array}{c}4 \text { th } \\
\text { (2-way tie) }\end{array}$ & 8 & 18th & 4 & $\begin{array}{c}7 \text { th } \\
\text { (9-way tie) }\end{array}$ \\
\hline
\end{tabular}

Table A.14

KC-46A Training Base Relative Influence

\begin{tabular}{|l|c|c|c|c|}
\hline & Mission & Capacity & Cost & Environment \\
\hline AF weight & 40 & 40 & 10 & 10 \\
\hline $\begin{array}{l}\text { Relative influence } \\
\text { top 10\% of scores }\end{array}$ & 23 & 44 & 18 & 15 \\
\hline $\begin{array}{l}\text { Relative influence } \\
\text { site visit received }\end{array}$ & 33 & 35 & 27 & 5 \\
\hline
\end{tabular}

The enterprise-wide look for the LiMA basing action (Tables A.15 and A.16) considered 172 installations. The top two scoring installations were selected as candidates. The two candidate bases tied for first place in the mission category. Twenty-five bases received a capacity score higher than at least one of the selected candidate bases; however, none of them could overcome the high mission scores of the two candidates.

Table A.15

LiMA Candidates

\begin{tabular}{|l|c|c|c|c|c|c|}
\hline \multirow{2}{*}{ Candidates } & \multicolumn{2}{|c|}{ Total } & \multicolumn{2}{c|}{$\begin{array}{c}\text { Mission } \\
\text { (Mission + Training) }\end{array}$} & \multicolumn{3}{c|}{ Capacity } \\
\cline { 2 - 7 } & Score & Rank & Score & Rank & Score & Rank \\
\hline Travis & 99 & 1 st & 65 & $\begin{array}{c}1 \text { st } \\
\text { (2-way tie) }\end{array}$ & 34 & $\begin{array}{c}\text { 2nd } \\
\text { (2-way tie) }\end{array}$ \\
\hline McGuire & 95 & 2nd & 65 & $\begin{array}{c}1 \text { st } \\
\text { (2-way tie) }\end{array}$ & 30 & $\begin{array}{c}\text { 4th } \\
\text { (12-way tie) }\end{array}$ \\
\hline
\end{tabular}


Table A.16

LiMA Relative Influence

\begin{tabular}{|l|c|c|}
\hline & $\begin{array}{c}\text { Mission } \\
\text { (Mission + Training) }\end{array}$ & $\begin{array}{c}\text { Capacity } \\
\text { (Facilities/Infrastructure + Support Capacity) }\end{array}$ \\
\hline AF weight & 65 & 35 \\
\hline $\begin{array}{l}\text { Relative influence } \\
\text { site visit received }\end{array}$ & 79 & 21 \\
\hline
\end{tabular}

The enterprise-wide look for the MC-12 basing action (Tables A.17 and A.18) considered 175 installations. The top five highest-scoring bases were selected as candidates. All five candidates had high capacity scores, but their performance in the three other categories was mixed.

Table A.17

MC-12 Candidates

\begin{tabular}{|c|c|c|c|c|c|c|c|c|c|c|}
\hline \multirow[b]{2}{*}{ Candidates } & \multicolumn{2}{|c|}{ Total } & \multicolumn{2}{|c|}{ Mission } & \multicolumn{2}{|c|}{ Capacity } & \multicolumn{2}{|c|}{ Cost } & \multicolumn{2}{|c|}{ Environment } \\
\hline & Score & Rank & Score & Rank & Score & Rank & Score & Rank & Score & Rank \\
\hline Beale & 87 & $1 \mathrm{st}$ & 47 & 4 th & 36 & $\begin{array}{c}\text { 4th } \\
\text { (2-way tie) }\end{array}$ & 1 & 36th & 4 & $\begin{array}{c}1 \mathrm{st} \\
\text { (19-way tie) }\end{array}$ \\
\hline Altus & 86 & 2nd & 42 & $21 \mathrm{st}$ & 38 & 2nd & 3 & $\begin{array}{c}16 \text { th } \\
\text { (2-way tie) }\end{array}$ & 4 & $\begin{array}{c}1 \mathrm{st} \\
\text { (19-way tie) }\end{array}$ \\
\hline Langley & 84 & $3 r d$ & 44 & 6 th & 35 & 5 th & 3 & $\begin{array}{c}14 \text { th } \\
\text { (5-way tie) }\end{array}$ & 1 & $\begin{array}{c}\text { 4th } \\
\text { (22-way tie) }\end{array}$ \\
\hline Robins & 83 & 4th & 44 & 8th & 32 & 11th & 4 & $\begin{array}{c}3 r d \\
\text { (4-way tie) }\end{array}$ & 3 & $\begin{array}{c}2 \mathrm{nd} \\
\text { (30-way tie) }\end{array}$ \\
\hline Key Field & 83 & 5th & 43 & 16th & 36 & $\begin{array}{c}\text { 4th } \\
\text { (2-way tie) }\end{array}$ & 3 & $\begin{array}{c}17 \text { th } \\
\text { (4-way tie) }\end{array}$ & 2 & $\begin{array}{c}\text { 3rd } \\
\text { (56-way tie) }\end{array}$ \\
\hline Whiteman & 82 & 6 th & 39 & 40th & 37 & $3 r d$ & 2 & $\begin{array}{c}21 \text { st } \\
\text { (3-way tie) }\end{array}$ & 4 & $\begin{array}{c}1 \mathrm{st} \\
\text { (19-way tie) }\end{array}$ \\
\hline
\end{tabular}

Table A.18

MC-12 Relative Influence

\begin{tabular}{|l|c|c|c|c|}
\hline & Mission & Capacity & Cost & Environment \\
\hline AF Weight & 52 & 40 & 4 & 4 \\
\hline $\begin{array}{l}\text { Relative Influence } \\
\text { Site Visit Received }\end{array}$ & 17 & 81 & 0 & 2 \\
\hline
\end{tabular}

The enterprise-wide look for the MQ-1/9 Remote Split Operations regular Air Force basing action (Tables A.19 and A.20) considered 161 installations. The top three scoring bases were chosen as candidates. All three candidates scored very well in mission, capacity, and environment. Hickam placed third in total score despite coming in last in the cost category. 
Table A.19

MQ-1/9 RSO Regular Air Force Candidates

\begin{tabular}{|c|c|c|c|c|c|c|c|c|c|c|}
\hline \multirow[b]{2}{*}{ Candidates } & \multicolumn{2}{|c|}{ Total } & \multicolumn{2}{|c|}{ Mission } & \multicolumn{2}{|c|}{$\begin{array}{c}\text { Capacity } \\
\text { (Comm Infrastructure } \\
\text { / Facilities) }\end{array}$} & \multicolumn{2}{|c|}{ Cost } & \multicolumn{2}{|c|}{ Timing } \\
\hline & Score & Rank & Score & Rank & Score & Rank & Score & Rank & Score & Rank \\
\hline Shaw & 91 & $1 \mathrm{st}$ & 48 & $\begin{array}{l}\text { 2nd } \\
(2-\text { way } \\
\text { tie) }\end{array}$ & 29 & $\begin{array}{c}\text { 3rd } \\
\text { (3-way tie) }\end{array}$ & 9 & 7th & 5 & $\begin{array}{c}1 \mathrm{st} \\
(13-w a y \text { tie) }\end{array}$ \\
\hline $\begin{array}{l}\text { Davis } \\
\text { Monthan }\end{array}$ & 88 & 2nd & 48 & $\begin{array}{l}\text { 2nd } \\
(2-\text {-way } \\
\text { tie) }\end{array}$ & 28 & $\begin{array}{c}\text { 4th } \\
\text { (2-way tie) }\end{array}$ & 9 & 18th & 3 & $\begin{array}{c}\text { 2nd } \\
\text { (8-way tie) }\end{array}$ \\
\hline Hickam & 87 & $3 r d$ & 52 & $1 \mathrm{st}$ & 29 & $\begin{array}{c}\text { 3rd } \\
\text { (3-way tie) }\end{array}$ & 1 & $\begin{array}{l}\text { Last } \\
\text { Place }\end{array}$ & 5 & $\begin{array}{c}1 \mathrm{st} \\
\text { (13-way tie) }\end{array}$ \\
\hline
\end{tabular}

Table A.20

MQ-1/9 RSO Regular Air Force Relative Influence

\begin{tabular}{|l|c|c|c|c|}
\hline & Mission & $\begin{array}{c}\text { Capacity } \\
\text { (Comm Infrastructure/ } \\
\text { Facilities) }\end{array}$ & Cost & Timing \\
\hline AF weight & 54 & 31 & 10 & 5 \\
\hline $\begin{array}{l}\text { Relative influence } \\
\text { site visit received }\end{array}$ & 41 & 35 & 5 & 19 \\
\hline
\end{tabular}

The enterprise-wide look for the MQ-1/9 RSO Air Force Reserve Command basing action (Tables A.21 and A.22) and considered 66 installations. Hurlburt Field was the only candidate chosen, even though five installations earned higher total scores. One installation, Eglin AFB, tied or beat Hurlburt Field in every category.

Table A.21

MQ-1/9 RSO AFRC Candidates

\begin{tabular}{|c|c|c|c|c|c|c|c|c|c|c|}
\hline & \multicolumn{2}{|c|}{ Total } & \multicolumn{2}{c|}{ Mission } & $\begin{array}{c}\text { Capacity } \\
\text { (Comm Infrastructure I } \\
\text { Facilities) }\end{array}$ & \multicolumn{2}{|c|}{ Cost } & \multicolumn{2}{c|}{ Environment } \\
\cline { 2 - 11 } Candidates & Score & Rank & Score & Score & Score & Rank & Score & Rank & Score & Rank \\
\hline Hurlburt Field & 65 & 6 th & 42 & 4 th & 3 & $\begin{array}{c}15 \text { th } \\
\text { (3-way tie) }\end{array}$ & 3 & $\begin{array}{c}\text { 9th } \\
\text { (2-way tie) }\end{array}$ & 0 & $\begin{array}{c}\text { Last place } \\
\text { (56-way tie) }\end{array}$ \\
\hline
\end{tabular}


Table A.22

MQ-1/9 RSO AFRC Relative Influence

\begin{tabular}{|l|c|c|c|c|}
\hline & Mission & $\begin{array}{c}\text { Capacity } \\
\text { (Comm Infrastructure / Facilities) }\end{array}$ & Cost & Timing \\
\hline AF weight & 49 & 35 & 4 & 12 \\
\hline $\begin{array}{l}\text { Relative influence } \\
\text { site visit received }\end{array}$ & 32 & 51 & 17 & 0 \\
\hline
\end{tabular}

The enterprise-wide look for the Tactical Air Control Party (TAC-P) basing action (Tables A.23 and A.24) considered 157 installations. The top two Air Education and Training Command installations were chosen as candidates. The selected candidates had higher mission scores than any other installations in the enterprise-wide look. Neither scored any points in the timing or cost categories. For timing, the P\&RA briefing states that there were "no significant issues." Although environment considerations were not part of the enterprise-wide look, the same briefing states that Lackland AFB had "low" environmental risk and Keesler AFB had "medium" risk.

Table A.23

TAC-P Candidates

\begin{tabular}{|l|c|c|c|c|c|c|c|c|c|c|}
\hline & \multicolumn{2}{|c|}{ Total } & \multicolumn{2}{c|}{ Mission } & \multicolumn{2}{c|}{ Capacity } & \multicolumn{2}{c|}{ Cost } & \multicolumn{2}{c|}{ Timing } \\
\cline { 2 - 11 } Candidates & Score & Rank & Score & Rank & Score & Rank & Score & Rank & Score & Rank \\
\hline Lackland AFB & 82 & 1 st & 57 & 1 st & 25 & 1 st & 0 & $\begin{array}{c}\text { Last place } \\
\text { (32-way tie) }\end{array}$ & 0 & $\begin{array}{c}\text { Last place } \\
\text { (136-way tie) }\end{array}$ \\
\hline Keesler AFB & 64 & 3rd & 44 & 2nd & 20 & $\begin{array}{c}\text { 2nd } \\
\text { (17-way tie) }\end{array}$ & 0 & $\begin{array}{c}\text { Last place } \\
\text { (32-way tie) }\end{array}$ & 0 & $\begin{array}{c}\text { Last place } \\
\text { (136-way tie) }\end{array}$ \\
\hline
\end{tabular}

Table A.24

TAC-P Relative Influence

\begin{tabular}{|l|c|c|c|c|}
\hline & Mission & Capacity & Cost & Timing \\
\hline AF weight & 60 & 30 & 5 & 5 \\
\hline $\begin{array}{l}\text { Relative influence } \\
\text { top 10\% of scores }\end{array}$ & 59 & 37 & 3 & 1 \\
\hline $\begin{array}{l}\text { Relative influence } \\
\text { site visit received }\end{array}$ & 58 & 28 & 13 & 0 \\
\hline
\end{tabular}





\section{Appendix B. Base Realignment and Closure 2005}

The main report addresses the USAF's strategic basing process. Decisions regarding basing, especially closures, are frequently contentious. This appendix provides background on the BRAC process.

\section{Introduction to BRAC 2005}

DoD faced difficulties reorganizing its portfolio of military installations in the decades immediately prior to 1988. The National Environmental Policy Act (NEPA) of 1969 required that DoD use procedures that take between 10 and 18 months when undertaking any "major" installation closure or realignment and release relevant DoD plans and studies to the public (Schlossberg, 2012). Publicity generated by proposed basing actions invited litigation and congressional interference that regularly delayed or scuttled DoD plans (Schlossberg, 2012). The Defense Authorization Amendments and Base Closure and Realignment Act of 1988 (P. L. 100526) authorized DoD to close and realign U.S. military installations without going through the process required by NEPA. The result was the first Base BRAC round in 1988. The reunification of Germany in 1990 and the imminent dissolution of the Warsaw Pact and end of the Cold War convinced Secretary of Defense Dick Cheney that further basing actions were necessary. Cheney attempted to reorganize military installations in 1990 following NEPA guidelines and without gaining congressional approval for a BRAC round but found the process too onerous. Congress subsequently passed the Defense Base Realignment and Closure Act of 1990 (P.L. 101-510), which allowed for further BRAC rounds. The BRAC Act of 1990 served as the guiding document for BRAC rounds in 1991, 1993, 1995, and 2005. Amendments were made to the act throughout this time period so that the various BRAC rounds were subtly different. The BRAC Act of 1990 has expired, leaving the NEPA process the only option currently available for making basing actions (Schlossberg, 2012). DoD has requested a new BRAC round, which would likely be similar to BRAC 2005. This section of the report details BRAC 2005, explaining the process that the 1990 Act requires.

On December 28, 2001, Congress authorized the BRAC round of 2005. The Secretary of Defense had three goals, which were announced on November 15, 2002: saving military expenses by reducing excess infrastructure, transforming the military, and fostering jointness. Prior BRACs in 1988, 1991, 1993, and 1995 focused exclusively on the first of these goals. DoD next proposed criteria to use to evaluate existing installations and potential changes to the organization of these installations. The criteria are listed in Table B.1 and were placed in the Federal Register, with opportunity for public comment, on December 23, 2003 (68 Fed. Reg. 74221 [2003]). 
Table B.1

\section{Department of Defense Criteria for the 2005 BRAC Round}

\begin{tabular}{|c|c|}
\hline Category & Criteria \\
\hline \multirow[t]{4}{*}{ Military value } & $\begin{array}{l}\text { The current and future mission capabilities and the impact on operations readiness of the total } \\
\text { force of DoD, including the impact on joint warfighting, training, and readiness. }\end{array}$ \\
\hline & $\begin{array}{l}\text { The availability and condition of land, facilities, and associated airspace (including training areas } \\
\text { suitable for maneuver by ground, naval, or air forces throughout a diversity of climate and terrain } \\
\text { areas and staging areas for use of the Armed Forces in homeland defense missions) at both } \\
\text { existing and potential receiving locations. }\end{array}$ \\
\hline & $\begin{array}{l}\text { The ability to accommodate contingency, mobilization, surge and future total force requirements } \\
\text { at both existing and potential receiving locations to support operations and training. }\end{array}$ \\
\hline & The cost of operations and the manpower implications. \\
\hline \multirow[t]{4}{*}{ Other } & $\begin{array}{l}\text { The extent and timing of potential costs and savings, including the number of years, beginning } \\
\text { with the date of completion of the closure or realignment, for the savings to exceed costs. }\end{array}$ \\
\hline & The economic impact on existing communities in the vicinity of military installations. \\
\hline & $\begin{array}{l}\text { The ability of the infrastructure of both the existing and potential receiving communities to } \\
\text { support forces, missions, and personnel. }\end{array}$ \\
\hline & $\begin{array}{l}\text { The environmental impact, including the impact of costs related to potential environmental } \\
\text { restoration, waste management, and environmental compliance activities. }\end{array}$ \\
\hline
\end{tabular}

SOURCE: GAO, 2013a.

DoD was required to furnish Congress with a plan for force structure, defining the size and composition of units needed to address threats to national security 20 years into the future. This requirement was new for the 2005 BRAC round. Analyses based on the force forecast and an inventory of existing installations led the Secretary of Defense to certify that there was a need for the closure and/or realignment of military bases on March 23, 2004. The secretary, as required, also certified that needed closures and realignments would yield annual net savings for each department of the military beginning no later than 2011.

Analytical teams from the individual departments of the military, together with an Infrastructure Steering Group representing seven “joint cross-service groups” investigating common such functions as medical services, and military intelligence, came up with options for the realignment and closure of bases (GAO, 2012). The Infrastructure Executive Council, a highlevel body within DoD, next evaluated the collected set of options. The council approved a reduced set of recommendations and forwarded this list to the Secretary of Defense. The secretary analyzed these recommendations and submitted a list of over 200 recommendations to the BRAC Commission on May 13, 2005 (GAO, 2012).

The BRAC Commission was an independent government agency responsible for analyzing DoD recommendations related to the 2005 BRAC round. Nine commissioners managed a staff of over 100 with backgrounds in the military, various government agencies, law, and academia (GAO, 2013a). Congress has amended the original BRAC Act of 1990 at various times to limit the number of current and former DoD staff working for the commission, and to allow the 
commission to recommend closure of bases that DoD had not recommended be closed (Schlossberg, 2012). The commission collected comments from interested parties and expert witnesses before voting on accepting, modifying, rejecting, or adding BRAC recommendations. The BRAC Commission rejected 13 DoD recommendations outright, added five new recommendations, modified 58, and approved 119 recommendations without modification to report a final list of 182 recommendations to the President on September 8, 2005 (GAO, 2013a). The President next had the power to approve or disapprove of the recommendations, as a whole. The President approved of the recommendations on September 15, 2005. Congress next had the opportunity to cancel the BRAC round by passing a resolution disapproving of the BRAC Commission recommendations before 45 days had elapsed or before Congress adjourned. Congress did not pass the required resolution, and the recommendations became binding. The process is, and has always been, an "all-or-nothing" process in which neither Congress nor the President can modify individual BRAC recommendations. The goal is to prevent politics from adversely affecting the military reorganization process.

Next, DoD began implementation. DoD was required to provide Congress annual reports detailing recommendation-specific cost and savings estimate updates (GAO, 2013a). The implementation of BRAC 2005 recommendations was legally required to terminate on September 15, 2011, six years after the President approved of the recommendations. On this date, the latest BRAC Act expired.

\section{Air Force Decisionmaking During BRAC 2005}

The SecAF identified four goals specifically for the Air Force during the BRAC round of 2005 (Department of the Air Force, 2005):

- Transform by maximizing the warfighting capability of each squadron.

- Transform by realigning USAF infrastructure with future defense strategy.

- Maximize operational capability by eliminating excess physical capacity.

- Capitalize on opportunities for join activity.

In support of these goals, there was a general desire to consolidate resources and have largersized squadrons. The Air Force noted that optimal- and acceptable-sized squadrons for fighter aircraft would include 24 and 18 aircraft, respectively (Department of the Air Force, 2005). For bombers and large transport aircraft, a squadron should have 12 aircraft, while for tactical transport and tanker aircraft, 16 aircraft would be optimal and 12 acceptable (Department of the Air Force, 2005). The Air Force recommendations for BRAC 2005 involved reorganizing the force to move toward the desired sized squadrons. For example, the fraction of the C-130 fleet in squadrons of 12 or 16 aircraft was to go from 5 percent in 2006 to 83 percent in 2011 (Department of the Air Force, 2005). 
The Air Force has identified 11 "Air Force basing principles" and five "Air Force basing imperatives" that were also important during the development of BRAC 2005 recommendations. These principles and imperatives are presented in Table B.2.

Table B.2

Air Force Basing Principles and Imperatives

\begin{abstract}
Air Force Basing Principles
Maintain squadrons within operationally efficient proximity to DoD-controlled airspace, ranges, military operations areas, and low-level routes

Optimize the size of our squadrons-in terms of aircraft model, aircraft assigned, and crew ratios applied (e.g., same mission design series)

Retain enough capacity to base worldwide Air Force forces entirely within the United States and its territories

Retain aerial refueling bases in optimal proximity to their missions

Better meet the needs of the Air Force by maintaining/placing Air Reserve Component (ARC) units in locations that best meet the demographic and mission requirements unique to the ARC

Ensure joint basing realignment actions (when compared with the status quo) increase the military value of a function, or decrease the cost for the same military value of that function

Ensure long-range strike bases provide flexible strategic response and strategic force protection

Support the American Expeditionary Forces construct by keeping two geographically separate munitions sites

Retain enough surge capacity to support deployments, evacuations, and base repairs

Consolidate and/or co-locate older fleets

Ensure global mobility by retaining two air mobility bases and one additional wide-body capable base on each coast

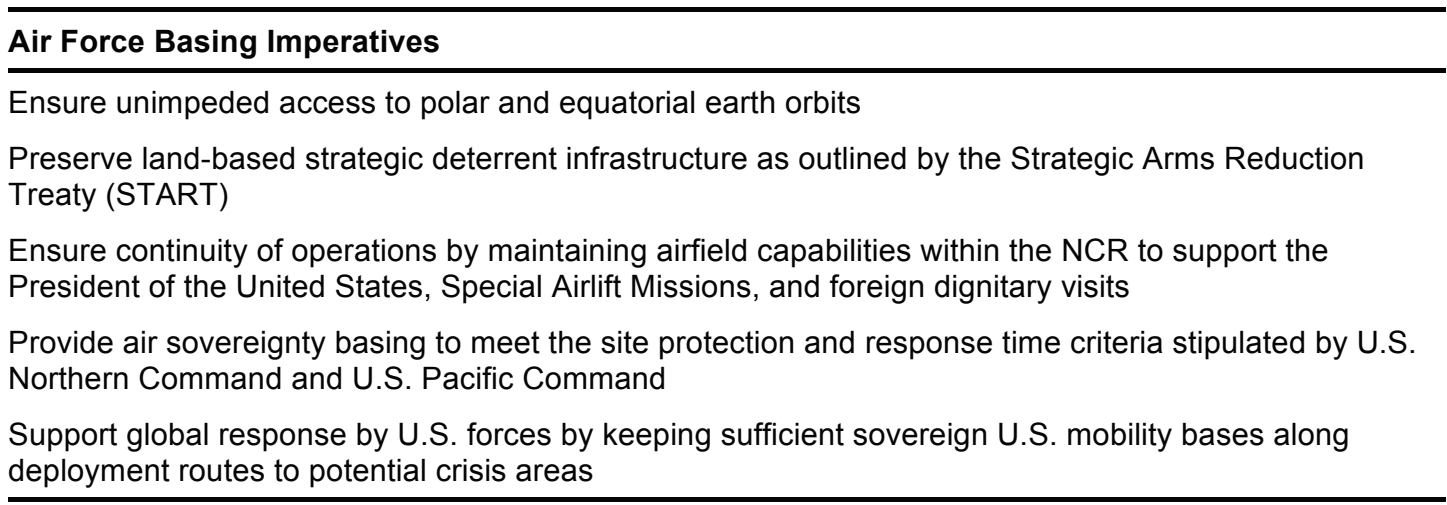

SOURCE: Department of the Air Force, 2005.

$\mathrm{SAF} / \mathrm{IE}$ was responsible for developing recommended USAF closure and realignment actions. SAF/IE set up the Base Closure Executive Group (BCEG) to manage this process. The principal charged with carrying out necessary analyses was the Deputy Assistant Secretary for Basing and Infrastructure Analysis (SAF/IEB). A Joint Cross-Service Division was set up within $\mathrm{SAF} / \mathrm{IEB}$, responsible for coordination and communication with DoD joint cross-service groups 
while the Base Realignment and Closure Division was responsible for USAF-specific recommendations.

To develop its recommendations, the Air Force utilized three analytical tools developed specifically for the Air Force: the Web-based Installation Data Gathering and Entry Tool (WIDGET), the BRAC Analysis Tool, and the Air Force Cueing Tool. The first of these tools was a web-based system that stored relevant data. A senior Commission analyst leading the BRAC 2005 USAF analysis team has written an article highly critical of USAF decisionmaking during BRAC 2005. The article claims that much of the data loaded into WIDGET by the installations. in WIDGET was "erroneous or outdated," noting, for example, that an installation in Reno, Nevada, capable of supporting 12 C-130 aircraft was listed as capable of supporting only 10 (Flinn, 2006). There were, however, clear benefits from using WIDGET: Storing relevant data in one accessible location ensured that analyses were consistent and reduced the effort required to maintain and update data.

The BRAC analysis tool assigned several scores, known as mission compatability indices (MCIs), to each individual base based on how well the base was able to host missions of various types (fighter, bomber, tanker, etc.). The MCIs have been criticized as favoring active duty installations over reserve installations and for being too similar across installations, raising the possibility of "data discrepancies" unduly influencing rankings (Flinn, 2006). Here, again, there are benefits associated with the use of the Air Force's software tool: The BRAC Analysis tool ensured a consistent methodology, and data sources were used to translate data describing USAF installations into indices more directly useful for selecting bases to close and bases to realign.

The Air Force Cueing Tool used "goal programming" to select an optimal set of bases based on the MCIs from the BRAC Analysis Tool and other inputs (Department of the Air Force, 2005). This tool was critical for ensuring that the portfolio of installations the Air Force manages, taken as a whole, met certain strategic requirements. The Cueing Tool appears to be based on an algorithm solving a binary programming problem in which installations' contribution to the objective function is based on the MCI scores, and various constraints ensure that portfolio-wide strategic requirements are met.

The Air Force also utilized the Installation Visualization Tool and the Cost of Base Realignment Actions (COBRA) model, both of which are service-common software products. The Installation Visualization Tool gives the Air Force a consistent way to access imagery and geospatial data associated with installations. The COBRA model is used to estimate the costs and benefits of base realignment and closure actions. The COBRA model was developed in 1988 by the Air Force Cost Center and produced all the cost estimates used by the various branches of the military for the initial 1988 BRAC round. The COBRA model has since been used in each BRAC round and has been improved several times through the work of a COBRA Joint Process Action Team within DoD (GAO, 2005).

The Air Force also undertook a capacity analysis of its installations. Factors that would prevent bases from adding force structure were identified, along with excess space on bases. 
The optimal portfolio of bases identified by the Air Force Cueing Tool and the results of the capacity analysis were used as a starting point for BCEG deliberation. The BCEG analyzed various scenarios proposed by the Base Realignment and Closure Division and the Joint CrossService Division in the context of the Cueing Tool results, the capacity analysis results, basemission scores, and the USAF basing principles and imperatives.

The last three criteria for the 2005 BRAC round identified by the Secretary of Defense and listed in Table B.1, covering the economic, community, and environmental impacts of BRAC actions, were treated somewhat separately from the other criteria. Three- and four-page narratives were written for each installation, covering environmental concerns and community infrastructure (Department of the Air Force, 2005). One- and two-page datasheets were also created for each impacted installation for each recommended action (Department of the Air Force, 2005). Finally, one- to two-page summary sheets were devised for each installation to cover the cumulative environmental impacts of all BRAC recommendations (Department of the Air Force, 2005).

USAF recommendations for BRAC 2005 affected 115 installations, 76 percent of all USAF installations (Department of the Air Force, 2005). The Air Force recommended closing ten Air Force installations, including seven reserve bases (Department of the Air Force, 2005). The agency also proposed a 20 percent reduction in the number of installations with operational flying missions. By its own calculations, the Air Force was to reduce unnecessary infrastructure by 79 percent, with remaining excess kept for surge and unforeseen future missions (Department of the Air Force, 2005). The Air Force improved opportunities to host or support joint activities with other branches of the military. For example, the Air Force established a joint initial training location for the Joint Strike Fighter at Eglin AFB, near available training airspace in the Gulf of Mexico.

\section{U.S. Government Accountability Office Criticisms of BRAC 2005}

GAO was requested by Congress and subsequently mandated by law to objectively observe and report on BRAC decisionmaking processes. As recommendations from BRAC commissions are approved, GAO also must review implementation actions. More recently, the House Armed Services Committee asked GAO to investigate BRAC 2005 and develop recommendations for improving future BRAC rounds (GAO, 2013a).

GAO has repeatedly noted that DoD used a reasonable, logical process for arriving at BRAC 2005 recommendations. GAO has also stressed that DoD uses data that are "sufficiently reliable" for cost and benefit estimation, based on its independent analysis of DoD data, DoD documents, and meetings with Office of the Secretary of Defense Basing Directorate personnel. GAO has endorsed the COBRA model as a "reasonable estimator" for developing cost and benefit figures (GAO, 2013a). 
The organization has, however, noted that having three goals for the 2005 BRAC, instead of the single cost-minimizing goal of prior BRAC rounds, made it more difficult for the BRAC Commission and DoD to select and implement recommendations. GAO also has drawn attention to the fact that the scale of the BRAC round of 2005 was relatively large. There were 813 total basing actions in BRAC 2005, compared with 43,75,163, and 106 for each of the previous BRAC rounds (GAO, 2012). Sixty percent of the actions were related to the Army National Guard and Army Reserve, a major change from prior BRAC (GAO, 2010c). According to GAO, estimating the impact of the BRAC round on bases that were to simultaneously lose and gain missions was challenging (GAO, 2010c). Some recommendations were contingent on the outcomes of external processes. For instance, Canon AFB was to be closed if the Secretary of Defense could not find a new mission for the base by the end of 2009 (GAO, 2013a). GAO believes that contingency clauses added to the complexity of overseeing BRAC recommendations.

The transformative and/or interdependent of certain recommendations also added to the complexity. For example, the Defense Logistics Agency was created and tasked with managing logistics activities throughout the military. This recommendation required high-level coordination across different branches of the military. In at least two instances, implementation of BRAC recommendations was delayed because personnel were scheduled to transfer to new facilities that were being occupied by other personnel delayed in their own transfer (GAO, 2012). Some recommendations involved many "bundled" base closures and realignments. GAO claimed these "bundled" recommendations lacked action-specific cost and benefit estimates, leading to their objection (GAO, 2013a). In a response to GAO comments, DoD noted its belief that "bundling" several actions when the actions have the same mission and purpose is warranted without being problematic (DoD comments included in GAO, 2013a). DoD noted that it provided the BRAC Commission with COBRA model outputs including action-specific cost and benefit estimates.

Particular problems were caused by construction projects and by information technology requirements. It was difficult to place personnel movements and military construction on a complementary schedule. In 2010, GAO noted that DoD was planning to complete 57 different construction projects required by $30 \mathrm{BRAC}$ recommendations within three months of the legal deadline for BRAC-related projects to finish (GAO, 2010c). That schedule left little room for slippage in project schedules due to unforeseen delays, and also made the movement of personnel before the legal deadline challenging. The Army used "swing space facilities" to temporarily house personnel, but GAO noted that there was, at times, a failure to report these as costs related to BRAC actions (GAO, 2010c). One incorrect assumption that a space being built for the National Geospatial-Intelligence Agency would be a "general administrative" space rather than a more secure type of space resulted in a $\$ 726$ million increase in construction costs (GAO, 2013a). The information technology costs associated with the creation of the Defense Logistics Agency increased from $\$ 30.9$ million to $\$ 190$ million (GAO, 2013a). 
Another challenge GAO highlighted is the loss of human capital that results when civilian employees working on a mission choose not to relocate with their mission. The Army recommended moving the headquarters of the Army Material Command, the U.S. Army Forces Command, the Training and Doctrine Command, the U.S. Army Reserve Command, and the First Army, causing some officials to worry about potential loss of Headquarters staff (GAO, 2010c). Convincing technical staff to move to, and hiring technical staff at, Aberdeen Proving Ground, Naval Air Station China Lake, and Fort Sam Houston proved difficult (GAO, 2010c).

GAO also noted that BRAC recommendations calling for installation growth led to problems in certain communities, particularly with regard to transportation systems. Table B.3 lists installations scheduled to grow substantially as a result of BRAC actions.

Table B.3

Estimated Growth from All DoD Sources at and Near BRAC-Affected Military Bases FY 2006 Through 2012, as of March 2008

\begin{tabular}{|c|c|c|c|c|}
\hline Base & $\begin{array}{l}\text { Total Change } \\
\text { in Military and } \\
\text { Civilian DoD } \\
\text { Population }\end{array}$ & $\begin{array}{l}\text { Total Change in } \\
\text { Population of } \\
\text { Military and Civilian } \\
\text { DoD Dependents }\end{array}$ & $\begin{array}{c}\text { Total } \\
\text { Population } \\
\text { Increase }\end{array}$ & $\begin{array}{c}\text { Current } \\
\text { Total } \\
\text { Regional } \\
\text { Population }\end{array}$ \\
\hline Aberdeen Proving Ground, MD & 3,400 & 2,200 & 5,600 & $2,512,000$ \\
\hline Bethesda National Naval Medical Center, MD & 2,500 & Not available & 2,500 & $4,331,000$ \\
\hline $\begin{array}{l}\text { Camp Lejeune, Cherry Point, and New River, } \\
\text { NC }\end{array}$ & 13,400 & 18,700 & 32,100 & 108,000 \\
\hline Eglin Air Force Base, FL & 3,600 & 5,900 & 9,500 & 190,000 \\
\hline Ford Belvoir, VA & 24,100 & 12,700 & 36,800 & $4,331,000$ \\
\hline Fort Benning, GA & 12,700 & 6,100 & 18,800 & 247,000 \\
\hline Fort Bliss, TX & 28,000 & 41,700 & 69,700 & 722,000 \\
\hline Fort Bragg, NC & 18,900 & 17,100 & 36,000 & 301,000 \\
\hline Fort Carson, CO & 10,400 & 14,400 & 24,800 & 514,000 \\
\hline Fort Knox, KY & $(2,900)$ & 4,500 & 1,600 & 117,000 \\
\hline Fort Lee, VA & 10,200 & 4,600 & 14,800 & 138,000 \\
\hline Fort Lewis, WA & 13,500 & 17,400 & 30,900 & $3,422,000$ \\
\hline Fort Meade, MD & 7,000 & 4,200 & 11,200 & $2,512,000$ \\
\hline Fort Sam Houston, TX & 10,900 & 6,100 & 17,000 & $1,416,000$ \\
\hline Fort Sill, OK & 3,700 & $(400)$ & 3,300 & 81,000 \\
\hline Fort Riley, KS & 10,900 & 15,000 & 25,900 & 109,000 \\
\hline Marine Corps Base Quantico, VA & 3,600 & 1,000 & 4,600 & 202,000 \\
\hline Redstone Arsenal, AL & 7,900 & 2,000 & 9,900 & 291,000 \\
\hline Total & 181,800 & 173,200 & 355,000 & \\
\hline
\end{tabular}

SOURCE: GAO, 2009a.

A DoD study of the National Naval Medical Center in Bethesda, Maryland, found that 15 out of 27 nearby intersections would experience deteriorating service levels during peak periods as a 
result of BRAC actions (GAO, 2009a). Many of these intersections would experience a "failing" service level using Transportation Research Board criteria. The Office of Economic Adjustment bears the primary responsibility for helping communities impacted by BRAC actions. GAO noted that the Office of Economic Adjustment "is not at an appropriate organizational level within DoD" to bear this responsibility, since there is a need to gather assistance from a diverse set of federal and other government agencies. The Defense Access Roads program is authorized to fund highway improvements related to BRAC actions. Unfortunately, this program has narrow eligibility criteria and, as of 2009, had only funded work near three installations suffering from BRAC-induced traffic growth (GAO, 2009a). The situation was especially problematic in Maryland, where Aberdeen Proving Grounds, Fort Meade, and the Bethesda National Naval Medical Center were scheduled to add over 12,000 personnel in total. The state of Maryland set aside almost $\$ 100$ million for intersection improvements around the three installations, but noted that as much as $\$ 470$ million more may be needed to complete the projects (GAO, 2009a).

GAO has pointed out that costs to implement BRAC Commission recommendations grew over time, while estimates of cost savings shrunk. The original estimated cost of recommended changes was $\$ 21$ billion (in 2005 dollars), but six years later the estimated cost had increased 53 percent, to $\$ 32.3$ billion (in 2005 dollars) (GAO, 2012). It is worth noting that the Air Force was the one armed service that saw a decline in BRAC implementation costs between FY 2009 and FY 2010 (GAO, 2009b). Cost increases in this period were driven by construction costs linked to ten specific recommendations shown in Table B.4 (from GAO, 2009b). Military construction costs were responsible for most of the cost increases for seven out of the ten recommendations listed in Table B.4. Indeed, military construction cost estimates increased $\$ 1.864$ billion from FY 2009 to FY 2010, while the overall costs of the BRAC round increased \$2.488 billion (GAO, 2009b). 
Table B.4

BRAC Recommendations with the Largest Increases in One-Time Estimated Costs from FY 2009 to FY 2010 (\$ millions)

\begin{tabular}{|c|c|c|c|}
\hline & $\begin{array}{l}\text { FY } 2009 \text { Cost } \\
\text { Estimate }\end{array}$ & $\begin{array}{l}\text { FY } 2010 \text { Cost } \\
\text { Estimate }\end{array}$ & $\begin{array}{l}\text { Net Cost } \\
\text { Increase }\end{array}$ \\
\hline \multicolumn{4}{|l|}{ Recommendation } \\
\hline $\begin{array}{l}\text { Realign Walter Reed Medical Center to Bethesda } \\
\text { National Naval Medical Center, MD, and to Fort Belvoir, } \\
\text { VA }\end{array}$ & $\$ 1,640$ & $\$ 2,418$ & $\$ 779$ \\
\hline Realign Army Maneuver Training to Fort Benning, GA & 1,509 & 1,763 & 254 \\
\hline $\begin{array}{l}\text { Co-locate miscellaneous Office of the Secretary of } \\
\text { Defense, defense agency, and field activity leased } \\
\text { locations in the National Capital Region }\end{array}$ & 1,194 & 1,440 & 245 \\
\hline Close Fort Monmouth, NJ & 1,595 & 1,751 & 156 \\
\hline $\begin{array}{l}\text { Establish San Antonio Regional Medical Center and } \\
\text { realign enlisted medical training to Fort Sam Houston, TX }\end{array}$ & 1,724 & 1,876 & 152 \\
\hline $\begin{array}{l}\text { Realign to establish Combat Service Support Center at } \\
\text { Fort Lee, VA }\end{array}$ & 1,270 & 1,418 & 148 \\
\hline $\begin{array}{l}\text { Relocate medical command headquarters in the National } \\
\text { Capital Region }\end{array}$ & 43 & 161 & 118 \\
\hline $\begin{array}{l}\text { Close National Geospatial-Intelligence Agency leased } \\
\text { locations and realign others at Fort Belvoir, VA }\end{array}$ & 2,441 & 2,554 & 113 \\
\hline Close Fort Gillem, GA & 101 & 160 & 59 \\
\hline $\begin{array}{l}\text { Relocate Army headquarters and field operating activities } \\
\text { in the National Capital Region }\end{array}$ & 444 & 490 & 47 \\
\hline $\begin{array}{l}\text { Total one-time estimated costs from the BRAC } \\
\text { recommendations listed above }\end{array}$ & $\$ 11,961$ & $\$ 14,031$ & $\$ 2,071$ \\
\hline Total one-time estimated costs for all recommendations & $\$ 32,433$ & $\$ 34,922$ & $\$ 2,488$ \\
\hline $\begin{array}{l}\text { Percentage of increase in one-time costs from } \\
\text { recommendations listed above of all recommendations }\end{array}$ & & & $83 \%$ \\
\hline
\end{tabular}

SOURCE: GAO, 2009b.

While expected costs increased, expected future savings decreased for the BRAC round of 2005. Estimated savings in operating expenses, for one year and over a 20 -year period, went from $\$ 4.2$ billion and \$36 billion, respectively, to revised estimates of \$3.8 billion and \$9.9 billion (GAO, 2012). The end result, according to GAO, is that the costs of the changes required by the 2005 BRAC round will not be recouped until 2018. Recall that to kick off the BRAC process, the Secretary of Defense had been required to certify that the process would yield annual net savings for each department of the military beginning no later than 2011. The largest decrease in estimated savings came from the recommendation to centralize medical command headquarters in the National Capital Region. DoD's FY 2010 budget indicated that this recommendation would result in no savings but rather a net cost of \$1 million per year (GAO, 2009b). Indeed, using the FY 2010 budget, GAO estimates that 76 BRAC recommendations will yield no net savings in the first 20 years after implementation (GAO, 2009b). 
DoD claims that cost growth during BRAC 2005 implementation was due to "implementation investment decisions" and to "congressional direction" rather than failures in DoD processes (DoD comments included in GAO, 2013a). DoD will update the "standard factor" used to estimate information technology costs within the COBRA model and will improve COBRA user manuals to "emphasize the importance of footnoting the source documentation for personnel changes" (DoD comments included in GAO, 2013a).

In addition to the above points, estimates of the recurring savings to DoD are often based on the costs of military personnel whose positions are being eliminated even when end-strength numbers are not expected to change (GAO, 2009b). Approximately half of the initially projected recurring savings came from eliminating positions (GAO, 2007). GAO has noted its objection to this practice. $\mathrm{GAO}$ also recommends that $\mathrm{DoD}$ develop and use metrics for performance tracking during the next BRAC round, and that Congress require the Secretary of Defense to fix "targets" that DoD will achieve (GAO, 2013a). DoD objects to this recommendation, noting "The premise that we should be required to close a particular number of bases or eliminate a particular number of civilian jobs is arbitrary, counterproductive, and would undermine military capability" (Conger, 2013). 



\section{Appendix C. Generalized Boosted Model}

This appendix provides additional detail on the Generalized Boosted Model (GBM) (Ridgeway, 2009) used in the main text to assess how well the weight assigned by the Air Force to each scoring category (e.g., mission, capacity) aligned with the actual influence of these categories on the choice of candidate bases. The decision to use GBM for this analysis was influenced by its successful application in Keller et al. (2014), which examined how the Weighted Airman Promotion System was functioning by using GBM to model promotion outcomes by AFSC.

To estimate the relative influence of covariates, it is necessary to first fit a GBM model of the outcome of interest as a function of the available covariates. In this context, the outcome of interest was whether each site was selected versus not, and the covariates are capacity, cost, environmental, and mission scores. The model-fitting process starts very simply, estimating equal probabilities of being selected for each observation in the analytic file. GBM then proceeds in an iterative fashion, gradually adding complexity to the model. For each iteration, the model adds or subtracts a small, constant value to the estimated probability of being selected for those bases whose scores fall above or below particular thresholds on one or two scores. Over hundreds or thousands of iterations of making such small changes to the predictions, GBM is able to recreate complex associations between the covariates and the probabilities associated with the outcomes of interest.

In this analysis, we used GBM to model the probability of a base being selected as a candidate for a basing decision (versus not being selected). GBM was used to calculate the probability through piecewise constant combinations of the explanatory variables (e.g., mission score and capacity score). For example, the first iteration may estimate that bases scoring below 90 for mission and below 15 in capacity have a slightly lower chance of being selected as a candidate for the basing action than all other bases. In this case, the model is said to "split" on mission and capacity. At the next iteration, the model may increase the probability of bases scoring 10 in environment becoming candidates. The model continues making thousands of such adjustments, each time adding or subtracting a small, constant value from the estimated probability of being selected for bases above or below the estimated thresholds.

If the GBM algorithm ran long enough, it would be able to fit the observed data perfectlyresulting in poor predictive performance. GBM uses two techniques to avoid such overfitting. First, to ensure changes to the probabilities are spread over the important variables, each iteration's adjustments to the probabilities are smaller than those that would optimize the fit. Second, GBM chooses an early stopping iteration in the algorithm using a method called ten-fold cross valuation. Cross valuation results in a simpler model than if GBM were allowed to run until it achieved a perfect fit. In ten-fold cross valuation, the dataset is randomly split into ten mutually exclusive subsets. The model is fit on nine-tenths of the data, and that model is used to 
predict the outcomes in the held-out tenth of the data; this process is repeated to produce out-ofsample predictions for all observations. The number of iterations that results in the best out-ofsample prediction is then used for the final GBM model that is fit to the entire dataset.

Key for this application, an additional output of GBM software is the "relative influence" of each explanatory variable on the outcome. Out of all of the variation explained by the model, the relative influence is the percentage that is attributable to each explanatory variable. This measure is insensitive to rescaling the explanatory variables, which makes it particularly appealing for this application.

To calculate the relative influence of each covariate, the software counts the percentage of splits that involve each covariate and weights this sum by the squared improvement at each step. The relative influence is standardized so that each covariate's relative influence is between zero and 100 percent and the relative influences sum to 100 percent (Friedman, 2001; Elith, Leathwick, and Hastie., 2008)

In Chapter Three, we discuss the results of our analysis for a sample of basing actions. Here we will walk through an example using the basing action to place a single squadron of F-35s. The Air Force considered 205 bases as potential locations for a squadron of F-35s. Each base was graded on its ability to support the mission (60 points), its existing capacity ( 25 points), cost factors (5 points), and the potential impact on the environment (10 points). We discuss these covariates in Chapter Two.

We wanted to know the relative influence of each scoring category on a base being selected for a site visit. We gave the GBM software a list of the 205 bases; their mission, capacity, cost, and environmental scores; and a field indicating if the base was selected for a site visit or not. GBM took the list of bases and randomly divided it into ten groups, each with 20 or 21 bases. GBM built a separate prediction model for each group so the model built using 184 or 185 bases' information can be assessed on the observed outcomes for the remaining 20 or 21 bases. From this exercise, GBM estimates an appropriate number of iterations or, equivalently, the appropriate model complexity. At this point, the final GBM model can be fit to produce the corresponding relative influence estimates.

For the basing action placing a single squadron of F-35s, the final GBM model estimates relative influences for capacity, mission, cost, and environment were 74 percent, 11 percent, 8 percent, and 7 percent, respectively. From these numbers, we know that the GBM model either splits most often on the capacity score, or, when it does, the model achieves relatively large improvements in model fit (or likely both). We conclude that capacity scores are substantially more important in predicting which bases were selected, even though mission accounts for more than twice as many points in the original measurement scale.

Readers interested in a technical description of GBM are encouraged to refer to Ridgeway (2009) and Section 8.1 of Friedman (2001). 


\section{Appendix D: The Role of Strategy in Basing Decisions at Home and Abroad}

DoD as a whole and the USAF in particular tend to approach basing decisions in CONUS and OCONUS as completely separate processes. In part, this may be due to the widespread assumption that one is more strategically driven than the other. Specifically, the conventional assumption is that overseas bases are chosen and maintained principally for their strategic and diplomatic value, while domestic bases are chosen and maintained because of mission, capacity, cost, environmental, and political considerations. Consequently, the CONUS basing process is usually coupled with the impact that base closures could have on their surrounding communities and the efforts of local and state officials to keep bases in their districts open.

For example, the USAF's proposal to consolidate the three Alaska-based fighter squadrons at Joint Base Elmendorf-Richardson in Anchorage was met with fierce resistance by local business leaders and politicians. The logic behind USAF's proposal was that moving the F-16 Aggressor squadron currently stationed at Eielson AFB near Fairbanks to Joint Base Elmendorf-Richardson would realize operational efficiencies and thereby decrease operating costs without reducing USAF's capability in the region (USAF, 2013, p. ES-2). The Fairbanks community, however, strongly objected to the plan because Eielson would lose its permanent aircraft and be downgraded to a "warm" base — one where the base remains open but with reduced staff, systems, and capabilities. This is in contrast to a "cold" base, which is closed temporarily or permanently through the BRAC process. The community claimed downgrading to a warm base would damage the local economy by raising the level of unemployment and significantly reducing the value of local homes. Opponents also argued that the Air Force had not considered all of the costs associated with the proposal, the congested airspace in Anchorage, or the fact that basing all fighter aircraft in one location would increase USAF vulnerability ("Murkowski Gets Transparency Pledge from Next USAF Chief of Staff," 2012). The Alaska delegation succeeded in delaying the move for a year, and, in October 2013, the Air Force announced that it was abandoning the plan because of lower-than-projected savings and the impact that the move would have on the local communities near Eielson (USAF, 2013a, 2013b).

By contrast, the debate over the U.S. overseas military presence centers on how DoD needs to alter its posture to better meet emerging threats in a period of fiscal austerity. For instance, Michael O'Hanlon and Bruce Riedel argue that the United States should permanently station 150 land-based fighter aircraft in the Persian Gulf to reduce the nation's dependence on expensive aircraft carriers (O'Hanlon and Riedel, 2013). Others have challenged this proposal on the grounds that it restricts USAF flexibility by tying down a large number of its combat aircraft and increases the probability that DoD will encounter access problems with its partners in the Gulf (Pettyjohn and Montgomery, 2013). According to this view, a mixed presence of ground- and 
sea-based combat aircraft is the appropriate posture. Similarly, China's rapidly expanding military capabilities and its more assertive behavior prompted DoD to announce that it was pivoting (or rebalancing) toward the Asia-Pacific region (Clinton, 2011; DoD, 2012). As a part of this initiative, DoD is seeking additional access in Southeast Asia and Oceania to improve the resiliency of its posture. Debates surrounding this policy have centered on whether the components of the pivot represent a significant change to the current posture; the sustainability of this shift; its effect on other critical regions, like the Middle East; and the risks of provoking an insecure China (Manyin et al., 2012; Ross, 2012; Saab, 2013; Sutter et al., 2013).

These examples clearly reflect the conventional view that domestic political concerns figure prominently in CONUS basing decisions, while strategic factors are paramount in OCONUS basing decisions. Existing studies tend to focus on either domestic or international bases, or on only one type of basing decision, especially closure (Sturm, 1969; Benson, 1982; Brown, 1990; Sorenson, 1998; Goren, 2003; Shaw, 2004; Sorenson, 2007).

\section{Types of Strategic Influences on Air Force Basing Decisions}

According to Edward Mead Earle, "Strategy is the art of controlling and utilizing the resources of a nation — or a coalition of nations - including its armed forces, to the end that its vital interests shall be effectively promoted and secured against enemies, actual, potential or merely presumed" (quoted in Kennedy, 1992, p. 2). If basing decisions were driven solely by national strategy, therefore, the Air Force would simply select the course of action-whether opening a new base, realigning bases, or closing a base - that is expected to best achieve its objective of enhancing U.S. security. In other words, basing decisions would be made through a rational process that aligned ends, means, and costs.

Strategic influences, however, may have different time horizons. On the one hand, there are short- or immediate-term strategic factors that are focused on preparing for present security challenges. Considerations such as a base's relevance for countering a current threat, concerns about the survivability of a facility, and an administration's preferred defense strategy fall under this rubric. On the other hand, there are long-term strategic factors that are focused on preparing for a distant and unknown future. Farsighted strategic considerations try to hedge against future uncertainty by ensuring that USAF base structure remains capable of dealing with unspecified future security challenges. Factors that fall within this category include ensuring that the Air Force maintains a flexible posture, protects unique facilities and assets that are difficult to recreate, and prioritizes bases that are best capable of supporting a particular mission. 


\section{Short-Term Strategic Influences}

\section{Relevance of Base for Countering Current Security Challenges}

One of the most important strategic influences on USAF basing decisions is the relevance of a particular facility for countering current security challenges. An airbase's utility for dealing with a particular threat is primarily a function of its geographic location. Because an airbase is the center of a plane's radius of flight, a base's location and the range of its aircraft determine what is within reach (Brown, 1990, p. 2; Warnock, 2004, p. 6). In short, aircraft need to be stationed at bases that are within the range of where they are expected to operate, or they will have to deploy from their home stations to forward operating locations. Accordingly, if current threats recede and new threats appear in different regions, some bases may become obsolete and new requirements may arise. Airbases that are not well situated to deal with current and emerging security challenges are often considered for closure, or they may be repurposed.

Geography — in particular, proximity to the anticipated operating area - has been especially important when deciding where to establish a new base. During World War I, for instance, the U.S. Army first developed a large number of CONUS airfields to facilitate the deployment of U.S. forces to Europe. Consequently, the vast majority of the airbases constructed during the World War I were situated East of the Mississippi River or along the Gulf of Mexico. U.S. troops would deploy from these inland locations to two clusters of facilities, on Long Island and near Washington, D.C., which were used as embarkation points to Europe (Brown, 1990, p. 48).

World War I-era Air Service bases were positioned to fight an expeditionary war against an adversary that posed no threat to the homeland. Consequently, throughout most of the interwar period there were few CONUS bases that were capable of supporting an air defense mission (Futrell, 1951, pp. 1-2). This began to change in the lead up to World War II, as U.S. officials became increasingly concerned about the threat posed by Nazi Germany and Japan. In the late 1930s, growing concerns about the destructive potential of airpower led President Franklin Delano Roosevelt to conclude that the relative geographic isolation of the United States could no longer provide sufficient protection (Reynolds, 2001, pp. 93-94). Consequently, Roosevelt asked Congress to fund measures that would enable the War Department to defend the nation and the entire Western Hemisphere from aggressors (Conn and Fairchild, 1989, p. 3; Conn, Engelman, and Fairchild, 1989).

As a part of this initiative, in 1940 the Army Air Corps (AAC) developed two air bridgesone running through the West Indies to South America and the other through Texas and Central America - composed of land and seaplane bases stretching from CONUS to Brazil. In total, the AAC built 48 airbases along these routes because of the relatively short range of the aircraft in its inventory (Conn and Fairchild, 1989, pp. 249-251; Pettyjohn, 2012, pp. 46-47). ${ }^{1}$ Because

\footnotetext{
${ }^{1}$ The Airport Development Plan was pursued secretly because of anticipated opposition from Latin American nations. For this reason, the Air Force relied on Pan American Airways to improve the airfields under the guise of
} 
U.S. military planners intended to use these bases to quickly deploy personnel and equipment to defend Brazil against a possible Axis attack, they selected sites located near the coasts to ease the task of supporting forces.

In an effort to bolster U.S. continental defenses, the AAC established a number of air defense bases situated near key industrial centers, such as New England. In general, therefore, CONUS air defense bases required peripheral locations near the likely avenues of an enemy's attack (USAF, 1963, p. 11). For many years this was primarily along the coastlines, but with the advent of long-range bombers that could navigate polar air routes during the early years of the Cold War, the focus shifted to the United States' northern borders (Haulman, 2004, p. 71).

Even though improvements in military technologies have extended the reach of many of USAF aircraft, AMC still uses the 3,500 nautical mile point-to-point range of its primary airlifter - the C-17-to determine its Atlantic en route basing needs today. ${ }^{2}$ AMC draws a 3,500 nautical mile range arc representing the distance that a $\mathrm{C}-17$ could fly from its east coast CONUS bases, and then draws a second 3,500 nautical mile range arc displaying the distance that a $\mathrm{C}-17$ could fly from a destination in Southwest Asia. The area where these two circles overlap, which can be reached from CONUS and Southwest Asian bases, is the "sweet spot" or "lens" where AMC requires en route bases (AMC, 2010, pp. 5-6).

\section{Vulnerability and Survivability of Base}

In addition to a base's distance from anticipated operating locations, USAF officials consider whether a base is vulnerable to attack by an adversary. Combatants first recognized that airbases were inviting targets during World War I and began to experiment with a host of defensive measures to reduce their exposure. ${ }^{3}$ Active and passive defenses increase an airbase's ability to resist an attack and the likelihood that forces stationed at the facility will survive. Yet deciding where an airbase is established - especially whether it is within or beyond the range of an adversary's weapons - is one of the most important ways of reducing vulnerability. Moreover, even in cases where an adversary's weapons can target an airbase, its location still influences warning time and therefore survivability. With early notice of an incoming attack, the aircraft at a base can disperse, increasing the probability that they escape unscathed.

During the Cold War, the Air Force in general, and the Strategic Air Command (SAC) in particular, worried about whether its forces could survive a preemptive strike by the Soviet Union. For example, after the Soviet Union successfully detonated an atomic bomb in August

\footnotetext{
expanding civil aviation needs on its behalf (Weathers, 1943, pp. 124-151).

${ }^{2} \mathrm{AMC}$ uses different planning factors for different regions to account for variation in the quality of infrastructure and the geography. For example, in Africa there is a dearth of airfields capable of handling USAF strategic airlifters and a lack of quality aviation fuel. Because of these constraints, AMC uses the unrefueled range of a C-17 as its Africa planning factor, meaning that a C-17 can only travel 2,000 nautical miles, offload its cargo with its engine running, and then return to its original point of embarkation without refueling (AMC, 2010, p. 4).

${ }^{3}$ For more see Kreis, 1988, pp. 3-22.
} 
1949, SAC decided to relocate its forces stationed in the United Kingdom (UK) from East Anglia (where they had operated from since 1948) to the British midlands northwest of London (where a string of air defense bases could protect the bombers). ${ }^{4}$ Similarly, in 1952, U.S. Air Forces in Europe (USAFE) reached an agreement with France to relocate its tactical fighter bases from the U.S. occupation zone in West Germany to bases in the French occupation zone, which were west of the Rhine River. Given the proximity of the U.S. sector to the central front, the first USAFE fighter airbases (Furstenfeldbruck, Neubiberg, and Giebelstadt) were likely to be quickly overrun in the event of a Soviet invasion. By contrast, the French airbases (Bitburg, Landstuhl, Spangdahlem, Hahn, and Sembach) offered more protection against an attack but were still close enough to the front lines to allow USAFE's short-range tactical aircraft to support ground operations on the central front (Sturm, 1969, p. 16; Benson, 1981, p. 34). ${ }^{5}$

Overseas bases, however, were not the only ones vulnerable to Soviet attack. By the late 1950s, the Air Force was extremely concerned about the survivability of its CONUS bomber bases, which were overcrowded because the pace of aircraft construction had exceeded that of base construction. A 1956 USAF study on base vulnerability argued that "the reduction of SAC's ground vulnerability will remain for several years the most important single military step that can be taken to deter the sudden outbreak of general war, i.e. a surprise air attack on the United States" (Leighton, 2001, p. 447). This statement resonated with broader audiences who recognized that, at that time, the United States' nuclear deterrent relied entirely on SAC's bombers, and therefore these audiences supported efforts to improve bomber bases' survivability, including expanding radar coverage, increased active defenses, and scattering SAC's bombers across many bases. ${ }^{6}$ The initial logic behind dispersal was straightforward: The USAF would proliferate the number of targets in the CONUS so that they exceeded the number of Soviet warheads (Haulman, 2004, p. 62). In 1955, therefore, the Air Force planned to expand from 34 to 55 bases (Leighton, 2001, pp. 446-447).

It quickly became apparent that there was no simple way of increasing the survivability of the strategic bomber force and that dispersal alone was insufficient. As SAC tried to reduce its vulnerability through a combination of active and passive defenses, the Soviets were simultaneously developing faster and longer-range bombers, which would reduce the warning time for two-thirds of SAC's bases to less an hour. Consequently, the Air Force began to move SAC toward the interior and southern part of CONUS.

Once the Soviets were on the verge of developing an intercontinental ballistic missile (ICBM), the severity of the threat to SAC's bases increased considerably. Because of the speed of missiles, SAC expected to have only 15 minutes of warning before a Soviet attack would

\footnotetext{
${ }^{4}$ The original four bases in the UK were RAF Scampton, RAF Marham, RAF Waddington, RAF Lakenheath. New bases are Fairford, Greenham Common, Brize Norton, and Upper Heyford Charles Hildreth (USAFE, 1967). See also Sturm, 1969, pp. 8-9; Benson, 1982, pp. 13-14.

${ }^{5}$ French bases had one significant drawback: the weather. They were plagued by frequent fog.

${ }^{6}$ For instance, the Killian panel in February 1955 urged dispersal program (Leighton, 2001, p. 445).
} 
strike its CONUS targets. In the mid-1950s, SAC's response was to create an alert program that enabled some bombers to be airborne before an ICBM could reach their base because they had their weapons loaded and crews on standby for immediate takeoff (Hopkins, 1986; Leighton, 2001, p. 635). In a 1956 white paper, General Curtis LeMay proposed a number of measures to ensure the survivability of the bomber force, including increasing the number of SAC bomber bases to 101 (Leighton, 2001, pp. 635-636). The cost of establishing and maintaining so many bases was exorbitant, however, and prevented SAC from ever realizing its extensive dispersal plans. SAC's CONUS base network reached its pinnacle in 1960, with 46 bases scattered across the United States (Hopkins and Goldberg, 1986, p. 89; Haulman, 2004, p. 65).

The Kennedy and Johnson administrations adopted a different approach to dealing with SAC's growing vulnerability. According to Secretary of Defense Robert McNamara, "The introduction of ballistic missiles is already exerting a major impact on the size, composition, and deployment of the manned bomber force, and this impact will become greater in the years ahead." Therefore, "as the number of . . . ballistic missiles increases, requirements for strategic aircraft will be gradually reduced." Because "the growing enemy missile capability will make grounded aircraft more vulnerable to sudden attack," SAC adopted a rearward basing concept to maximize its warning time (Hopkins and Goldberg, 1986, p. 105). SAC's B-52s, therefore, were moved from northern bases, such as Dow in Maine, Glasgow in Montana, Larson in Washington, and Lincoln in Nebraska to southern bases, including Barksdale in Louisiana, Carswell in Texas, and March in Southern California (Marion, 2004, pp. 107-110). As a more affordable alternative to wholesale dispersal, in 1969 SAC began deploying its alert force to satellite bases - CONUS bases that were not owned by SAC - to complicate the Soviet's targeting and reduce the time required to launch the bombers (Headquarters Strategic Air Command, Office of the Historian, 1970, p. 19).

Concerns about vulnerability are not limited to the Cold War. Today, for example, China's increased ability to hold forward-based USAF forces at risk has led DoD to seek a more "geographically distributed" posture in the Asia-Pacific region (Gates, 2010). For the Air Force, this means seeking additional access for rotational forces in Australia and Southeast Asia (Defense Writers Group, 2013).

\section{Preferred Defense Strategy of Administration in Office}

Although U.S. officials often have the same goal, namely protecting U.S. security and interests, they may hold different views on how the military can best achieve these ends. Consequently, an additional strategic factor that influences basing decisions is the administration's preferred defense strategy, or "the link between military and political ends, the scheme for how to make one produce the other" (Betts, 2000, p. 5). Because a defense strategy may prioritize certain threats, military capabilities, or specific regions, the particular strategy adopted by an administration affects the shape of USAF posture. 
During the Cold War, for instance, all U.S. presidents agreed that the Soviet Union posed a threat to the United States and therefore must be contained. Yet the Truman, Eisenhower, and Kennedy administrations differed in how they used U.S. forces to deter Soviet aggression. After facing Soviet-backed communist aggression on the Korean Peninsula, the Truman administration adopted an expansive strategy (articulated in NSC-68) of countering communist aggression across the globe. This included rolling back communist expansion in Korea while deterring the outbreak of a general war in Europe. The adoption of NSC-68 led to a dramatic expansion of USAF's network of bases at home and abroad. Because of the magnitude of the threat that the United States faced, NSC-68 called for comprehensive rearmament. In other words, NSC-68 did not prioritize one mission or subset of missions over the others. For the Air Force, this meant that while the strategic nuclear mission remained the foundation of the United States' deterrent, nuclear weapons alone were not believed to be capable of winning a protracted war against the Soviet Union (Millett and Maslowski, 1994, p. 516). Instead, the Truman administration believed that the United States also needed formidable conventional forces, including large numbers of tactical aircraft (Lemmer, 1974, p. 141; Millett and Maslowski, 1994, pp. 517-518).

President Dwight D. Eisenhower questioned the assumption that underlined the Truman administration's vast rearmament program, namely that resources would expand to meet security requirements. Consequently, the Eisenhower administration's New Look strategy stressed that containment needed to be affordable, because a strong free market economy was the foundation of the United States' military strength (Huntington, 1961, pp. 64-84; Gaddis, 2005, pp. 130132). Eisenhower feared that unrestrained defense spending would undermine the U.S. economy and maintained that the United States needed "security with solvency" (Millett and Maslowski, 1994, p. 534). The New Look strategy, therefore, emphasized the deterrent value of nuclear weapons and continental defenses, while deemphasizing conventional forces (Huntington, 1961, p. 78). According to this logic, deterrence rested primarily on the credible threat to massively retaliate to any aggression with nuclear weapons coupled with strengthened air defenses. Because of this focus on nuclear retaliation, SAC and to a lesser extent Air Defense Command received the preponderance of the USAF's budget and base structure. To reduce military expenditures while expanding nuclear and air defense forces, the Eisenhower administration cut the budget of other USAF commands, also leading to reductions in their base structure (Haulman, 2004, p. 75).

This changed when John F. Kennedy entered the White House in 1961. Kennedy and his Secretary of Defense, Robert McNamara, believed that there were many circumstances where it was not appropriate to employ nuclear forces and, therefore, that the Eisenhower administration's threat of massive retaliation lacked credibility (Kaplan, Landa, and Drea, 2006, pp. 293-294). Believing that a strong deterrent rested on the threat of a calibrated and proportional response, the Kennedy administration shifted to a defense strategy of flexible response (Millett and Maslowski, 1994, p. 553; Gaddis, 2005, pp. 214-215). Flexible response's emphasis on conventional forces was reflected in how the budget was allocated among the USAF 
commands. The Kennedy administration ended SAC's ascendency and insisted that the command rely more heavily on missiles instead of bombers. As a result, SAC's vast network of CONUS bases declined by nearly 40 percent, while mobility air forces, which were needed to deploy ground forces, and tactical air forces, which supported ground units, gained new bases. ${ }^{7}$ For instance between 1961 and 1972 Tactical Air Command gained nine additional CONUS bases (Marion, 2004, p. 122). The Military Air Transport Service and its successor Military Airlift Command obtained only two additional bases between 1961 and 1974, but the Air Force's airlift capacity significantly expanded due to the development of larger, more capable intercontinental airlifters (Marion, 2004, p. 103; Millett and Maslowski, 1994, p. 560).

\section{Long-Term Strategic Influences}

\section{Maintain a Flexible Posture}

Because the international environment can rapidly and unexpectedly change, a strategic factor that influences USAF basing decisions is a desire to preserve flexibility. In other words, the Air Force wants to maintain a base structure that can adapt to unforeseen demands. Flexibility is important because making changes to the Air Force's posture at home and abroad is a timeconsuming and expensive process (Calder, 2007, p. 35; Schlossberg, 2012, pp. 3-5). At home, the Air Force must engage in lengthy and comprehensive environmental studies and secure resources from Congress for military construction. The overseas process is even more complicated because the United States must also negotiate with a host nation and navigate its domestic political processes. Flexibility may involve a number of factors, including an expandable base structure, protecting difficult to reconstitute assets, geographic balance, and prioritizing bases that provide reach into multiple regions.

To be capable of accommodating new demands, a base structure may need some excess capacity in the form of standby or inactive bases. Alternatively, flexibility may be embedded in a base structure if the current bases can be enlarged to expand existing activities or add additional missions. As the Air Force reduced its CONUS and OCONUS base structure in the 1990s, it sought to maintain a posture that enabled to it adjust to changing circumstances (DoD, 1978, $\mathrm{p}$. 13; Sahaida, 2004, p. 157). During the 1995 round of base closures, 12 of the tactical aircraft bases that DoD retained had the potential to accommodate 378 additional aircraft at relatively little cost (DoD, 1999, p. 33). Consequently, the Air Force concluded that its CONUS base structure "retain[ed] the flexibility to absorb overseas force structure, provide surge capability, and accommodate changes in the strategic threat" (Department of the Air Force, 1995, p. 14).

Similarly, the Bush administration's 2004 Global Defense Posture Review (GDPR) sought to enable the United States to deal with an extremely fluid and uncertain environment characterized by asymmetric threats. Because the Bush administration believed that the "principal

\footnotetext{
${ }^{7}$ Between 1961 and 1969, the number of major SAC bases in the United States fell from 46 to 28 (Marion, 2004, p. 107).
} 
characteristic of security environment" was "uncertainty," the 2004 GDPR proposed a number of changes to improve the agility of U.S. armed forces (DoD, 2004, pp. 9-15; JCS, 2004, p. 7). In particular, the GDPR sought to eliminate static formations in Europe and Asia by moving away from large main operating bases (MOBs) in favor of access to cold and warm facilities that could be scaled up or scaled down as needed (DoD, 2004, p. 10; Henry, 2006, p. 38). A nimble posture consisting primarily of expandable facilities would allow U.S. forces "to reach any potential crisis spot quickly" (Henry, 2006, p. 39).

At other times, the desire to preserve geographic balance has shaped USAF basing decisions. Concentrating bases limits the reach of USAF aircraft. Maintaining a network of geographically dispersed bases that offer adequate coverage of multiple regions guarantees that the Air Force can project power globally. AMC, for example, seeks to maintain an en route network across the world. Thus, even though it identified Southwest Asia, Southeast Asia, Korea, Africa, and the Black Sea as its focus, AMC seeks to improve its en route facilities in Latin America and to maintain its European locations so that it has "global coverage" (AMC, 2010, pp. 30-31). At home, the Air Force's mobility forces have retained terminals on each coast to facilitate deployments across the globe.

An additional way of creating an agile force posture is obtaining bases that provide reach into multiple regions. For instance, during and immediately after World War II, the Joint Chiefs of Staff developed basing plans for the postwar world. The Joint Chiefs had not identified any potential adversary, yet they sought to create a network of overseas bases along the perimeters of the European and Asian continents that would allow the United States "to rapidly deploy forces in any desired direction" (JCS, 1945). This posture of perimeter defense-in-depth emphasized offshore locations that could strike many directions and basing rights instead of large fixed garrisons.

\section{Protect Unique Assets}

As the United States' network of bases at home and abroad has contracted, DoD in general, and the Air Force in particular, have sought to protect particular unique assets that might be needed in the future and are difficult to recreate. While many physical structures (such as runways and buildings) can be easily rebuilt, other military possessions may be impossible — or at least very difficult and expensive - to reconstitute. The latter category includes things that require certain topographical or geophysical characteristics that are relatively rare in today's world, including "large, contiguous, unencumbered areas with specific characteristics needed to fulfill a military requirement" (DoD, 1999, p. 4). Examples of difficult-to-reconstitute assets are deep-water ports, large maneuver areas, airspace, and air training ranges. Nellis Air Force Base, for example, was excused from the 1995 BRAC because it offers an "irreplaceable" and "extensive" range complex (Department of the Air Force, 1995, pp. 23-24).

Among these difficult-to-reconstitute assets, the Air Force has prioritized protecting the CONUS airspace that it controls. When Reese Air Force Base was selected for closure in 1995, 
the Air Force transferred the control of its airspace to nearby bases that remained active (DoD, 1999, p. 14). The map on the left of Figure D.1 illustrates the special use airspace in the United States as of 1999, while the map on the right depicts the military airspace that was relinquished through the 1995 round of BRAC (DoD, 1999, p. 16). The pictures clearly demonstrate that while closing surplus ground facilities, the Air Force and the Navy have preserved nearly all of the airspace under their jurisdiction.

Figure D.1

Special Use Airspace in 1999 (left) and Airspace Ceded as a Part of BRAC Through 1995 (right)
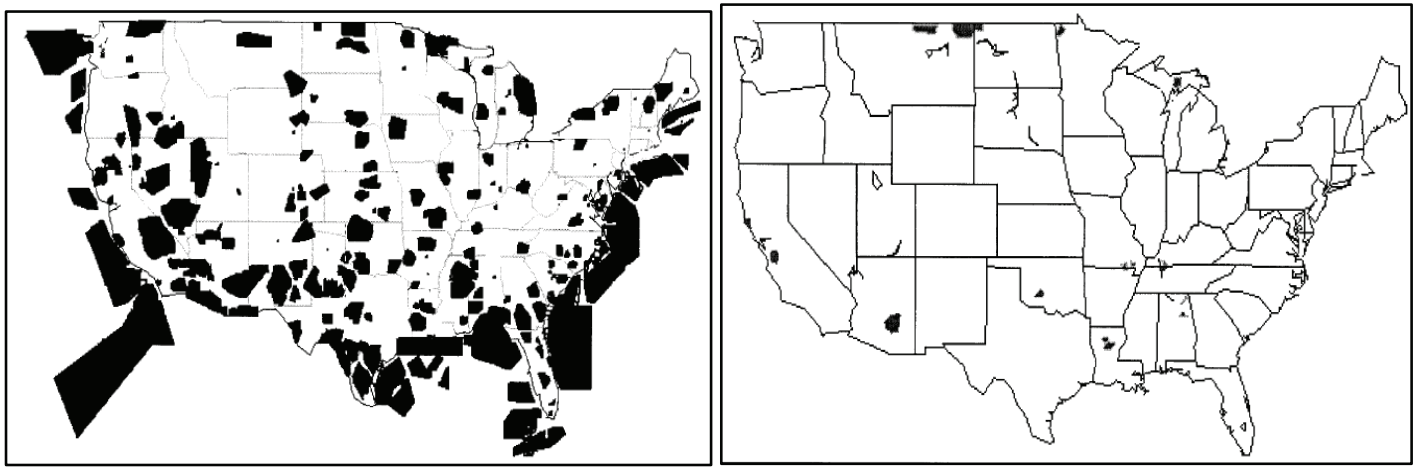

At other times, the Air Force exempts bases that are "unique," or "mission essential," from the BRAC process. Some space ground stations, for example, need to be at specific locations to provide continuous coverage of satellites, or to provide access to the proper space orbit (Sturm, 1969 , p. 93). Other facilities may offer a unique and strategically valuable geography. Andersen Air Force Base on Guam, for instance, was excluded from BRAC because it offers "an irreplaceable resource for overseas contingencies" (Department of the Air Force, 1995, pp. 2324). Other protected assets include live training ranges, hazardous material storage, and weapon and system testing locations (DoD, 1999, p. 13).

\section{Support Planned Mission}

One of the primary strategic factors that influences basing decisions is the ability of a location to support the planned mission. The suitability of an existing or potential base site depends on two separate factors: geophysical characteristics and existing capacity. There are certain geophysical requirements for all airfields, namely level, well-drained parcels of unobstructed land that provide adequate space for a runway with safe approach and departure routes (USAF, 1963; Brown, 1990, p. 2; Marion, 2004, p. 103). Early aircraft needed only a few hundred acres of clear land to serve as an airfield, but over time, as aircraft have grown larger and heavier, the space required for an airfield has significantly increased (Brown, 1990, p. 2).

Additional necessary characteristics depend on the specific weapon system stationed at the base. For example, it is essential that ballistic missile bases have a particular soil composition 
and enough room to disperse the launch sites within the base. For tactical fighter airbases, fighter pilots must be able to regularly train for combat. Consequently, one of the most important factors in choosing where to station a fighter wing is the base's proximity to training ranges. Because of the hazards associated with combat training, suitable locations need large tracts of undeveloped land that have year-round good weather and uncongested airspace. Locations with welldeveloped transportation networks, which often are in urban areas, are preferred for intertheater airlift bases to facilitate the transloading of cargo. For example, the Air Force has favored bases along the U.S. coasts to maximize the unrefueled range and cargo payload capacity of its intercontinental airlifters (Sahaida, 2004, p. 173).

In addition to the geophysical characteristics, another factor that influences the ability of an existing base to support its assigned mission is its infrastructural capacity (Sahaida, 2004, pp. 157, 162). In particular, the Air Force weighs whether an existing base has sufficient infrastructure in good condition to support its mission. Old or deteriorating infrastructure demands frequent maintenance, major repairs, and perhaps even extensive upgrades, which increase the operating costs of a base. The Air Force can improve runways, ramps, hangars, and other supporting facilities, but these types of renovations are often very expensive. Therefore, when deciding which bases it should retain or use for new weapon systems, the Air Force considers whether there is adequate infrastructure at a site. For instance, as a part of the 1988 BRAC process, the Air Force recommended the closure of Norton Air Force Base over other airlift bases because of the poor quality of its warehouses and its lack of family housing and support facilities (Mayer, 1999). Also, when the Air Force seeks new bases, it has typically preferred locations that have significant infrastructural capacity. While under the command of General Curtis LeMay, SAC was notorious for using CONUS bases with the best infrastructure from other commands, while offloading its worst facilities (Haulman, 2004, p. 57).

Similarly, the Air Force has prioritized maintaining access to the most capable airbases overseas; however, at times this has been difficult and costly, as host nations can leverage this dependence during base rights negotiations. In Saudi Arabia, for example, the United States built Dhahran Airport in 1946 to facilitate the movement of forces between the European and Pacific theaters. As relations with the Soviet Union deteriorated, Dhahran became an important strategic asset because it was capable of supporting U.S. bomber operations. To retain basing rights at Dhahran, however, U.S. officials engaged in years of negotiations with the Saudis and secured only a short five-year lease in return for considerable financial and military aid (Gormly, 1994, pp. 203-204).

\section{Extent of Strategy Influence on USAF Basing Decisions}

This section focuses solely on strategic considerations and explores when and how strategy influences domestic basing decisions. It is difficult, or even impossible, to determine with any precision the degree to which strategic versus nonstrategic factors dictate basing outcomes- 
especially across time. For much of the Air Force's history, it did not have a formalized basing process, but instead made decisions on an ad hoc basis. Consequently, many basing recommendations are not well documented. ${ }^{8}$ Furthermore, because policymakers often claim that strategic calculations drove their decisions, it can be difficult to distinguish rhetoric from reality. ${ }^{9}$

Nevertheless, it is possible to conclude that strategy plays a role in the Air Force's CONUS and OCONUS basing decisions irrespective of the level of threat. Moreover, threat perceptions have influenced the type of strategic factors that have been most important. When the threat level is thought to be high, there is an urgent need to act, and short-term strategic factors tend to guide basing decisions. In contrast, when there is little to no threat, long-term strategic considerations play a less visible but important role in basing decisions. This distinction is not meant to be mutually exclusive. At all times, both long-term and short-term strategic and nonstrategic factors play a role in basing decisions. Nevertheless, an examination of the historical record reveals that at particular times certain strategic factors tend to dominate over others. Moreover, the role that strategy plays in CONUS and OCONUS basing decisions is remarkably similar. However, because threats can be geographically differentiated, since the end of the Cold War domestic basing decisions have occurred within the context of a relatively low threat environment, while at times overseas the level of threat has spiked.

The United States' experience during both world wars illustrates the importance of focusing on short-term concerns when vital U.S. interests are in peril. In April 1917, "practically no military aviation infrastructure existed in the country" (Warnock, 2004). As a result, the Army Air Service built nearly 105 airbases, but because the threat was contained to the European theater, there was no need to create air defenses. Instead, the airbases built during World War I were situated to facilitate the deployment of the American Expeditionary Forces to Europe (Warnock, 2004, p. 12). This base structure was determined to be inadequate as fears of an enemy attack on the United States increased in the late 1930s. The Army Air Corps Board even concluded that "in the past Air Corps stations have not been located solely in accordance with tactical and strategic requirements" (Futrell, 1951, p. 3). Yet this is an incorrect assessment. The airbases established during World War I were built primarily with immediate strategic requirements in mind, and these conditions differed significantly from the conditions during World War II. Beginning in 1939, the AAC constructed new airbases in the United States and Central and Southern America to remedy the deficiencies of its legacy posture and enable it to implement the President's strategy of hemispheric defensive (Pettyjohn, 2012, pp. 39-48; Warnock, 2004, pp. 22-23). This initiative included establishing airbases to defend critical parts of the nation that were currently vulnerable. Moreover, because of concerns about an attack on the East Coast, the AAC chose locations away from the coastlines to complicate enemy aircraft's

\footnotetext{
${ }^{8}$ Even in the 1990s, there have been questions about USAF BRAC decisions and the lack of documentation. See GAO, 1993, p. 5.

${ }^{9}$ Moreover, criteria can be applied inconsistently_either intentionally or unintentionally. See GAO, 1991, p. 3.
} 
targeting problem. The Japanese attack on Pearl Harbor further amplified the AAC's concerns about airbase vulnerability, resulting in an order that new airbases be dispersed and built at least 350 miles inland (Futrell, 1951, p. 77).

At times, a focus on current exigencies has led to the creation of a posture that quickly became obsolete. During World War II, for example, the Army Air Force (AAF) relied on the capabilities of its current aircraft for all basing decisions, even though new aircraft were scheduled to be operational in the near future. This was a sensible but inefficient approach, as technological improvements often outstripped the pace of base construction. As a result, the AAF built many airfields that were not needed when planes with longer ranges entered into service. In the Pacific, the United States had planned to launch a bombing campaign against Japanese cities and therefore sought bases that would allow its medium bombers, such as the B-25, to strike targets in Japan. Yet by the time that the United States' island-hopping campaign had secured airbases within the B-25's range, longer-range B-24 and B-29 aircraft had entered the inventory and formed the core of air fleet used in the air campaign against Japan (Blaker, 1990, p. 27).

Similarly, as General Curtis LeMay noted, SAC built "bases in relation to specific emergency war plans and specific operations orders instead of developing them in accordance with intermediate or long range plans" (U.S. Air Force, Directorate of Information, History and Research Division, 1962, p. 4). Consequently, SAC's basing requirements dramatically changed as a result of the development of more capable bombers, the introduction of reliable aerial refueling, and the growing ability of the Soviet Union to strike SAC's overseas bases. For example, because of their limited (3,700 mile) ranges, SAC's B-29 bombers had to deploy overseas for strike missions, which were called Reflex operations (U.S. Air Force, Directorate of Information, History and Research Division, 1962, p. 1). To simplify their deployment, B-29s were based near atomic stockpiles in the U.S. southwest. Other SAC bases, such as MacDill AFB in Florida and Hunter AFB in Georgia, were used as transit stops by the bombers on their way to forward operating bases in Europe and North Africa (Haulman, 2004, p. 58). By 1948, however, SAC acquired its first intercontinental bomber, the B-36 Peacemaker (with a 10,000 mile unrefueled range), enabling it to launch attacks on targets in the Soviet Union from CONUS. While the B-36 could not reach the Soviet Union from many of SAC's current southwestern bases, it could from locations in the northeastern United States. As a result, SAC began to build Limestone (later Loring) airbase in northeastern Maine in 1947 (Mueller, 1989, p. 327).

In 1953, a RAND analysis led by Albert Wohlstetter prompted wholesale changes to SAC's global posture and its concept of operations. Prior to this analysis, SAC, which had always emphasized offensive operations, had never given serious thought to the vulnerability of its bomber force. Yet Wohlstetter's work revealed that the United States' nuclear deterrent rested on a "house of cards," as SAC's overseas bases were vulnerable to a Soviet first strike (Kaplan, 1983 , p. 98). RAND concluded that 68 percent of SAC's foreign bases were within the range of 
Soviet short-range jet bombers and that all of its OCONUS bases were within the unrefueled range of Soviet medium bombers (Wohlstetter et al., 1954, p. 237). Concerns about the survivability of SAC's overseas bases expanded when the Soviet Union successfully tested its first hydrogen bomb in August 1953.

Because of these revelations, the Air Force began to experiment, in an exercise called Full House, with its new B-47 bombers, which had a limited (2,000 nautical mile) range, but were capable of in-flight refueling, to see whether they could successfully launch a bombing strike on the Soviet Union from CONUS. Full House demonstrated that SAC could carry out strikes from CONUS and, therefore, that it needed overseas bases only for tankers and post-strike recovery (Strum, 1969, p. 23). Consequently, SAC ended its Reflex operations and began an extensive base construction program in the northeastern United States, Newfoundland, and Canada (U.S. Air Force, Directorate of Information, History and Research Division, 1962, p. 5; Mueller, 1989, pp. 467, 475-476). In the United States, SAC made improvements to an inactive base in Pearse, New Hampshire, constructed a new airbase in Plattsburgh, New York, and acquired Westover AFB in Massachusetts from the Military Air Transport Service (Mueller, 1989, pp. 467, 475476). The Full House initiative also called for the development of 21 Royal Canadian Air Force (RCAF) bases in Canada. ${ }^{10}$

Yet SAC's posture was again made obsolete by technological advances, in particular the Soviet Union's development of ICBMs, which called into question the survivability of northern airbases. While improvements to Canadian airbases were dramatically scaled back due to budgetary concerns, it still took almost three years for the Canadian and U.S. governments to accept a modified plan to upgrade four airbases. By the time that the construction at the RCAF bases was completed in 1960, the Soviet Union had already successfully tested an ICBM, undermining the viability of the original Full House concept of operations (Sturm, 1969, p. 24). Moreover, in 1963 SAC was completing its transition from the B-47 to the B-52 bomber, which reduced its requirement for northern tanker bases and ultimately prompted the Air Force to withdraw its KC-97 tankers and close its last RCAF base in 1964 (Sturm, 1969 pp. 52-53). Because the long-range B-52 bomber (which had an unrefueled radius of 4,000 nautical miles that could be extended through air refueling) began to enter into service in 1955, SAC could reach most targets in the Soviet Union from anywhere in CONUS. Therefore, the B-52s were stationed at the former B-36 bases in the southwest to maximize their warning times, allowing Secretary McNamara to close nine former B-47 bases, which were primarily in the northeastern part of the United States (USAF, 1963, p. 4; Sturm, 1969, pp. 107, 110). This shift was also a product of the Kennedy administration's strategy of flexible response, which emphasized the importance of conventional forces in addition to nuclear forces for deterrence. While flexible response necessitated a costly buildup of conventional U.S. forces, the Kennedy and Johnson

\footnotetext{
${ }^{10}$ At that time, SAC only had one tanker base in Canada, at Goose Bay, which was a holdover from the Bases for Destroyers Agreement (Sturm, 1969, p. 23).
} 
administrations simultaneously sought to control defense expenditures by decreasing SAC's reliance on bombers in favor of ICBMs, which were seen as more cost-efficient, dependable, and survivable (Strum, 1969, p. 113). As this discussion makes clear, the rapid pace of technological developments and changing strategies in the early years of the Cold War generated a shifting set of basing requirements.

More recently, the level of threat at home and abroad has diverged. The dissolution of the Soviet Union in 1991 dramatically reduced the probability of a superpower confrontation, and since that time existential threats to the U.S. homeland have disappeared. By contrast, threats have continued to emerge overseas, creating new basing requirements. For example, in 1990, the United States deployed hundreds of thousands of troops to the Persian Gulf to deter Iraq from attacking Saudi Arabia. U.S. forces then forcibly expelled Iraqi troops from Kuwait, because U.S. policymakers believed that the potential for Saddam Hussein to control a large portion of the world's oil supply posed a serious threat to U.S. interests (Brands, 2004, pp. 117-118). Even after defeating the Iraqi forces and driving them back into their country, U.S. officials believed that Saddam Hussein remained a serious concern and therefore sought to undermine his ability to threaten his neighbors by establishing an economic sanctions regime and two no-fly zones. ${ }^{11}$ At the time, however, the United States had only limited peacetime access to a few airbases in Oman, which were too remote for enforcing a no-fly zone over Iraq. Consequently, the United States acquired the right to use closer airbases in Saudi Arabia, the United Arab Emirates, Kuwait, and Qatar (Cordesman, 1998).

While the 9/11 terrorist attack struck the United States at home, the existing USAF base structure remained sufficient to provide for the increasingly important mission of homeland defense. NORAD had previously focused on external approaches to the U.S. homeland, but after 9/11 its mandate expanded to the United States' interior airspace as well. Since 2001, as a part of Operation Noble Eagle, the Air Force has expanded the number of defense combat air patrols (CAPs) over key U.S. cities and increased the number of NORAD sites that are on strip alert. Yet the vast majority of these duties have been carried out by the Air National Guard, using its existing force structure and posture (Hebert, 2005).

\footnotetext{
${ }^{11}$ For more on this period, see Knights, 2005, Chapters 5-8.
} 



\section{Appendix E: Basing Decisionmaking Processes of the U.S. Army and U.S. Navy}

The U.S. Army and U.S. Navy provide interesting basing decision alternatives. In examining the basing decisionmaking processes in these services, we reviewed service guidance documents, decision packages for specific basing decisions, and supporting documentation, such as environmental analyses. ${ }^{1}$ We also examined relevant studies by other government agencies, such as the U.S. Government Accountability Office (GAO) and the Congressional Research Service, and interviewed selected officials involved with basing decisions. Our purpose for a high-level examination of the basing process in the Army and the Navy was to reveal major differences in the process and add context to the discussion around basing, rather than to conduct a detailed comparison of basing processes across the services.

\section{Army Stationing Decisions}

\section{Authorities and Strategic Guidance}

The Army term for basing or beddown decisions is stationing. Decision authority for stationing actions varies with the size of the unit affected. The Secretary of Defense approves stationing changes for Army divisions, the Secretary of the Army does so for brigades, and the Assistant Secretary of the Army has authority for BRAC-related discretionary actions. ${ }^{2}$ Most other stationing decisions are delegated to the Deputy Chief of the Army Staff, G-3/5/7, including units at battalion level and below (AR 5-10, 2010, p.10).

This differs from USAF practice, in which squadron-level basing decisions (equivalent to battalions, in that both units are commanded by O-5s) are made by the SecAF. It also marks a difference with the Navy, where homeporting decisions for any ship (including destroyers, also commanded by O-5s) are made by the Secretary of the Navy.

Although this difference appears significant, it is somewhat less so in actual practice. Many stationing decisions made by the G-3/5/7 simply implement force posture moves that are at least implied, and sometimes explicitly directed, by strategic guidance. For example, a recent decision to move an aviation battalion to Joint Base Lewis-McChord was an implementing action for a larger initiative to establish a combat aviation brigade there. That initiative was approved by the Vice Chief of Staff of the Army in 2011 and was itself part of the larger Army Transformation

\footnotetext{
${ }^{1}$ The basing process for the U.S. Marine Corps is not explicitly reviewed in this appendix.

2 BRAC discretionary actions are decisions regarding minor tenants at installations slated for closure under BRAC. BRAC decisions typically identify new stations for major tenants and leave the disposition of smaller tenants to the services' discretion.
} 
plan approved by the Secretary of the Army. The Army Transformation plan is intended to migrate the Army from a division- to a brigade-centric force, providing more useful force packages that are easier to deploy, especially for small- and medium-sized contingencies. The plan includes a number of reorganizations, which necessitate rebasing many units. Thus, while the G-3/5/7 may appear to have some of the same authorities as the other services' secretaries, in many cases this authority is limited to approving the execution of moves already directed by senior leaders' guidance. ${ }^{3}$

\section{Process and Supporting Analyses}

Proposals for stationing actions are referred to as stationing packages. Stationing packages are submitted to the Army staff by commands with a direct administrative reporting chain to Army Headquarters. ${ }^{4}$ This closely parallels the Air Force, whose MAJCOMs are responsible for submitting basing proposals and include many similar commands. Stationing packages have several components. The most important of these are the stationing summary, environmental documentation, facility requirements summary, and information for members of Congress (IMC). ${ }^{5}$ Besides summarizing the contents of the entire package, the stationing summary includes an analysis of the military value of the proposed action.

\section{Military Value Analyses}

Stationing packages must include consideration of operational issues, but Army guidance does not prescribe specific considerations. Instead, it acknowledges that operational issues are likely to differ from action to action, and requires that stationing summaries describe the proposed action's impact on strategy, operations, and (at an unclassified level) on plans (AR 5-10, 2010, p. 12).

The Army also mandates that stationing actions consider alternatives to the proposed stationing. There is no requirement for a specific number of alternatives that must be considered, but at a minimum, the options must include a "no-action" alternative. If multiple alternatives are studied, the package must explain what screening and evaluation criteria were used and how the

\footnotetext{
${ }^{3}$ Other stationing decisions made by the G-3/5/7 may involve offices rather than tactical units. Two recent examples include the relocation of the Army Marketing Research Group from Fort Knox, Kentucky, to the Washington, D.C., area, and the Army Intermodal Distribution Platform Management Office from Tobyhanna Army Depot, Pennsylvania, to Scott Air Force Base, Illinois.

${ }^{4}$ These commands fall into three categories: Army commands, such as Army Materiel Command; Army service component commands, such as U.S. Army Europe; and direct reporting units, such as the Army Corps of Engineers and Army Medical Command.

5 Other elements of the stationing package include the manpower migration diagram (a document showing changes in the size or chain of command of units affected by the stationing action), civilian employee impacts (a document detailing the cost or savings of any changes in civilian employees caused by the action), public notification documents, and community impact analyses (where applicable).
} 
criteria support the proposed action. Stationing packages must also consider the ability to support the "training density" at the gaining installation (AR 5-10, 2010, p. 13).

Just as strategic guidance dictates certain stationing actions, it may also underpin the military value of such an action. This has been the case in several recent stationing actions directed by the Army Transformation plan. This plan, as noted above, is intended to result in a more effective Army. It is therefore typically cited as providing the military value of moves that it directs. This was the case in the relocation of aviation units to Joint Base Lewis-McChord, mentioned above. This move was an element of the Army Transformation plan's goal of establishing a combat aviation brigade at the base. The stationing package's military value discussion referred to this element of the plan (HQDA, 2012).

\section{Facility and Capacity Analyses}

Army stationing planners obtain facilities data from three sources: centralized information systems and databases, requests to individual facilities, and site visits. The primary information system for facilities planning is the Real Property Planning and Analysis System. This system provides analyses of facility assets against allowances, evaluates the impact of candidate stationing actions, and validates construction programs (AR 5-10, 2010, pp. 11-12). ${ }^{6}$ There are also at least seven Army databases with additional information on facility capacities, capabilities, and requirements. These databases provide information on the following (from AR 5-10, 2010, pp. 11-12):

1. current and future-year authorized civilian and military populations, by installation (Army Stationing and Installation Plan [ASIP])

2. real property facility data (Integrated Facilities System)

3. allowances, personnel, and equipment lists for tenant units, by installation (Facility Planning System)

4. facility conditions (installation status reports)

5. directed or major weapon-specific facility considerations (such as logistics, maintenance, training, special physical security, or safety needs) (Support Facility Annex)

6. training facilities data (active and inactive range inventories)

7. environmental cleanup requirements, by installation (Army Environmental Database).

A second step in obtaining facility information is through data calls to installations. These calls are routed through Army Installations Management Command, which vets the requests, forwards them to installations for response, and vets the responses before returning them to the initiating Army command/Army service component command/direct reporting unit. Army Installations Management Command also vets draft final stationing packages before they are formally submitted to Headquarters Department of the Army.

\footnotetext{
${ }^{6}$ GAO has raised some concerns about the Army's management information systems and databases. In 2010, GAO found cases in which some of these systems held inaccurate information or returned unusual results. GAO cited a case in which one system reported a requirement for 74 baseball fields at Fort Bragg (GAO, 2010b).
} 
Site surveys are a third means of obtaining facility data. Army guidance anticipates that site surveys will be conducted after the first two steps have been taken. The data from the prior steps may limit the number of candidate installations, thus reducing the number of site surveys required (AR 5-10, 2010, p.7).

\section{Environmental Analyses}

Army guidance specifically requires that stationing actions comply with NEPA. As noted earlier, the Army does not require that any specific minimum number of alternatives be studied, other than a "no-action" alternative (AR 5-10, 2010, pp. 12-13). Army guidance also does not discuss whether any alternatives can be eliminated based on non-environmental factors (such as military value and facilities requirements) before determining which alternatives will be considered in the environmental analysis. In recent years, the Army has completed broad environmental impact statements for multiple potential stationing actions before deciding whether to implement them.

If not included in NEPA documentation, Army stationing packages must include a separate community impact analysis. Community impact analyses contain estimates of the stationing action's impact on the population and economy of the surrounding communities, including businesses, schools, housing, and public services. A model developed by the Army Construction Engineering Research Lab, the Economic Impact Forecast System, is available to support these analyses (AR 5-10, 2010, p. 13).

\section{Congressional Notification and Timelines}

Information for members of Congress (IMC) is another component of stationing packages. IMC is typically a single-page summary explaining the "who, what, where, when, and why" of the stationing action. The Army's Chief of Legislative Liaison determines which members of Congress will receive this information and obtains Secretary of the Army approval regarding what IMC will be shared (AR 5-10, 2010, p. 13).

The Army informs Congress that a stationing study has begun only in exceptional, "highly politically sensitive" cases. Such cases require approval from senior Army leadership and are usually decided in initial briefings to such leaders. ${ }^{7}$ This appears to contrast with the Air Force approach, where the service routinely shares information with Congress near the beginning of the analysis, during the decision process, and after a decision is reached.

Army guidance directs that stationing actions requiring military construction at the gaining installation be submitted to the Army staff at least five years before the proposed effective date. This allows time for approvals and coordination, with a further goal of having all designs complete and contracts awarded three years before the effective date. For actions not requiring

\footnotetext{
${ }^{7}$ The Office of the Secretary of Defense must be notified before Congress in cases where a stationing action will close or substantially reduce the population of an installation, result in the release of 50 or more civilian personnel from government employment, or substantially reduce contract operations or employment involving 100 or more people (see Department of Defense Directive 5410.10, 1960).
} 
military construction, the Army requires that stationing packages be submitted at least 18 months before the proposed effective date (AR 5-10, 2010, pp. 7-8).

In practice, some recent stationing actions have not met these goals. In a 2010 report, GAO found that some actions requiring military construction were submitted for approval less than one year before the effective date. Several of these moves went forward, with units occupying trailers and other temporary facilities at their new stations. In some cases, even temporary facilities were unavailable, and newly arrived units were forced to occupy spaces vacated by deployed personnel. In some situations, this required that the new tenants move from building to building as deployed soldiers returned to home station (GAO, 2010b).

\section{Navy Homeporting Decisions}

\section{Authorities and Strategic Guidance}

The U.S. Navy term for basing decisions is homeporting. The Secretary of the Navy is authorized to make decisions regarding homeports for new ships, as well as any temporary homeport change exceeding nine months' duration. This authority is delegated for temporary homeport changes lasting less than nine months. Temporary homeport changes typically occur for maintenance.

\section{Strategic Guidance}

The Navy uses a variety of strategic guidance documents to allocate ships to the Atlantic and Pacific Fleets. This allocation, which the Navy terms its strategic laydown, uses input from the most recent Quadrennial Defense Review, Navy strategy and vision documents, and other sources. The resulting Strategic Laydown Plan is updated annually (OPNAVINST 5400.44a, 2011b, p. 3-2; GAO, 2010a, pp. 30-31). Annual updates may modify the allocation of ships between the fleets based on changes in force structure, the international security environment, or shipbuilding or aviation procurement programs (OPNAVINST 5400.44a, 2011b, p. 3-2).

After the determining the fleet in which a ship or ships will be homeported, the Navy's decision process focuses on strategic dispersal. This term refers to the distribution of ships within a fleet by homeport (GAO, 2010a, p. 31). The Navy's type commands for air, surface, and submarine forces use the strategic laydown plans to narrow homeport options for new ships. They then consider the new ships' manning, training, maintenance, and other requirements. If environmental documentation is not required, the type commands recommend specific ports for new assets. If environmental documentation is required, the NEPA process begins and homeport decisions are deferred until it is complete. The Navy's approach to NEPA documentation is discussed in more detail below (OPNAVINST 5400.44a, 2011b, p. 3-3).

Strategic dispersal has been an issue of historical importance to the Navy. As it grew toward 600 ships in the 1980s, the Navy pursued a Strategic Homeporting initiative that sought to increase the number of ports capable of hosting battle groups and smaller formations. The Navy 
advocated Strategic Homeporting based on the vulnerability of a concentrated fleet to small numbers of Soviet strikes (O'Rourke, 1987). ${ }^{8}$ Dispersal remains a significant aspect of military value for the Navy today. This is seen in part in the Mayport decision discussed below.

\section{Process and Supporting Analyses}

\section{Military Value Analyses}

The Navy does not dictate specific measures of military value for homeporting requests to consider. Guidance is limited to directing that the command requesting the homeporting action state the reason for the request (OPNAVINST 5400.44a, 2011b, pp. 1-17). In a recent decision to move an aircraft carrier from Hampton Roads, Virginia, to Mayport, Florida, the Navy cited three main operational benefits (U.S. Department of Defense and Department of the Navy, 2009). The first was reduced steaming time to the open ocean to approximately one hour in Mayport as compared with 3.5 hours in Hampton Roads (GAO, 2010a, pp. 30-31). The second operational benefit cited in the Mayport decision was lessened risk from natural and manmade disasters. The Navy noted a lower risk of terror attack at Mayport compared with Hampton Roads. It also cited the possibility of losing access to the open ocean at Hampton Roads due to terror attacks or natural disasters affecting choke points between the carrier piers and the ocean. The third operational benefit relates to dispersal. The Navy cited the risk of having all of the Atlantic Fleet's nuclear carrier-trained crews and support infrastructure concentrated at Hampton Roads. Moving a carrier, its crew, and support infrastructure to Mayport reduced this risk (GAO, 2010a, pp. 30-31).

The Navy does not require that homeporting actions consider a specific number of alternatives. In deciding whether to homeport an aircraft carrier at Mayport, the Navy considered 13 alternatives, and all but one (a "no-action" alternative) involved homeporting different mixes of ships at Mayport. No other ports were considered. The Navy reportedly "worked on the assumption that it would not establish a new carrier homeport but upgrade an existing" one to support a nuclear-powered ship (GAO, 2010a, p. 31).

\section{Facilities Issues}

Navy homeporting requests include two types of information with respect to facilities: buildings and land and personnel impacts. Data concerning buildings and land include the square footage occupied by the affected command(s), the value of the buildings and any stationary equipment within them, and the cost of maintaining the buildings and equipment over a three-year period. If land and/or buildings must be acquired at the gaining installation, homeport requests must include acquisition cost and further detail whether the buildings are to be permanent, semipermanent, or temporary (OPNAVINST 5400.44a, 2011b).

\footnotetext{
${ }^{8}$ See also O'Rourke, 1990.
} 


\section{Environmental Impact}

The Navy explicitly requires that homeporting actions comply with NEPA. As noted earlier, the Navy does not require that any minimum number of alternatives be considered beyond a noaction option. The Navy does, however, highlight the importance of explaining what alternatives were considered in terms of "what requirements are essential to achieving the proposed action's purpose" and what alternatives would achieve it. This is especially important in the case of Environmental Impact Statements, which should include a "description of proposed action and alternatives (DOPAA) (OPNAVINST 5090.1C, 2011a, p. 5-40). Where screening criteria such as operational or location needs are used, they must be identified and explained (OPNAVINST, 2011a, pp. 5-52-5-53).

\section{Congressional Notification and Timelines}

Navy guidance requires that homeporting requests identify members of Congress with districts affected by the proposed action. There is no requirement to include a draft summary of information to be provided to Congress. Navy guidance acknowledges the possibility that a homeporting action will have been discussed with interested members of Congress before formal submission to the Office of the Chief of Naval Operations. In such cases, the homeporting request must indicate which members of Congress were advised of the potential action, and the forum or venue in which the exchange took place.

\section{Summary}

Strategic guidance strongly affects basing decisions for the Army and Navy. In the Army, such guidance may explicitly define stationing actions. The Deputy Chief of Staff G-3/5/7, although nominally empowered to base battalion and smaller-sized units, is often implementing strategic guidance when doing so. In the Navy, the division of ships between the Atlantic and Pacific Fleets is determined by strategic guidance, and the Navy also perceives a strategic need to disperse the fleet to the extent possible. This aspect of strategic guidance may also influence many homeporting decisions.

Strategic guidance may also describe the military value of many basing decisions in both services. The Army's Transformation Plan is a strategic initiative designed to give the entire service more military value. It directs (either implicitly or explicitly) a number of stationing actions in pursuit of this goal. The Navy's Strategic Homeporting initiative of the late Cold War era is another historical example of a strategy that defined the military value of a number of homeporting decisions.

Neither the Army nor the Navy requires that a specific number of basing alternatives be considered in environmental analyses, beyond a "no-action" alternative. Navy guidance suggests the possibility of ruling out some options based on non-environmental factors, before deciding which alternatives will be considered in an environmental impact statement. 
Finally, both the Army and the Navy have a default position of sharing basing decisions with Congress after they are made. Each service recognizes that there may be exceptions to this rule, but neither plans for the series of engagements with Congress that the Air Force does in making its basing decisions.

Table E.1 summarizes key aspects of the USAF basing decisionmaking process compared with those of the Army and the Navy.

Table E.1

Comparison of Service Basing Decisionmaking Processes

\begin{tabular}{|c|c|c|c|}
\hline Key Aspect & Air Force & Army & Navy \\
\hline \multicolumn{4}{|l|}{ Decision Authority } \\
\hline $\begin{array}{l}\text { O-6-level } \\
\text { commands }\end{array}$ & SecAF & Secretary of the Army & Secretary of the Navy \\
\hline $\begin{array}{l}\text { O-5-level } \\
\text { commands }\end{array}$ & SecAF & $\begin{array}{l}\text { Deputy Chief of Staff } \\
\text { G-3/5/7a }\end{array}$ & Secretary of the Navy \\
\hline \multicolumn{4}{|l|}{ Supporting analyses } \\
\hline Military value & $\begin{array}{l}\text { Considered by } \\
\text { BRRP and USAF } \\
\text { leadership }\end{array}$ & $\begin{array}{l}\text { May be inherent in strategic } \\
\text { guidance }\end{array}$ & $\begin{array}{l}\text { May be inherent in strategic } \\
\text { guidance }\end{array}$ \\
\hline $\begin{array}{l}\text { Environmental } \\
\text { issues }\end{array}$ & $\begin{array}{l}\text { Included as criteria in } \\
\text { strategic basing process }\end{array}$ & $\begin{array}{c}\text { May encompass multiple } \\
\text { potential moves, where } \\
\text { envisioned by strategic } \\
\text { guidance }\end{array}$ & $\begin{array}{l}\text { Alternatives may be eliminated } \\
\text { based on requirements to achieve } \\
\text { proposed action's purpose. }\end{array}$ \\
\hline $\begin{array}{l}\text { Congressional } \\
\text { notification }\end{array}$ & Multiple points & Post-decision $^{\mathrm{b}}$ & Post-decision $^{c}$ \\
\hline $\begin{array}{l}\text { Timeline for proposal } \\
\text { submission } \\
\text { (months before } \\
\text { execution) }\end{array}$ & $\begin{array}{l}\text { Varies, proponent } \\
\text { MAJCOM is } \\
\text { responsible }\end{array}$ & $\begin{array}{l}60 \text { (if military construction) } \\
18 \text { (no military construction) }\end{array}$ & 14 \\
\hline
\end{tabular}

${ }^{a}$ Often implementing stationing actions decided or implied by higher-level strategic guidance.

${ }^{\mathrm{b}}$ Exceptions in highly sensitive cases, with SA approval.

${ }^{\mathrm{C}}$ Navy guidance acknowledges possibility that some information will have been shared with Congress before the final decision. 


\section{References}

AFI-See Air Force Instruction.

Air Force Instruction 10-503, Strategic Basing, Washington, D.C.: Department of the Air Force, September 27, 2010. As of November 11, 2015:

http://www.acq.osd.mil/dpap/ccap/cc/jcchb/Files/FormsPubsRegs/Pubs/afi10-503.pdf

Air Mobility Command, Air Mobility Command Global En Route Strategy White Paper, version 7.2.1, July 14, 2010.

Alaska Delegation, letter to Secretary Donley and General Schwartz, March 7, 2012. As of November 11, 2015:

http://www.murkowski.senate.gov/public/?a=Files.Serve\&File_id=a1bdf937-34dd-4b9ab6a8-181c7037bd9a

$\mathrm{AMC}-$ See Air Mobility Command.

AR_-See Army Regulation.

Army Regulation 5-10, Stationing, Washington, D.C.: Headquarters Department of the Army, August 20, 2010.

Bender, Bryan, “As Jets Seem Bound for Vt., Questions of Political Influence Arise,” The Boston Globe, April 14, 2013. As of November 11, 2015:

http://www.bostonglobe.com/news/nation/2013/04/13/selection-vermont-guard-base-for-jetswas-based-flawed-data-raising-questions-political-

influence/pmhiPtI1BPWxwC3yK1adAL/story.html

Benson, Lawrence R., USAF Aircraft Basing in Europe, North Africa, and the Middle East, 1945-1980, Ramstein Air Base, Germany: Office of History, Headquarters United States Air Forces in Europe, 1982.

Betts, Richard K., “Is Strategy an Illusion?” International Security, Vol. 25, No. 2, 2000.

Blaker, James R., The United States Overseas Basing: An Anatomy of the Dilemma, New York: Praeger, 1990.

Brands, H. W., "George Bush and the Gulf War of 1991," Presidential Studies Quarterly, Vol. 34, No. 1, March 2004.

Brown, Jerold E., Where Eagles Land: Planning and Development of U.S. Army Airfields, 1910 1941, New York: Praeger, 1990. 
Calder, Kent E., Embattled Garrisons: Competitive Base Politics and American Globalism, Princeton, N.J.: Princeton University Press, 2007.

Chief of Naval Operations Instruction 5090.1C, Environmental Readiness Program Manual, Washington, D.C.: Office of the Chief of Naval Operations, July 18, 2011 a.

Chief of Naval Operations Instruction 5400.44a, Washington, D.C.: Office of the Chief of Naval Operations, Navy Organization Change Manual, October 13, $2011 \mathrm{~b}$.

Clinton, Hillary, “America’s Pacific Century,” Foreign Policy, November 2011.

Conger, John, "Is Base Realignment and Closure (BRAC) Appropriate at this Time?" testimony before the Subcommittee on Readiness of the Committee on Armed Services, House of Representatives, H.A.S.C. No. 113-18, Washington, D.C., March 14, 2013. As of November 11, 2015: http://www.gpo.gov/fdsys/pkg/CHRG-113hhrg80188/html/CHRG-113hhrg80188.htm

Conn, Stetson, Rose C. Engelman, and Byron Fairchild, Guarding the United States and Its Outposts, Washington, D.C.: U.S. Army Center of Military History, 1989.

Conn, Stetson, and Byron Fairchild, The Framework of Hemisphere Defense, Washington, D.C.: U.S. Army Center of Military History, 1989.

Cordesman, Anthony H., CENTCOM and Its Area of Operations: Cooperation, Burden Sharing, Arms Sales, and Analysis by Country and Subregion, Washington, D.C.: Center for Strategic and International Studies, April 1998.

Defense Writers Group, interview of General Herbert J. "Hawk" Carlisle, commander of Pacific Air Forces to the Defense Writers Group, transcript, July 29, 2013. As of November 11, 2015:

http://www.airforcemag.com/DWG/Documents/2013/July\%202013/072913Carlisle.pdf

Department of Defense Directive 5410.10, Coordination and Clearance of Announcements of Personnel Reductions, Closures of Installations, and Reductions of Contract Operations Within the United States, February 2, 1960 (incorporating Change 1, July 22, 1968).

"Department of Defense Draft Selection Criteria for Closing and Realigning Military Installations Inside the United States," Federal Register, Vol. 68, No. 246, December 23, 2003, pp. 74221-74222.

Department of the Air Force, Department of the Air Force Analyses and Recommendations, 1960 Base Closure and Realignment Report to the Commission, Vol. V, February 1995.

- Analysis and Recommendations BRAC 2005, Department of Defense Report to the Defense Base Closure and Realignment Commission, Volume V, Part 1, May 2005. DoD_See U.S. Department of Defense. 
DWG—See Defense Writers Group.

Elith, Jane, John R. Leathwick, and Trevor Hastie. "A Working Guide to Boosted Regression Trees,” Journal of Animal Ecology, Vol, 77, No. 4, 2008, pp. 802-813.

Flinn, Michael H., "Air Force BRAC Recommendations for Consolidating C-130s: A BRAC Commission Perspective," Air \& Space Power Journal, September 2006, pp. 1-11.

Friedman, J.H. "Greedy Function Approximation: A Gradient Boosting Machine," Annals of Statistics, Vol. 29, No. 5, 2001, pp. 1189-1232.

Futrell, Robert Frank, Development of AAF Base Facilities in the United States, 1939-1945, USAF Historical Study No. 69, Montgomery, Ala.: Air Force Historical Research Agency, Maxwell Air Force Base, 1951.

GAO—See U.S. Government Accountability Office.

Gaddis, John Lewis, Strategies of Containment: A Critical Appraisal of American National Security Policy During the Cold War, New York: Oxford University Press, 2005.

Gates, Robert M., Remarks as Delivered by Secretary of Defense Robert M. Gates, International Institute for Strategic Studies (Shangri-La-Asia Security), Shagri-La Hotel, Singapore, Saturday, June 5, 2010.

Goren, Lilly J., The Politics of Military Base Closings: Not in My District, New York: Peter Lang, 2003.

Gormly, James L., "Keeping the Door Open in Saudi Arabia: The United States and Dhahran Airfield, 1945-46," Diplomatic History, Vol. 4, No. 2, 1994, pp. 203-204.

Hammack, Katherine, "Is Base Realignment and Closure (BRAC) Appropriate at this Time?" testimony before the Subcommittee on Readiness of the Committee on Armed Services, House of Representatives, H.A.S.C. No. 113-18, Washington, D.C., March 14, 2013. As of November 11, 2015: http://www.gpo.gov/fdsys/pkg/CHRG-113hhrg80188/html/CHRG-113hhrg80188.htm

Haulman, Daniel L., “Air Force Bases, 1947-1960,” in Frederick J. Shaw, ed., Locating Air Force Base Sites: History's Legacy, Washington, D.C.: Air Force History and Museums Program, United States Air Force, 2004.

Headquarters, Department of the Army, Stationing Package for FY 12-13 Relocation of 1st Bn, 229th Air Cavalry Squadron and D Co., 123rd Aviation Regiment to Joint Base LewisMcChord, Washington, D.C., May 20, 2012.

Headquarters Strategic Air Command, Office of the Historian, History of Strategic Air Command FY1969, Historical Study No 116, Vol. I Narrative, March 1970.

Hebert, Adam J., “Noble Eagle Without End,” Air Force Magazine, February 2005. 
Heinrich, Bernd, Marcus Kaiser, and Mathias Klier, "How to Measure Data Quality? A Metric Based Approach," in S. Rivard and J. Webster, eds., Proceedings of the 28th International Conference on Information Systems (ICIS), Montreal (Canada): Association for Information Systems, December 2007. As of November 11, 2015:

http://www.wi-if.de/paperliste/paper/wi-205.pdf

Henry, Ryan, "Transforming the U.S. Global Defense Posture," in Lord Carnes, ed., Reposturing the Force: U.S. Overseas Presence in the Twenty-First Century, Newport, R.I.: Naval War College Press, 2006.

Hopkins, J. C., and Sheldon A. Goldberg, The Development of Strategic Air Command 19461986, Offutt Air Force Base, Nebraska: Office of the Historian, Headquarters Strategic Air Command, 1986.

HQDA—See Headquarters Department of the Army.

JCS-See Joint Chiefs of Staff.

Joint Chiefs of Staff, Enclosure C: Overall Examination of United States Requirements for Military Bases and Base Rights, JCS 570/40, RG 218, Combined Chiefs of Staff Series 360 (19-9-42), November 7, 1945.

— The National Military Strategy of the United States of America: A Strategy for Today; a Vision for Tomorrow, Washington, D.C.: Office of the Chairman of the Joint Chiefs of Staff, 2004.

Kaplan, Fred, The Wizards of Armageddon, Stanford, Calif.: Stanford University Press, 1983.

Kaplan, Lawrence S., Ronald D. Landa, and Edward J. Drea, History of the Office of the Secretary of Defense, Volume V: The McNamara Ascendancy, 1961-1965, Washington, D.C.: Historical Office, Office of the Secretary of Defense, 2006.

Keller, Kirsten, Sean Robson, Kevin O’Neill, Paul D. Emslie, Lane F. Burgette, Lisa M. Harrington, Dennis Curran, Promoting Airmen with the Potential to Lead: A Study of the Air Force Master Sergeant Promotion System, Santa Monica, Calif.: RAND Corporation, RR581-AF, 2014. As of November 11, 2015: http://www.rand.org/pubs/research_reports/RR581.html

Kennedy, Paul, Grand Strategies in War and Peace, New Haven, Conn.: Yale University Press, 1992.

Knights, Michael, Cradle of Conflict: Iraq and the Birth of Modern U.S. Military Power, Annapolis, Md.: Naval Institute Press, 2005.

Kreis, John F., Air Warfare and Air Base Air Defense, Washington, D.C.: Office of Air Force History, United States Air Force, 1988. 
Leighton, Richard M., History of the Office of the Secretary of Defense Vol. III, Strategy, Money, and the New Look, 1953-1956, Washington, D.C.: Historical Office of the Secretary of Defense, 2001.

Lemmer, George F., "Bases," in Alfred Goldberg, ed., A History of the United States Air Force, New York: Arno Press, 1974.

Manyin, Mark E., Stephen Daggett, Ben Dolven, Susan V. Lawrence, Michael F. Martin, Ronald O'Rourke, and Bruce Vaughn, Pivot to the Pacific? The Obama Administration's "Rebalancing” Toward Asia, Washington, D.C.: Congressional Research Service, March 28, 2012.

Marion, Forrest L., "Retrenchment, Consolidation, and Stabilization, 1961-1987," in Frederick J. Shaw, ed., Locating Air Force Base Sites: History's Legacy, Washington, D.C.: Air Force History and Museums Program, United States Air Force, 2004.

Mayer, Kenneth R., "The Limits of Delegation: The Rise and Fall of BRAC," Regulation, Vol. 22, No. 3, 1999, p. 33.

Millett, Allan R., and Peter Maslowski, For the Common Defense: A Military History of the United States of America, New York: The Free Press, 1994.

Mueller, Robert, Air Force Bases Volume I: Active Air Force Bases Within the United States of America on 17 September 1982, Washington, D.C.: Office of Air Force History, 1989.

"Murkowski Gets Transparency Pledge from Next USAF Chief of Staff," Alaska Monthly, July 2012. As of December 15, 2015:

http://www.akbizmag.com/Alaska-Business-Monthly/July-2012/Murkowski-GetsTransparency-Pledge-from-Next-USAF-Chief-of-Staff/

NSC-68-See National Security Council.

National Security Council, "NSC 68: United States Objectives and Programs for National Security (April 14, 1950)," Naval War College Review, Vol. 28, May-June 1975, pp. 51108. As of November 11, 2015:

https://www.mtholyoke.edu/acad/intrel/nsc-68/nsc68-1.htm

O'Hanlon, Michael and Bruce Riedel, "Why the United States Should Open More Bases in the Middle East," Foreign Affairs, July 2, 2013.

O'Rourke, Ronald, The Navy's Strategic Homeporting Program: Issues for Congress,

Washington, D.C.: Congressional Research Service, June 11, 1987.

- Strategic Homeporting Reconsidered, Washington, D.C.: Congressional Research Service, December 20, 1990.

OPNAVINST_-See Chief of Naval Operations Instruction. 
Pettyjohn, Stacie L., U.S. Global Defense Posture, 1783-2011, Santa Monica, Calif.: RAND Corporation, MG-1244-AF, 2012. As of November 11, 2015:

http://www.rand.org/pubs/monographs/MG1244.html

Pettyjohn, Stacie L., and Evan Montgomery, "By Land and by Sea," Foreign Affairs, July 19, 2013.

Pohlmeier, Mark, “Air Force Strategic Basing Division,” AF/A8PB, briefing, November 2012.

Public Law 91-190, National Environmental Policy Act, January 1, 1970.

Public Law 100-526, Defense Authorization Amendments and Base Closure and Realignment Act, October 24, 1988.

Public Law 101-510, Defense Base Realignment and Closure Act of 1990, November 5, 1990.

Reynolds, David, From Munich to Pearl Harbor: Roosevelt's America and the Origins of the Second World War, Chicago, Ill.: Ivan R. Dee, 2001.

Ridgeway, G., "Generalized Boosted Models: A Guide to the GBM Package," September 21, 2009. As of November 9, 2014:

https://r-forge.r-

project.org/scm/viewvc.php/*checkout*/pkg/inst/doc/gbm.pdf?revision=18\&root=gbm\&path $\mathrm{rev}=22$

Ross, Robert S., "The Problem with the Pivot: Obama's New Asia Policy Is Unnecessary and Counterproductive," Foreign Affairs, November/December 2012.

Saab, Bilal Y., “Asia Pivot, Step One: Ease Gulf Worries,” National Interest, June 20, 2013.

Sahaida, Jeffrey P., "Reorganization After the Cold War, 1988-2003," in Frederick J. Shaw, ed., Locating Air Force Base Sites: History's Legacy, Washington, D.C.: Air Force History and Museums Program, United States Air Force, 2004.

Schlossberg, George, "How Congress Cleared the Bases: A Legislative History of BRAC," Journal of Defense Communities, Vol. 1, 2012, pp. 1-12.

Shaw, Frederick J., ed., Locating Air Force Base Sites: History's Legacy, Washington, D.C.: Air Force History and Museums Program, United States Air Force, 2004.

Sorenson, David S., Shutting Down the Cold War: The Politics of Military Base Closure, New York: Palgrave MacMillian, 1998.

—-, Military Base Closure: A Reference Handbook, Westport, Conn.: Praeger Security International, 2007.

Sturm, Thomas, USAF Overseas Forces and Bases: 1947-1967, Washington, D.C.: Office of Air Force History, 1969. 
Sutter, Robert G., Michael E. Brown, and Timothy J. A. Adamson, with Mike M. Mochizuki, and Deepa Ollapally, Balancing Acts: The U.S. Rebalance and Asia-Pacific Stability, Washington, D.C.: Elliott School of International Affairs, George Washington University, August 2013. As of November 11, 2015:

http://www2.gwu.edu/ sigur/assets/docs/BalancingActs_Compiled1.pdf

USAF—See U.S. Air Force.

USAFE-See U.S. Air Forces in Europe.

U.S. Air Force, Directorate of Information, History and Research Division, Overseas Bases: A Military and Political Evaluation, April 2, 1962.

—_, Proposal to Relocate the 18th Aggressor Squadron (18 AGRS) from Eielson Air Force Base (EAFB), Alaska to Joint Base Elmendorf-Richardson (JBER), Alaska and to Right-Size the Remaining Wing/Overhead/Base Operating Support at EAFB, Alaska, Draft Environmental Impact Statement, Hickam Air Force Base, HI: Air Force Civil Engineer Center Pacific Air Forces, May 2013a.

__, "Air Force Announces Aggressors Will Remain at Eielson," News post, Eielson Air Force Base Web site, October 2, 2013b. As of January 7, 2013:

http://www.eielson.af.mil/news/story.asp?id=123365696

U.S. Air Force, Ideal Base Study, 1963.

U.S. Air Forces in Europe, Short History and Chronology of the USAF in the United Kingdom, Historical Division Office of Information Third Air Force, United States Air Forces in Europe, May 1967.

U.S. Department of Defense, Department of Defense Base Realignment Policy, Hearing Before the Subcommittee on Military Construction and Stockpiles of the Committee on Armed Services, United States Senate, Ninety-Fifth Congress, Second Session, Washington, DC: U.S. Government Printing Office, August 41978.

—, Report on the Effect of Base Closures on Future Mobilization Options, Washington, D.C.: Office of the Deputy Under Secretary of Defense (Installations), November 10, 1999.

—, Strengthening U.S. Global Defense Posture Report to Congress, Washington, D.C., September 2004.

—_, National Defense Strategy, Washington, D.C., June 2008.

_- Sustaining U.S. Global Leadership: Priorities for 21st Century Defense, Washington, D.C., January 2012. 
U.S. Department of Defense and Department of the Navy, Record of Decision for Homeporting of Additional Surface Ships and Naval Station Mayport, Florida, Washington, D.C., January 14, 2009.

U.S. Government Accountability Office, Military Bases: Observations on Analyses Supporting Proposed Closures and Realignments, GAO/NSIAD-91-224, Washington, D.C., May 1991.

—-, Military Bases: Analysis of DoD's Recommendations and Selection Process for Closures and Realignments, GAO/ NSIAD-93-173, Washington, D.C., April 1993.

—- Military Base Closures: Observations on Prior and Current BRAC Rounds, Statement Before the Defense Base Closure and Realignment Commission, GAO-05-614, Washington, D.C., May 3, 2005.

—- Military Base Realignments and Closures: Observations Related to the 2005 Round, Letter to Congress, GAO-07-1203R, Washington, D.C., September 6, 2007.

—_, Military Base Realignments and Closures: Transportation Impact of Personnel Increases Will be Significant, but Long-Term Costs Are Uncertain and Direct Federal Support Is Limited, Report to Congressional Committees, GAO-09-750, Washington, D.C., September 9, 2009a.

_-, Military Base Realignments and Closures: Estimated Costs Have Increased While Savings Estimates Have Decreased Since Fiscal Year 2009, Letter to Chairmen and Ranking Members of Congressional Committees, GAO-10-98R, Washington, D.C., November 13, $2009 \mathrm{~b}$.

—- Defense Infrastructure: Opportunities Exist to Improve the Navy's Basing Decision Process and DOD Oversight, GAO-10-482, Washington, D.C., May 2010a.

—- Defense Infrastructure: Army Needs to Improve its Facility Planning Systems to Better Support Installations Experiencing Significant Growth, GAO-10-602, Washington, D.C., June 24, 2010b.

—_, Military Base Realignments and Closures: DOD Is Taking Steps to Mitigate Challenges but Is Not Fully Reporting Some Additional Costs, Letter to Congressional Committees, GAO-10-725R, Washington, D.C., July 21, 2010c.

—_, Military Base Realignments and Closures: Key Factors Contributing to BRAC 2005 Results, Testimony Before the Subcommittee on Readiness, Committee on Armed Services, House of Representatives, GAO-12-513T, Washington, D.C., March 8, 2012.

—- Military Bases: Opportunities Exist to Improve Future Base Realignment and Closure Rounds, Report to Congressional Committees, GAO-13-149, Washington, D.C., March 7, 2013a. 
Warnock, A. Timothy, "Locating Army Air Installations, 1907-1947," in Frederick J. Shaw, ed., Locating Air Force Base Sites: History's Legacy, Washington, D.C.: Air Force History and Museums Program, United States Air Force, 2004.

Weathers, Bynum E., Jr., Acquisition of Air Bases in Latin America, June 1939-June 1943, Maxwell Air Force Base, Ala.: U.S. Air Force Historical Division, Research Studies Institute, 1943.

The White House, National Security Strategy, Washington, D.C., May 2010.

Wohlstetter, A. J., Fred S. Hoffman, R. J. Lutz, and Henry S. Rowen, Selection and Use of Strategic Air Bases, R-266, Santa Monica, Calif.: RAND Corporation, 1954. As of November 11, 2015:

http://www.rand.org/pubs/reports/R0266.html 
RAND PROJECT AIR FORCE

\section{www.rand.org}

$\$ 32.00$

ISBN-10 0-8330-9205-7

ISBN-13 978-0-8330-9205-2
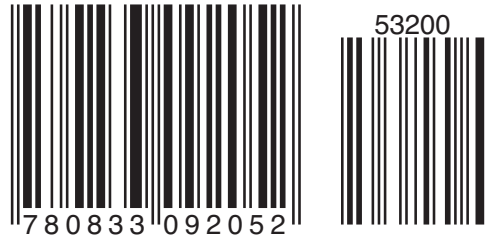